\title{
SMALL-SCALE SOLAR CENTRAL RECEIVER SYSTEM DESIGN AND ANALYSIS
}

\author{
A Thesis \\ presented to \\ the Faculty at California Polytechnic State University \\ San Luis Obispo
}

\author{
In Partial Fulfillment \\ of the Requirements for the Degree \\ Master of Science in Mechanical Engineering
}

By

Daniel James Murray

June 2012 
(C) 2012

Daniel James Murray

ALL RIGHTS RESERVED 


\section{COMMITTEE MEMBERSHIP}

TITLE:

AUTHOR:

DATE SUBMITTED:

COMMITTEE CHAIR:

COMMITTEE MEMBER:

COMMITTEE MEMBER:
Small-Scale Solar Central Receiver System Design and Analysis

Daniel James Murray

June 2012
Andrew Kean, Associate Professor of Mechanical Engineering

Jesse Maddren, Professor of Mechanical Engineering

Craig Baltimore, Professor of Architectural Engineering 


\section{Abstract \\ Small-Scale Solar Central Receiver Design and Analysis Daniel James Murray}

This thesis develops an analytical model of a small-scale solar central receiver power plant located at the California Polytechnic State University in San Luis Obispo, California at $35.28^{\circ} \mathrm{N}, 120.66^{\circ}$ W. The model is used to analyze typical energy output at any time during the year. The power plant is designed to produce an output of $100 \mathrm{~kW}$ electrical power, and is supplemented by the combustion of

natural gas. Methodologies for determining the proper size and layout of heliostats, optimal tower height, receiver size, and turbine engine selection are developed. In this specific design, solar shares of up to $73.2 \%$ and an annual average of $44 \%$ are possible through the use of a gas-solar hybrid microturbine engine. Larger solar shares are not possible due to the limited size of land (about 0.5 acres used for this project) which limits the number of possible heliostat installations. 


\section{Table of Contents}

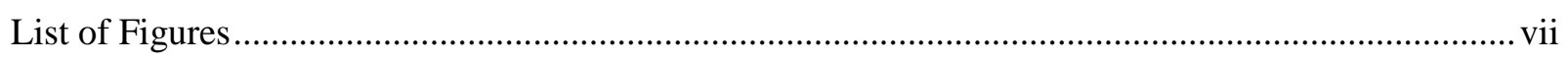

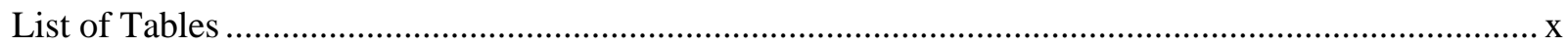

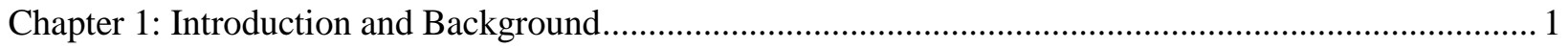

$1.1 \quad$ Scope

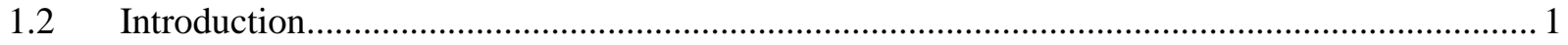

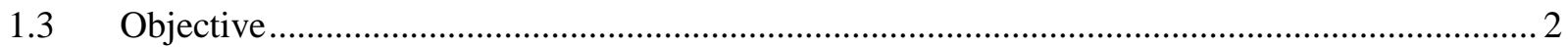

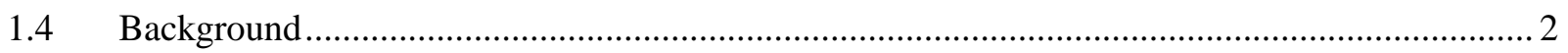

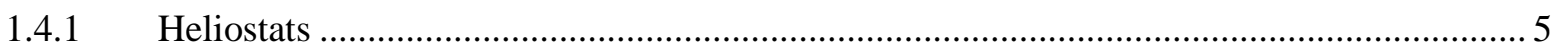

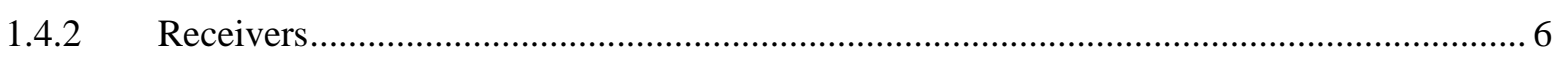

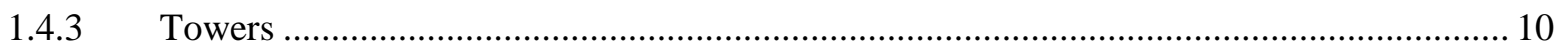

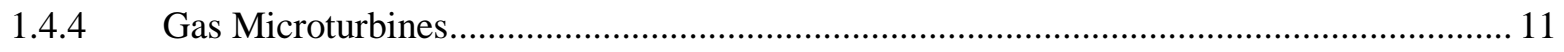

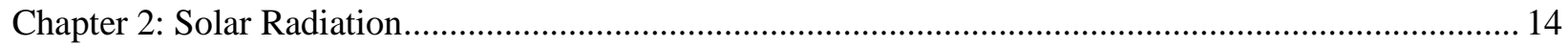

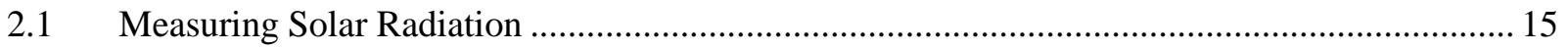

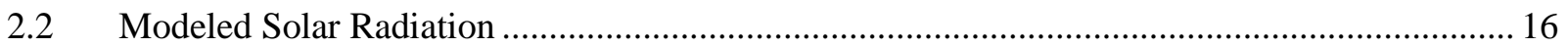

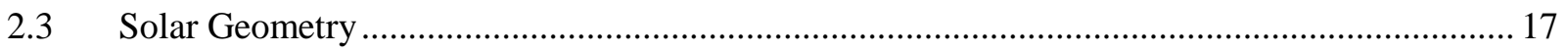

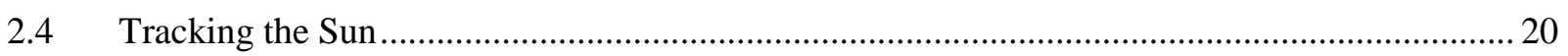

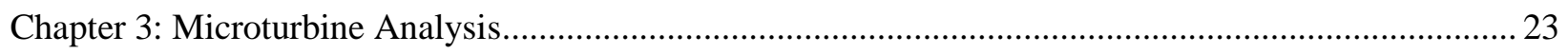

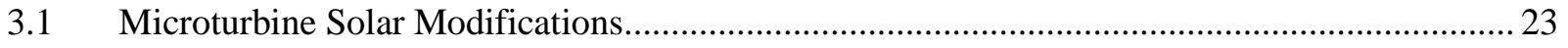

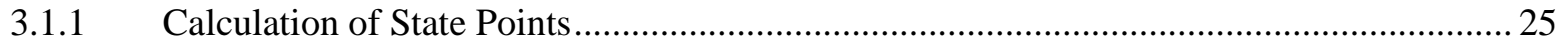

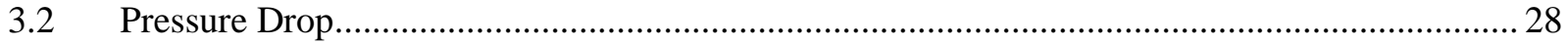

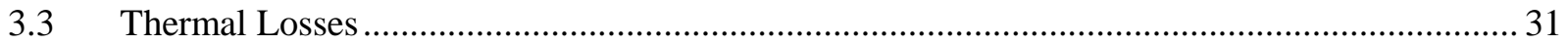

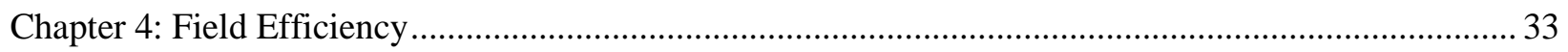

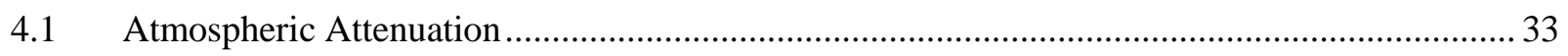

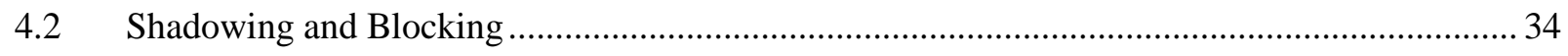

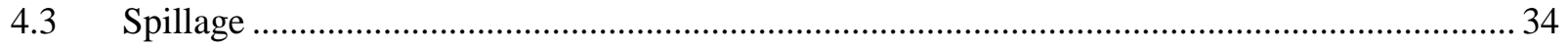

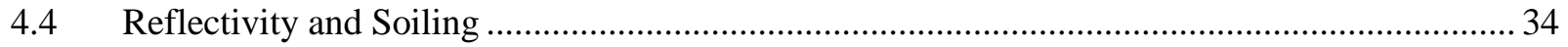

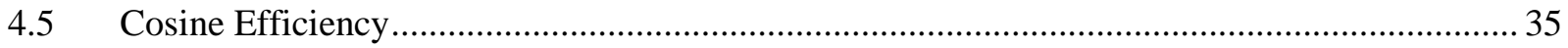

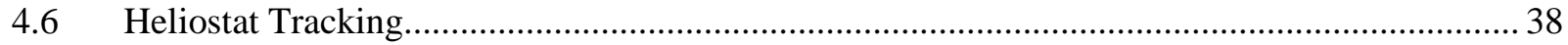

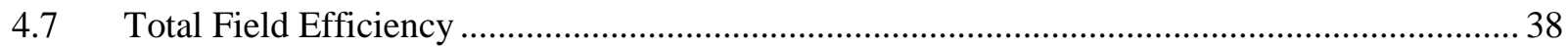

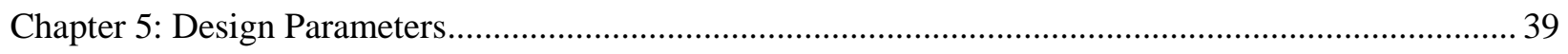

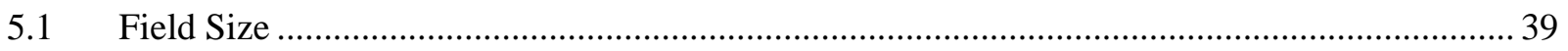




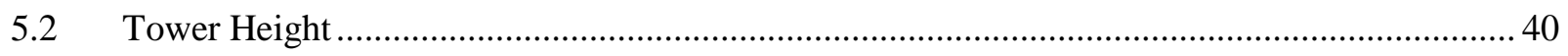

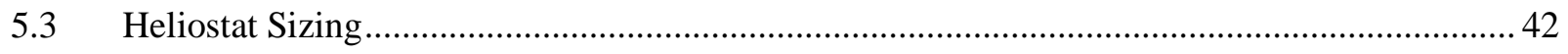

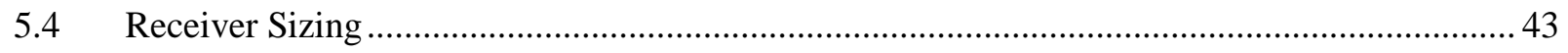

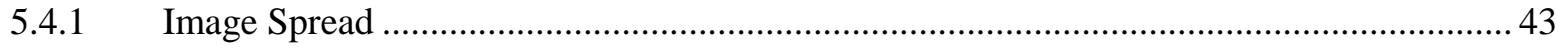

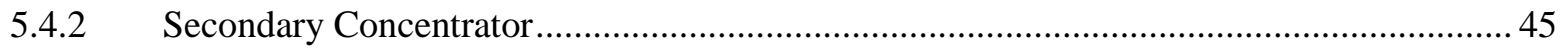

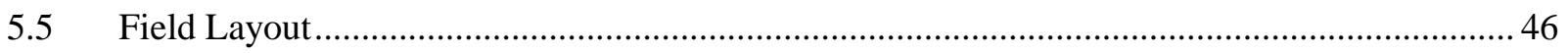

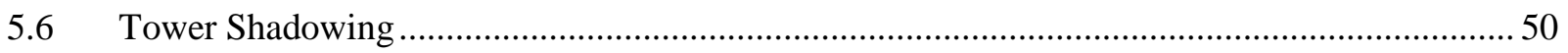

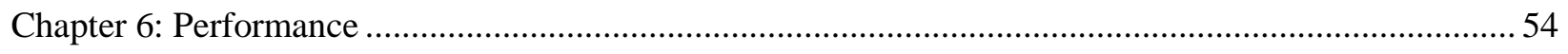

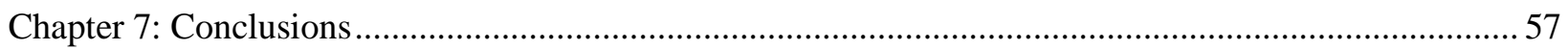

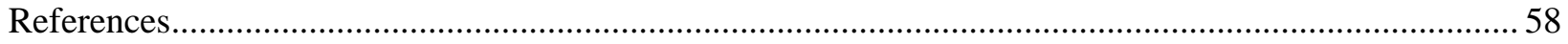

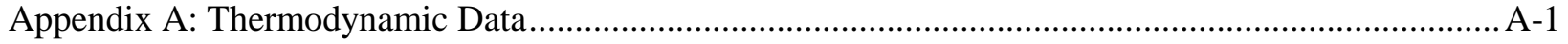




\section{List of Figures}

Figure 1-1: The Solar One plant in Barstow, California [4]. 3

Figure 1-2: The PS10 Solar Power Plant, an 11 MW system in Sevilla, Spain. There are $624120 \mathrm{~m}^{2}$

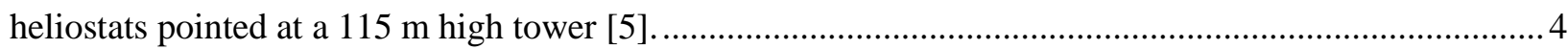

Figure 1-3: In this view of the PS10, the dust in the air makes the reflected beams visible [6]................ 4

Figure 1-4: A heliostat containing a set of mirrors each individually pointed towards the tower [7]..........5

Figure 1-5: Practical Solar $1 \times 1 \mathrm{~m}$ heliostat used for small-scale applications [9] ................................ 6

Figure 1-6: The external receiver of the Solar One facility in Barstow, CA [7]...................................... 7

Figure 1-7: A cavity type receiver with four apertures [10]......................................................... 8

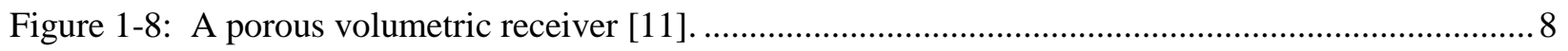

Figure 1-9: A pressurized volumetric receiver [14] ....................................................................

Figure 1-10: The clustering of pressurized volumetric receivers [14] ............................................... 10

Figure 1-11: The two main tower designs: free-standing steel (left) and concrete (right) [15]............... 11

Figure 1-12: Typical gas microturbine system schematic [16] ........................................................ 12

Figure 1-13: Pressure-volume (left) and temperature-entropy (right) diagrams for the air Brayton

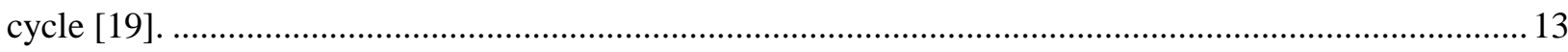

Figure 2-1: Radiation from the sun via diffuse, direct, and reflected modes [20]................................ 14

Figure 2-2: A device designed to measure diffuse horizontal irradiance, global horizontal irradiance,

and direct normal irradiance using two pyranometers and one pyrheliometer [21] .............................. 15

Figure 2-3: Coordinate system for observer at Q showing solar azimuth angle $\left(\gamma_{\mathrm{s}}\right)$, altitude angle $(\alpha)$, solar zenith angle $\left(\theta_{\mathrm{z}}\right)$, and solar unit vector $\mathrm{S}$. Unit vectors $\mathrm{i}, \mathrm{j}$, and $\mathrm{k}$ are also shown for reference [7]. 18

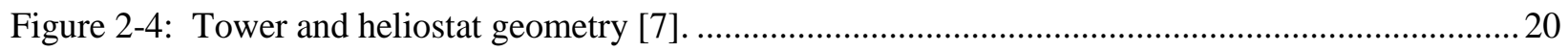

Figure 3-1: The schematic for a gas-solar hybrid microturbine .......................................................... 23

Figure 3-2: Detailed pressure-volume diagram for a gas-solar hybrid microturbine...............................2 24

Figure 3-3: Temperature-entropy diagram for a gas-solar hybrid microturbine....................................2 25 


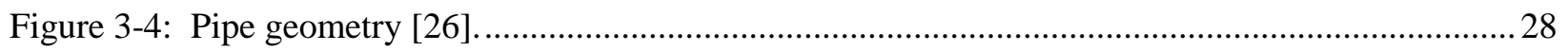

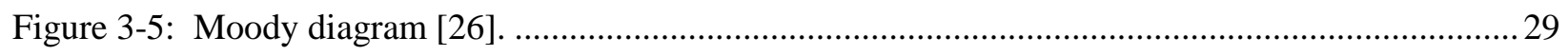

Figure 3-6: Cross section of a pipe with insulation showing diameter (D), h and $k$ values defined as

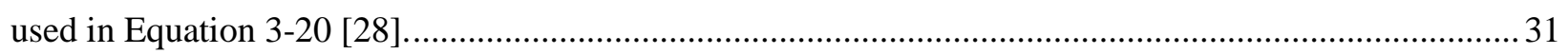

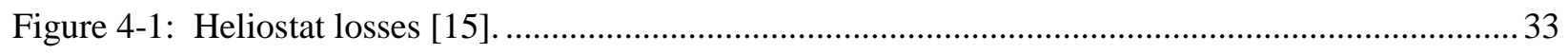

Figure 4-2: Heliostat effective area reduction through the cosine effect. ............................................... 35

Figure 4-3: The benefits of a northern field over a southern field, with respect to the tower [7]............. 36

Figure 4-4: Cosine efficiencies for different positions in a virtual field on March $21^{\text {st }}$ in San Luis

Obispo, CA. The distance from the tower is normalized by the tower height. The origin represents the

tower.

Figure 5-1: Diagram of the land area to be used for solar equipment on Cal Poly campus property.........39

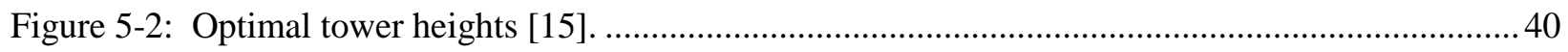

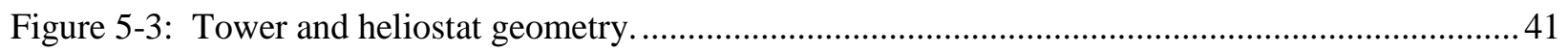

Figure 5-4: A heliostat with 6 mirrors from Thermata [29]. Each mirror is independently controlled.

The heliostat has a width of $5.68 \mathrm{~m}$ and a depth of $1.6 \mathrm{~m}$, with mirror surfaces $0.913 \mathrm{~m} \times 1.095 \mathrm{~m}$

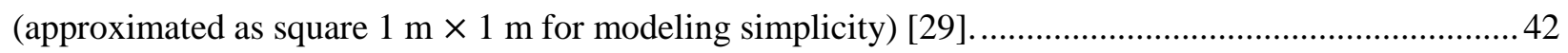

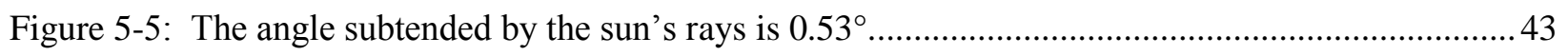

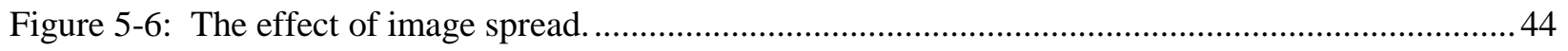

Figure 5-7: Secondary concentrator geometry [14] .................................................................... 45

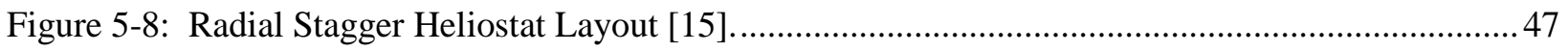

Figure 5-9: Heliostat placement for rough field dimensions of 210 X 100 feet. The origin represents

the tower.

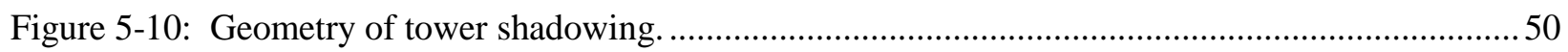

Figure 5-11: Tower shadow points overlaying the heliostat coordinates. Shadow points are calculated for a March $21^{\text {st }}$ day, which gives values similar to annual averages. The origin represents the tower. ...52 
Figure 6-1: Solar heat input and solar share values for the designed solar central receiver power plant in San Luis Obispo, CA as a function of time of day for January through June.

Figure 6-2: Solar heat input and solar share values for the designed solar central receiver power plant in San Luis Obispo, CA as a function of time of day for July through December. 


\section{List of Tables}

Table 2-1: Defining the solar and surface angles and their symbols [23].......................................... 17

Table 3-1: Calculated state points for the gas-solar hybrid microturbine.............................................. 27

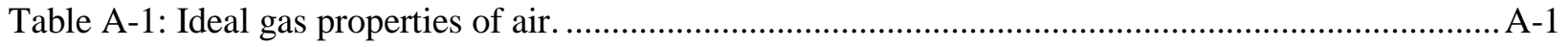




\section{Chapter 1: Introduction and Background}

\subsection{Scope}

The California Energy Commission (CEC) has issued the California Polytechnic State University in San Luis Obispo, California a grant for $\$ 397,000$ in order to assemble a predesigned concentrated solar power and natural gas hybrid power plant with off-the-shelf components on campus property. The goal of the power plant is to reduce non-renewable energy consumption in commercial buildings with solar thermal energy. The goal is to use this solar thermal energy to produce $100 \mathrm{~kW}$ of electric power through the use of a 0.5 acre area of land on campus property. It is also desired that the system displace electricity needs even further through the use of the waste heat of the system to run industrial equipment in the building. This thesis summarizes the analysis and design work done in the initial phase of the project.

\subsection{Introduction}

The use of fossil fuels has produced large amounts of air pollution due to the release of harmful gases as combustion byproducts. Also, increasing levels of carbon dioxide in the atmosphere from fossil fuel combustion is believed by some to be the main source of global warming over the past 150 years [1]. Additionally, power plants often release large amounts of waste heat to the environment. This can lead to thermal pollution in rivers and lakes causing harm to many forms of plant and animal life [1].

Ever since the demand for fossil fuels has begun to rise, industries have been turning towards new, clean solutions to their energy needs. Solar energy has long been a potential solution to these needs. The power intercepted by the earth from the sun is estimated at about $1.8 \times 10^{11} \mathrm{MW}$ [1]. In fact, the sun provides enough energy in one hour to supply the earth with its energy needs for a whole year.

However, there are many challenges that must be overcome when considering solar energy usage. The main issue faced today with implementing solar power is the extremely high capital costs involved with installing new solar power plants. Because solar power plants are most efficient in sunny climates and due to large space requirements, solar power plants are often designed in desert climates, sometimes 
miles from the nearest town. This presents difficulties in transporting the produced electricity. Additionally, even in the hottest places in the world, the radiation flux usually does not reach levels higher than $1 \mathrm{~kW} / \mathrm{m}^{2}$, making solar energy a dilute power source [1]. This leads to the need for large collection facilities in order to maximize the energy potential from solar radiation.

Solar energy is cyclical; variation in energy availability occurs daily and seasonally, and depends very highly on weather conditions. This leads to the need for solar energy storage or an external supplementation during the hours sunshine is not as intense.

Solar energy electricity production can be broken down into two categories: thermal and photovoltaic. Thermal systems operate using the heat of the sun to drive turbomachinery. Photovoltaic systems convert photons in sunlight to electricity via the photovoltaic effect.

Thermal systems are most often concentrated solar power (CSP) systems, as they produce high temperatures. These systems increase temperatures by reflecting radiation from a large area to a smaller area, in order to concentrate the radiation. This thesis will explore one example of a solar thermal power production plant: the solar central receiver power plant.

\subsection{Objective}

The objective of this thesis is to provide a method for sizing and designing a small-scale solar central receiver power plant system located in San Luis Obispo, California on Cal Poly campus property.

\subsection{Background}

A solar central receiver power plant involves the use of a field of mirrors called heliostats pointed towards a receiver atop a large tower. The field of heliostats acts as a large parabolic reflector broken into small segments. The receiver heats up due to the incoming solar radiation flux and transmits heat to a heat transfer fluid. This fluid is usually water, air, or molten salt. The heat transfer fluid is then used, directly or indirectly, to run a turbine that produces electricity through a generator. 
Concentration ratios (total area of the heliostats to area of the receiver) as high as 3000 may be achieved with solar central receiver systems [2].

The concept of solar central receiver power plants began with Sandia National Laboratories in 1976 with the establishment of the National Solar Thermal Test Facility in Albuquerque, New Mexico [3]. Soon thereafter, several pilot facilities were built around the world, the largest of which was the Solar One plant in Barstow, California, as seen in Figure 1-1. Solar One was rated at $10 \mathrm{MW}$ and consisted of 1818 heliostats each with a reflective area of $39.9 \mathrm{~m}^{2}$, covering 72 acres of land. The receiver sat atop a $90.8 \mathrm{~m}(298 \mathrm{feet})$ tower and produced steam at $516^{\circ} \mathrm{C}\left(960^{\circ} \mathrm{F}\right)$. It operated from 1982 to 1988 after which it was dismantled, and parts of it were used in another 10 MW test facility called Solar Two.

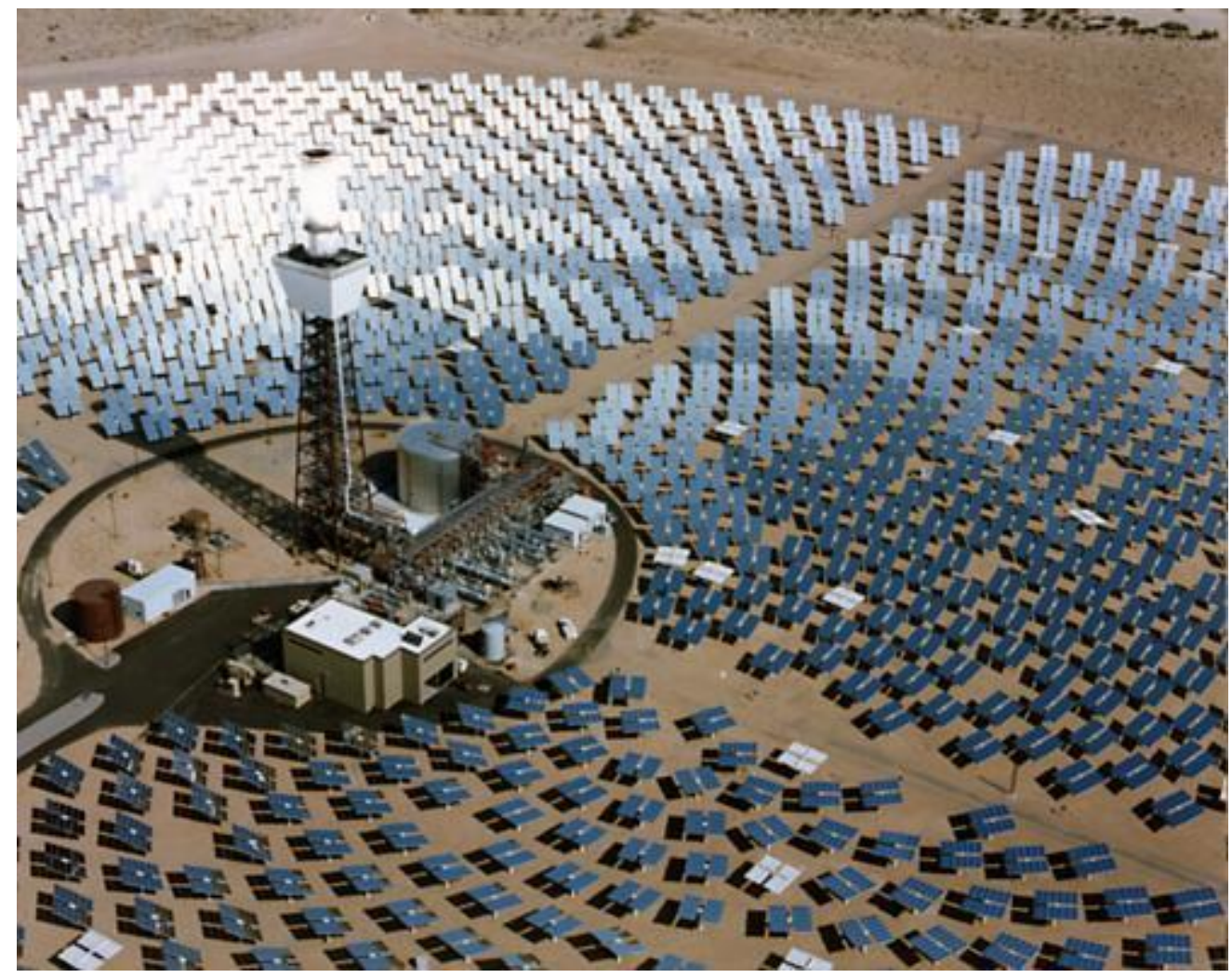

Figure 1-1: The Solar One plant in Barstow, California [4]. 
Figure 1-2 and Figure 1-3 show the PS10 solar central receiver power plant that is currently operational in Spain.

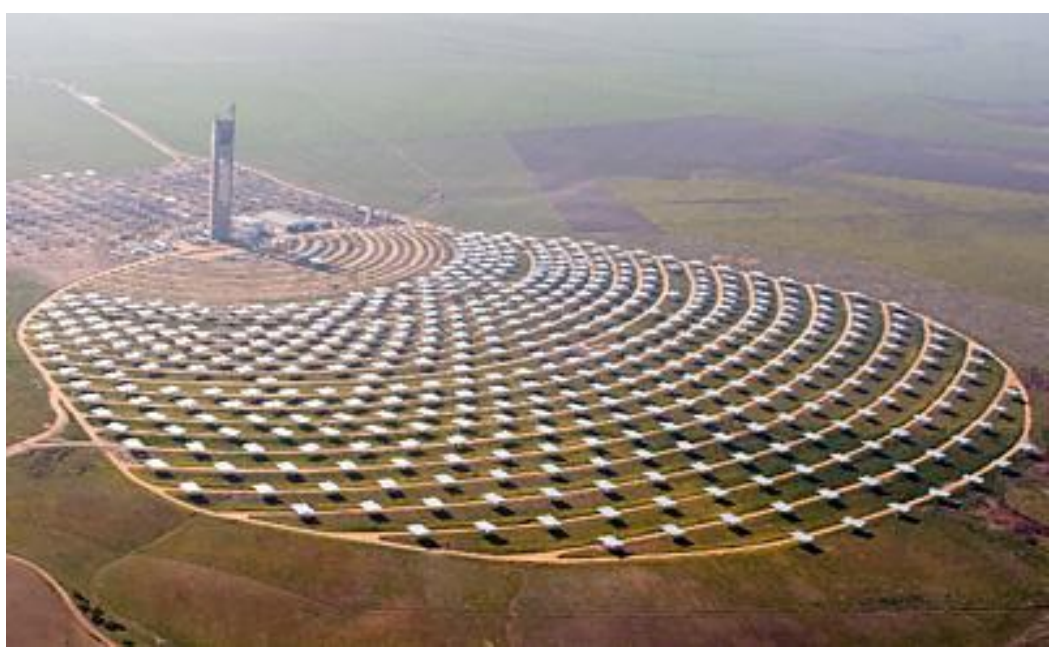

Figure 1-2: The PS10 Solar Power Plant, an 11 MW system in Sevilla, Spain. There are $624120 \mathrm{~m}^{2}$ heliostats pointed at a $115 \mathrm{~m}$ high tower [5].

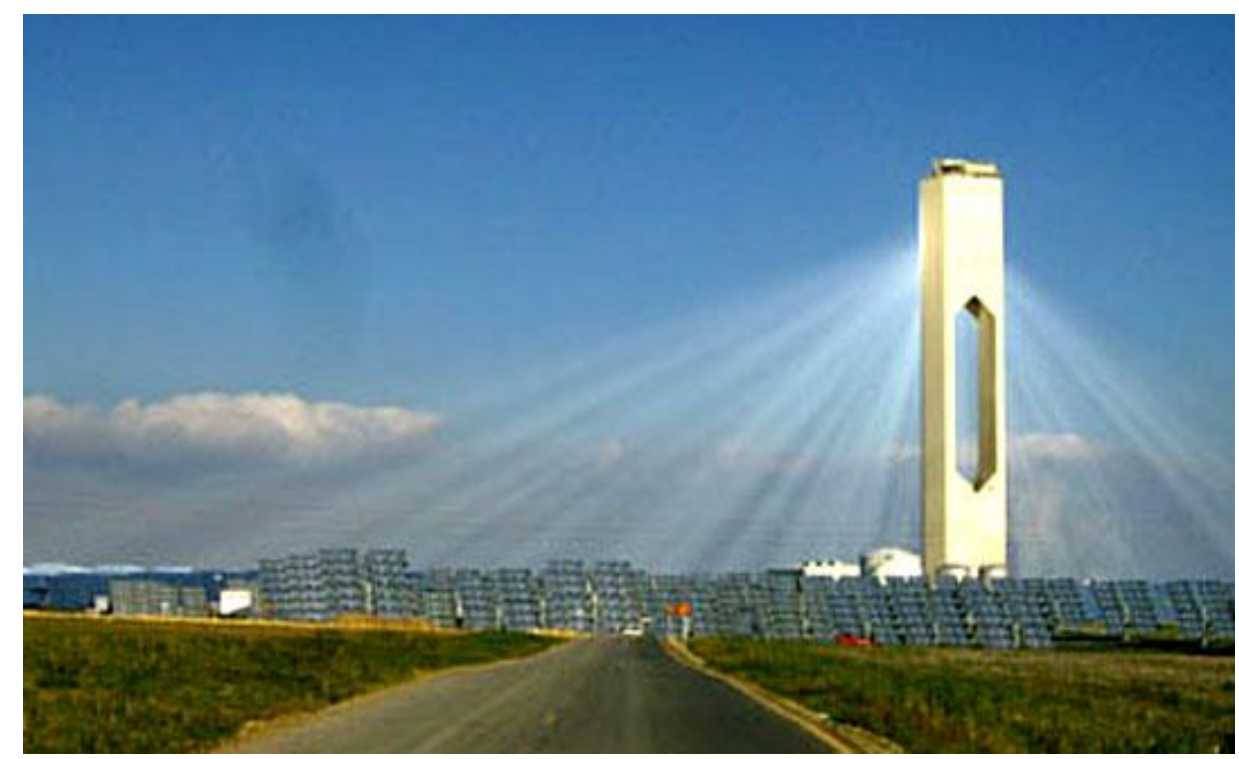

Figure 1-3: In this view of the PS10, the dust in the air makes the reflected beams visible [6].

The main components of a solar central receiver power plant include the heliostats, the receiver, the tower, and the turbine. These components are described in more detail in the sections that follow. 


\subsubsection{Heliostats}

A heliostat is a large mirror or set of mirrors attached to a tracking control system that moves about two axes throughout the day in order to track the sun and keep the sun's radiation reflected onto the center of the receiver. The reflecting surface is usually a thin, low-iron glass mirror [7]. The heliostat is capable of rotating up and down (tilt) and left to right (surface azimuth adjustments). Another main purpose of the tracking control system is to store the heliostat in a safe, downward position when not in use. The tracking system uses motors controlled by a central computer that accurately points the heliostats in a way that bisects the angle between the vector coming from the sun and a vector pointing from the heliostat origin to the receiver. This bisection is done by analyzing the astronomical equations for the positioning of the sun, as well as the coordinates for the known position of the individual heliostat and the tower. This process minimizes the incident angle of the radiation beam and thereby maximizes the reflected radiation. Although most heliostats operate through the use of motors controlled by computers, some use sensors such as photoresistors to track the orientation of the sun, while others are operated manually at various times throughout the day [8].

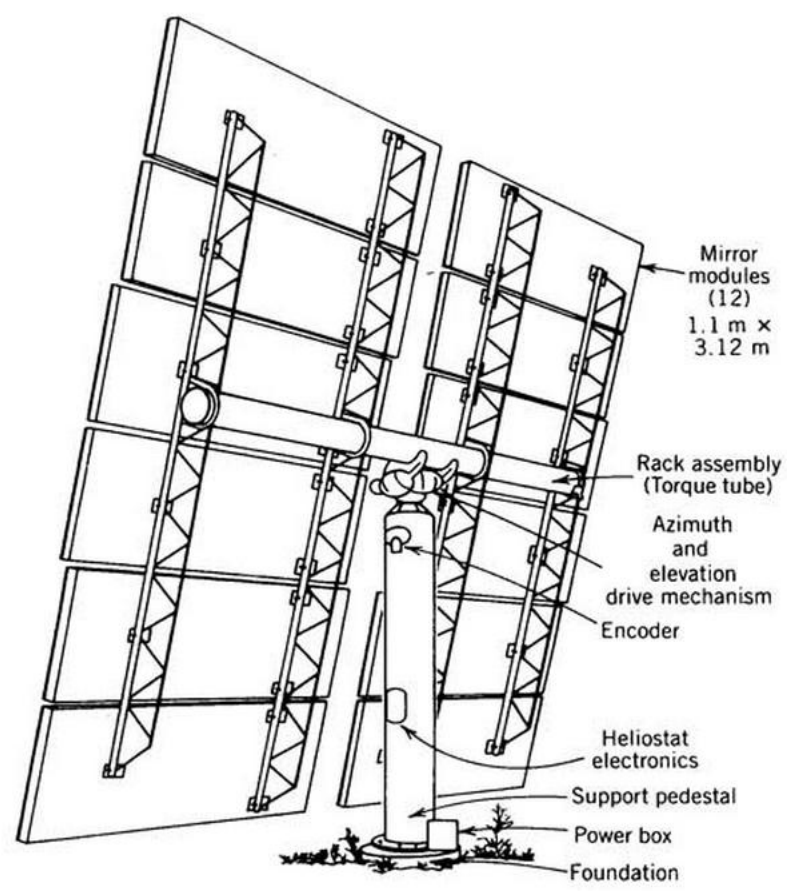

Figure 1-4: A heliostat containing a set of mirrors each individually pointed towards the tower [7]. 
Heliostats are also used in small-scale applications, either to provide natural lighting or modest water heating, as shown in Figure 1-5.

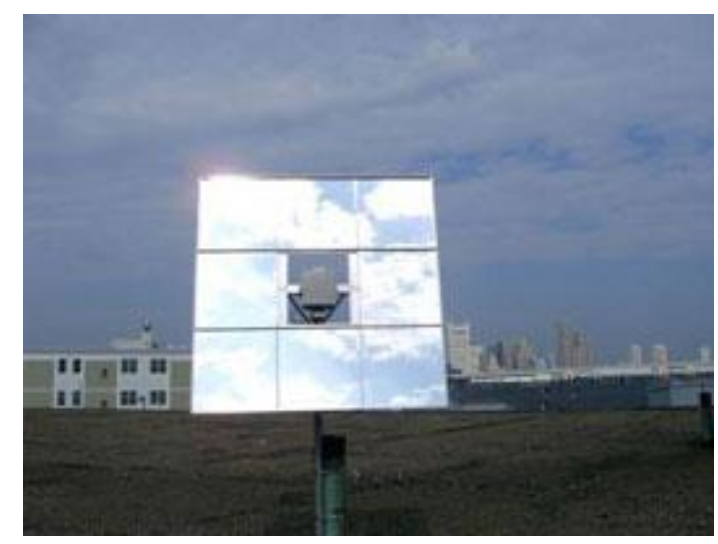

Figure 1-5: Practical Solar $1 \times 1 \mathrm{~m}$ heliostat used for small-scale applications [9].

\subsubsection{Receivers}

The receiver transfers the energy from the incoming reflected solar radiation to a heat transfer fluid which runs a turbine. Receivers are positioned at the top of the tower and high above the level of the heliostats on the tower in order to minimize the effect of shadowing and blocking (Section 4.2) among neighboring heliostats. In this way, the reflected energy from the heliostats is collected as efficiently as possible. Receiver apertures (absorbers) are sized to approximate the size of the image of the sun from the farthest heliostat (Section 5.4.1). Aperture size also must be minimized in order to minimize heat loss due to convection and radiation, which is directly proportional to the aperture area. In general, two main types of receivers are used: external and cavity receivers.

\section{External Receivers}

External receivers usually consist of panels of tubes welded together in a cylindrical fashion, as shown in Figure 1-6. The tubes supply heat transfer fluid that is heated and collected for use in a turbine. External receivers usually have a height to diameter ratio of 1:1 to 2:1 [7]. Heat transfer fluids are typically those with high thermal conductivities, such as liquid sodium, water/steam, or molten nitrate salt. In the case of liquid sodium, the receiver surface area may be reduced slightly because of the high 
heat capacity of the fluid. For water/steam and molten nitrate salt, the surface area must be larger in order to compensate for the relatively low heat capacity of these fluids.

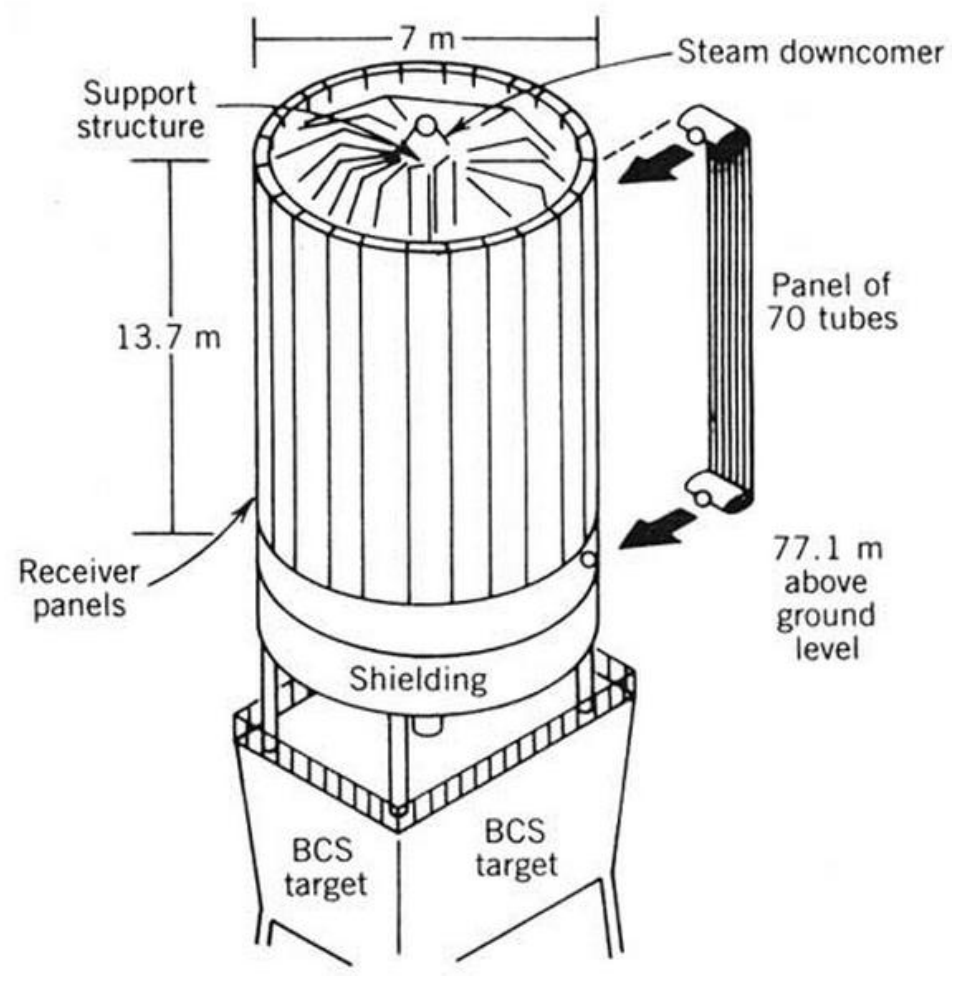

Figure 1-6: The external receiver of the Solar One facility in Barstow, CA [7].

\section{Cavity (Internal) Receivers}

The main advantage of cavity receivers is that the heat absorbing surface is placed inside an insulated cavity in order to reduce heat loss to the surroundings. This also allows losses from receiver aperture reflection to be lowered. Cavity receivers generally have a structure between the aperture and the ambient called a secondary concentrator, which serves to further concentrate the incoming reflected radiation from the heliostats. 
An example of a large cavity receiver with four apertures is shown in Figure 1-7.

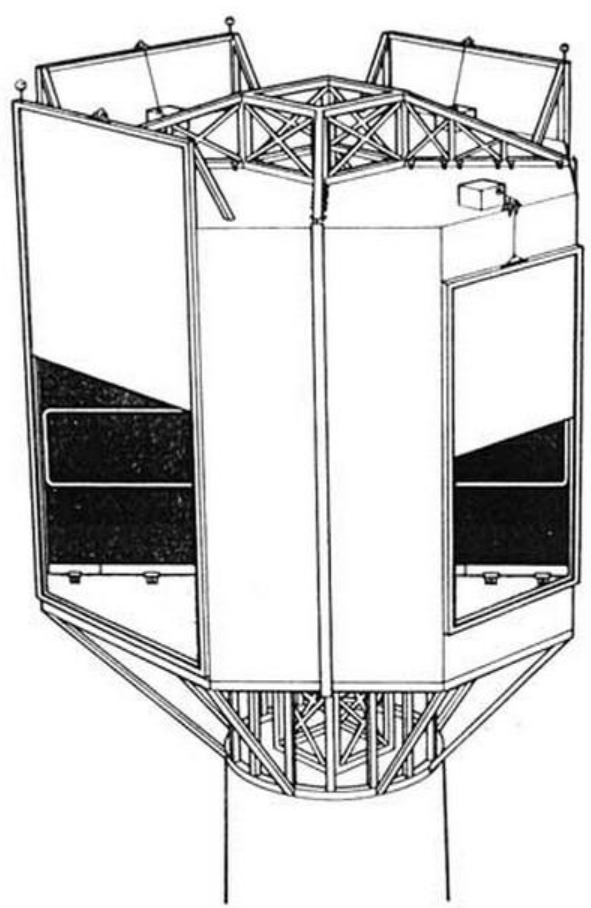

Figure 1-7: A cavity type receiver with four apertures [10].

\section{Volumetric Receivers}

Porous, high temperature resistant materials are often used in cavity receivers. Ambient air is heated by flowing through the porous material located at the aperture. These receivers are called volumetric receivers, because due to their porosity, much of the radiation is absorbed in the volume of the material [11]. Figure 1-8 shows a schematic for porous material receivers.

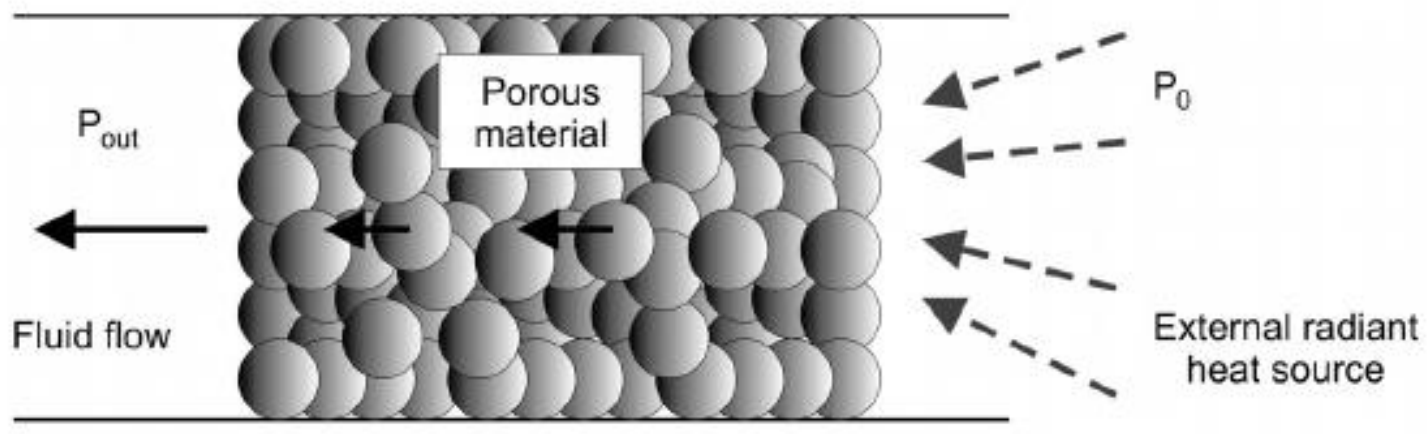

Figure 1-8: A porous volumetric receiver [11]. 
The use of air as a heat transfer fluid simplifies the system, making volumetric receivers advantageous. Fluid leaks are not a concern and there is less auxiliary equipment required [12].

Operation, maintenance, and fabrication costs are reduced due to the simplicity of the materials and their configuration. Low thermal inertia of porous materials also allows for rapid start up times for the power plant. Additionally, because cool air is sucked in through the radiated side of the material, the face of the material is kept relatively cool, thereby minimizing heat loss due to radiation and convection. However, because volumetric receivers use atmospheric air, a heat exchanger must be installed in order to distribute heat to the actual heat transfer fluid used in the cycle.

\section{Pressurized Volumetric Receivers}

When solar heating of pressurized air is desired, such as with gas turbine applications, pressurized volumetric receivers are used. These receivers implement similar porous absorbers located behind a domed quartz window [13]. The window allows the pressurized air coming from the compressor of the turbine to remain pressurized as it is heated. The absorber consists of layers of wire mesh screens. This receiver can achieve air temperatures of about $800^{\circ} \mathrm{C}\left(1472^{\circ} \mathrm{F}\right)$ [14]. If higher temperatures are desired, ceramic absorber materials are utilized.

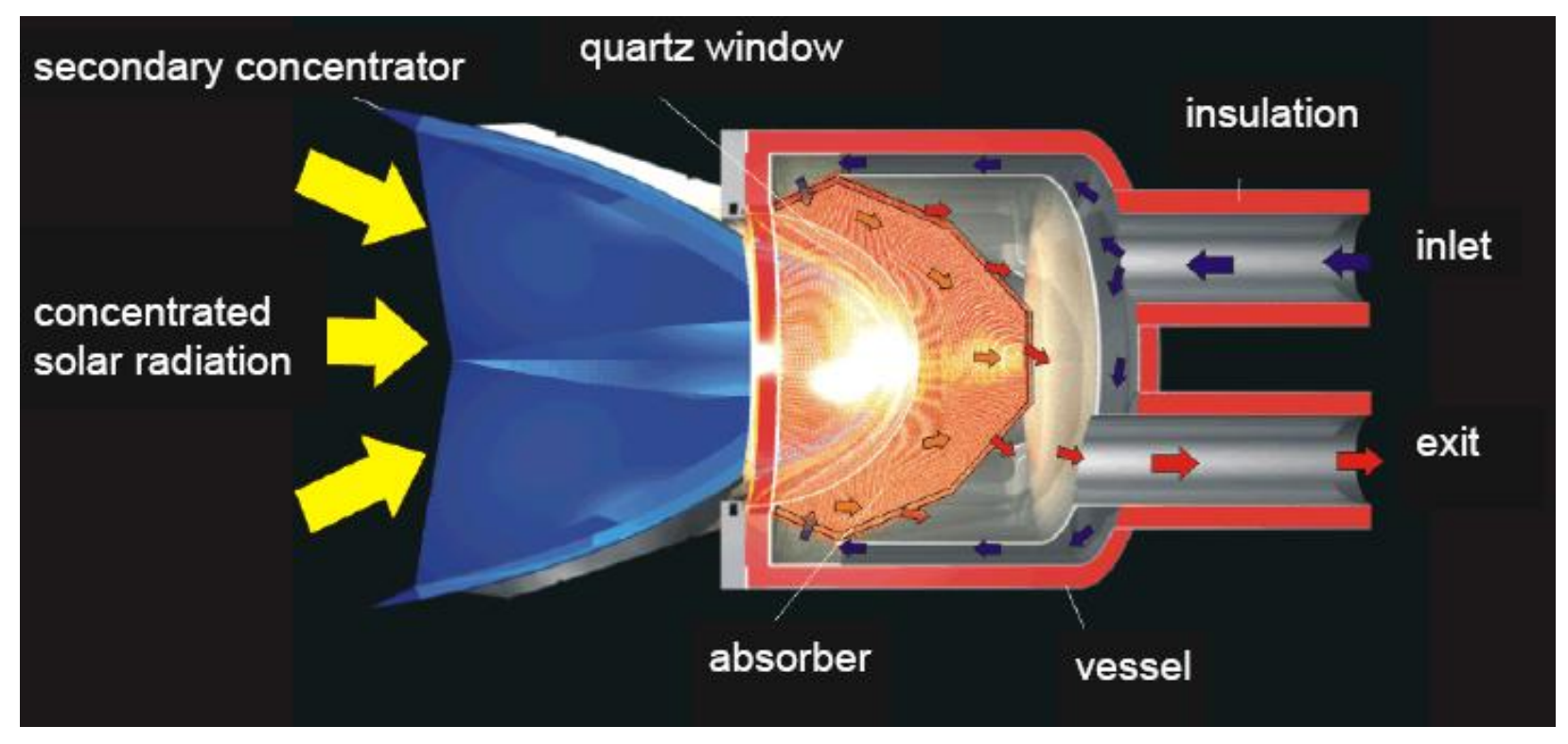

Figure 1-9: A pressurized volumetric receiver [14]. 
These receivers are often placed in a cluster as shown in Figure 1-10 due to the limited size of the quartz window.
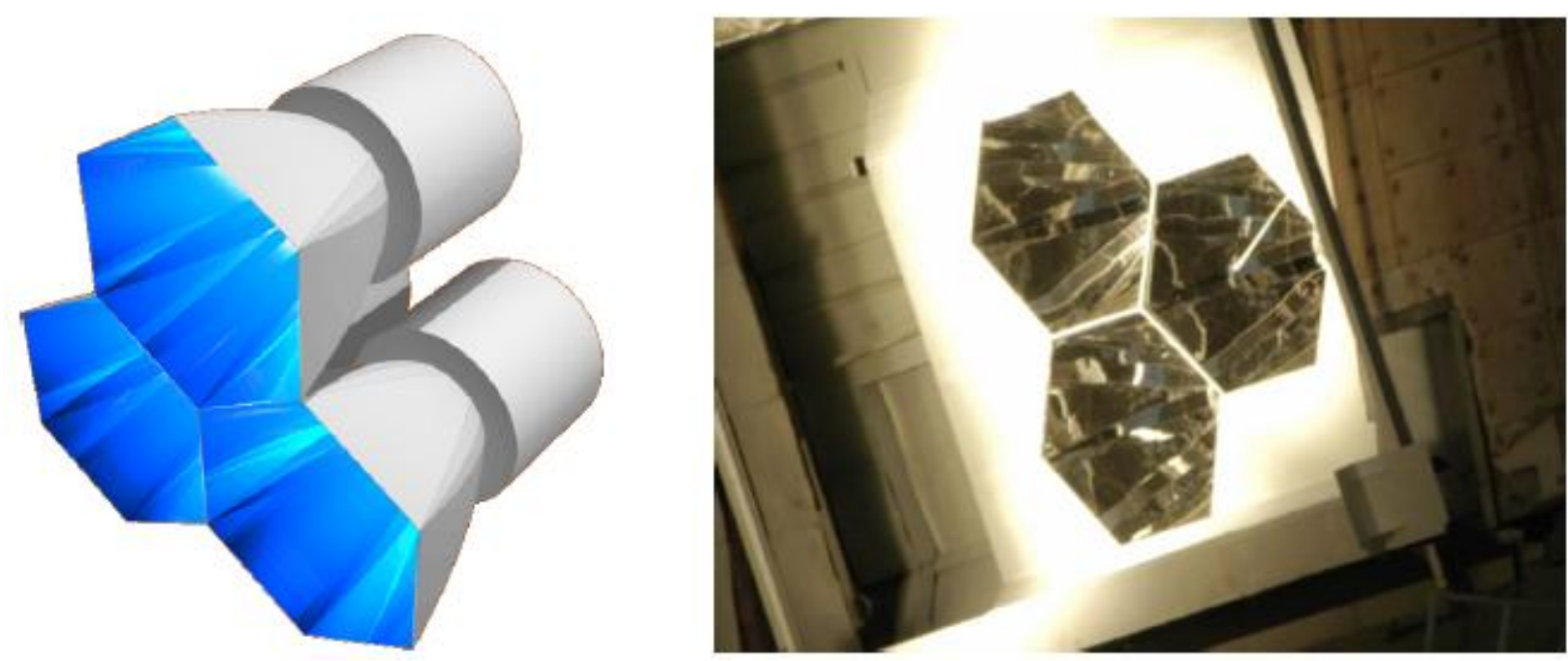

Figure 1-10: The clustering of pressurized volumetric receivers [14].

\subsubsection{Towers}

It is desirable to build the tower relatively high in order to minimize interference between neighboring heliostats. However, the height of the tower is usually limited by its cost. Wind, receiver weight, and seismic loads are the three most important factors considered when designing a tower. Receiver weight loads are variable, but many towers have been designed to withstand wind and seismic loads of $90 \mathrm{mph}$ and $0.25 \mathrm{~g}$, respectively [7].

Often times the tower has structures located just below the receiver called beam characterization targets (see Figure 1-6). These are used for periodic beam radiation measurements and heliostat calibration. They are not intended to receive the radiation from more than one or two heliostats at a time [7].

Towers are mainly constructed from either reinforced concrete or free-standing steel. Freestanding steel towers are generally more cost effective at tower heights below $120 \mathrm{~m}$ (400 feet).

Reinforced concrete towers have proven more cost effective at tower heights greater than $120 \mathrm{~m} \mathrm{[15].}$ The foundation of the tower is most often constructed from reinforced concrete in order to transfer loads to the underlying soil. 
Figure 1-11 shows the two main tower designs.
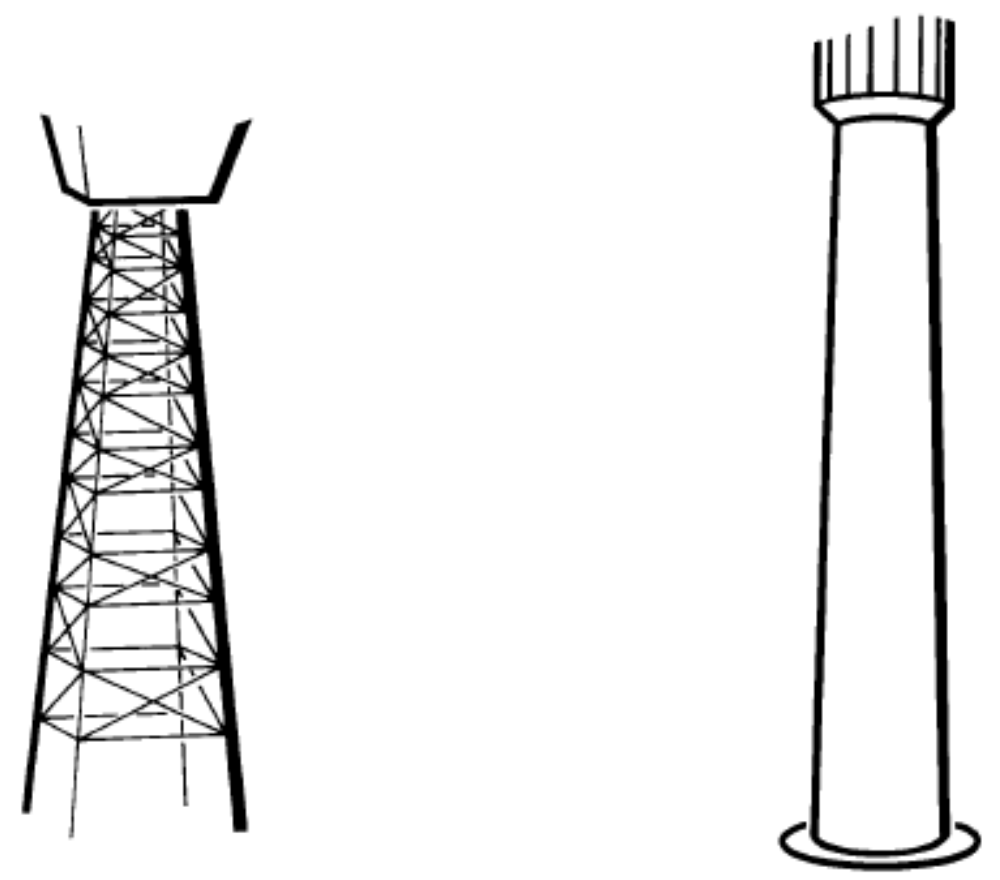

Figure 1-11: The two main tower designs: free-standing steel (left) and concrete (right) [15].

\subsubsection{Gas Microturbines}

Gas turbine engines are generally categorized as microturbines when their nominal electrical capacity is $250 \mathrm{~kW}$ or less [16]. This thesis uses specifications from a $100 \mathrm{~kW}$ microturbine [17] to meet the goal of $100 \mathrm{~kW}$ of electrical power production. Microturbines use the combustion of gaseous and liquid fuels to produce high speed rotation that turns an electrical generator. Microturbine technology was selected for this application due to the relatively high efficiencies in small-scale applications. Most central receiver systems in existence use steam turbine engines running on the Rankine cycle. However, steam cycles are most efficient and more practical at high power levels, reaching up to $36 \%$ efficiency in the megawatt capacity range. At small-scale power levels, efficiencies can drop as low as $10 \%$.

Microturbines operating on the Brayton cycle can reach efficiencies as high as 30\% at small-scale power levels [16]. 
Microturbines are able to achieve these relatively high efficiencies due to their internal heat exchangers, called recuperators, which capture much of the exhaust heat and transfer it to the compressed air before entering the combustor. Inlet air is compressed by a radial flow compressor and subsequently heated through the recuperator before entering the combustor. High pressure air and fuel (typically natural gas) are mixed and ignited in the combustor. The hot gas is then expanded across the turbine which turns the compressor and the generator. The exhaust gas is then used for preheating compressed air in the recuperator before it leaves the engine. A schematic of a typical microturbine system is shown in Figure 1-12 below.

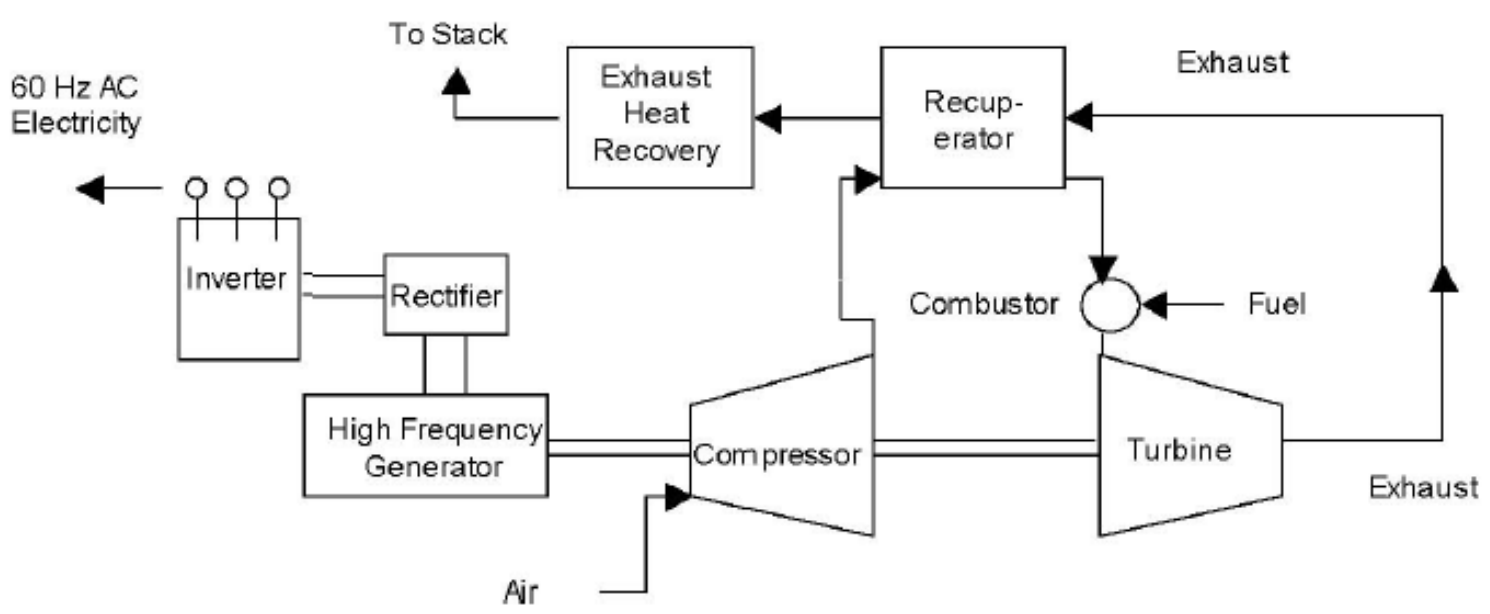

Figure 1-12: Typical gas microturbine system schematic [16]. 
Microturbines operate on the Brayton cycle, where gas is compressed, heated, and expanded to perform work. This cycle is shown in Figure 1-13. Useful work is produced from the turbine once the work needed to turn the compressor has been extracted. The power absorbed is directly proportional to the absolute temperature of the gas [16], so operating at maximum turbine inlet temperatures and minimum compressor inlet temperatures is highly desirable. To enable the use of affordable materials in construction, turbine inlet temperatures are limited to about $1800^{\circ} \mathrm{F}\left(982^{\circ} \mathrm{C}\right)$. In general, turbine inlet temperatures are in the range of $1550-1750^{\circ} \mathrm{F}$ (about $840^{\circ} \mathrm{C}$ to $950^{\circ} \mathrm{C}$ ) [18]. As turbine inlet temperatures rise, optimal pressure ratios (compressor outlet pressure to inlet pressure) also rise. Typical microturbine pressure ratios are in the range of 3.5 to 4 [16].
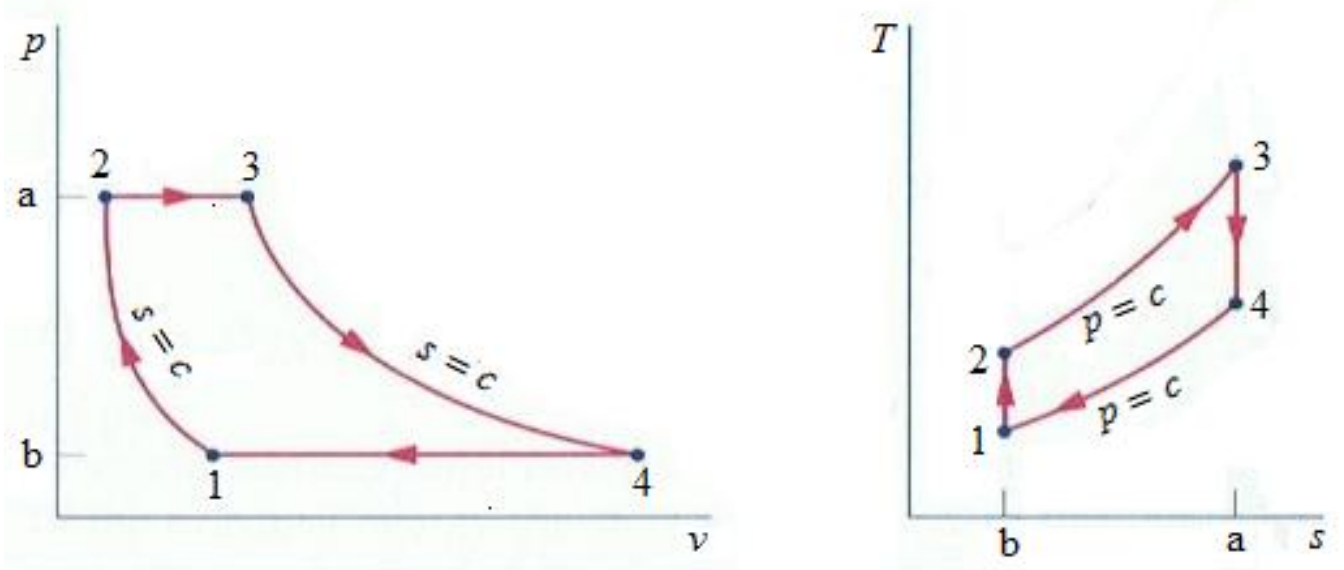

Figure 1-13: Pressure-volume (left) and temperature-entropy (right) diagrams for the air Brayton cycle [19]. 


\section{Chapter 2: Solar Radiation}

Incoming solar radiation is composed of three components: direct normal, diffuse, and reflected radiation, as shown in Figure 2-1. Radiation is often called irradiance in the solar industry, and is expressed in watts per square meter $\left(\mathrm{W} / \mathrm{m}^{2}\right)$. Direct normal irradiance (DNI) is the direct component of the sun beam that hits a surface perpendicular to the beam. Diffuse irradiance is the radiation that is reflected off clouds and the atmosphere before received by an object at the ground level. Reflected irradiance is the radiation that bounces off the ground or other objects above ground level before received at the collector surface. Typically, irradiance values are either described using DNI or global horizontal irradiance (GHI) measurements. Global horizontal irradiance values are made up of diffuse and direct normal irradiance values on a horizontal surface. Because diffuse and reflected irradiance is coming in at low levels from all angles, it is very difficult to concentrate and is therefore not used in the calculations presented in this thesis. The DNI component is used for concentration calculations, as it has a distinct direction and large magnitude. Thus, during a cloudy day, when only diffuse and reflected irradiance are present, the power plant effectively receives no solar input.

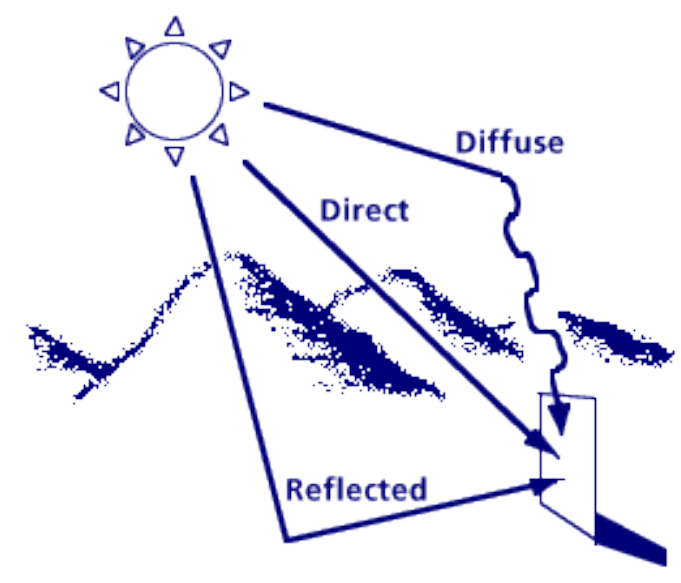

Figure 2-1: Radiation from the sun via diffuse, direct, and reflected modes [20]. 


\subsection{Measuring Solar Radiation}

In order to predict the amount of energy attainable from the sun, there must be an estimate of the incoming solar radiation. There are two main devices used to measure solar radiation: the pyranometer and the pyrheliometer.

Pyranometers have a hemispherical view of the sky and measure the sun's energy from all directions. They use insulated thermocouples connected in series (thermopiles) attached to a black absorbing surface. The surface reaches a temperature that is proportional to the radiant energy absorbed. The radiation absorbed is taken as the GHI. In some instances, by blocking the sun's disk they are used to measure diffuse radiation only (see Figure 2-2). Pyranometers are typically oriented high above obstructions in a horizontal orientation in order to measure GHI [7].

The pyrheliometer is essentially a long tube with a thermopile at the end. The tube has an acceptance angle of about $5^{\circ}$, and uses a two-axis tracking mechanism in order to maintain the sun's disk within this $5^{\circ}$. Because it keeps the sun's disk in the acceptance region of the tube, it essentially blocks out diffuse radiation and therefore gives a measurement of the direct normal irradiance (DNI) only.

Figure 2-2 shows the difference between these two instruments.

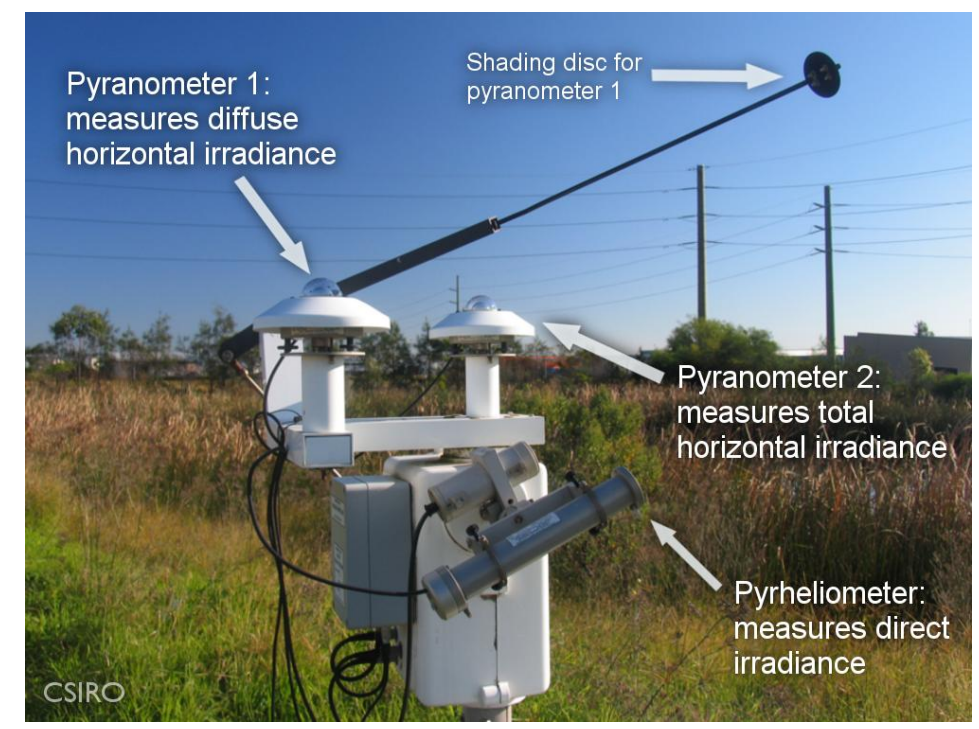

Figure 2-2: A device designed to measure diffuse horizontal irradiance, global horizontal irradiance, and direct normal irradiance using two pyranometers and one pyrheliometer [21]. 


\subsection{Modeled Solar Radiation}

There are also organizations that produce solar radiation data for many cities in the U.S. based on historical measurements. The most renowned database in current use is produced by the National Renewable Energies Laboratory (NREL, www.rredc/nrel/solar). They create databases for over 1000 cities in the U.S. based on average weather and solar data over a 15-year time period. This averaging creates what is called a typical meteorological year (TMY). The latest TMY set is TMY3, which uses data from 1991-2005. The database is formed by choosing which month out of the 15-year time period is the most typical, as deemed by the algorithm developed at NREL. For example, the TMY3 database for San Luis Obispo is made up of January from 1999, February from 1994, March from 1995, etc. As previously stated, the DNI is the most useful parameter for the solar central receiver system. The TMY should not be used to predict solar conditions at a certain time, but rather as a general forecast of a typical year[22].

It is important to note that the TMY3 data base provides hourly DNI values based on solar time. Solar time is the apparent time of day, based on the position of the sun in the sky, where solar noon is when the sun is located due south of a location. It is usually slightly different from what is read from watches or clocks (standard time), as seen in (2-1. The reader should see reference [1] for further explanation on converting solar time to standard clock time for a specific location.

$$
\begin{array}{r}
\text { Solar time }=\text { Standard Time } \pm 4(\text { Standard time longitude }- \\
\text { longitude of location+Equation of time correction }
\end{array}
$$

Values of DNI are assumed constant throughout the hour for which they are reported. During certain hours, DNI values are very low or zero because of cloud coverage. This means that the year deemed most typical for each particular month also includes typical weather. 


\subsection{Solar Geometry}

In order to predict the location of the sun for heliostat tracking, the geometry is defined as follows:

Table 2-1: Defining the solar and surface angles and their symbols [23].

\begin{tabular}{|c|c|c|}
\hline$\varphi$ & Latitude & $\begin{array}{l}\text { The angular location north or south of the equator, north positive; }-90^{\circ} \leq \\
\varphi \leq 90^{\circ} \text {. }\end{array}$ \\
\hline$\delta$ & Declination & $\begin{array}{l}\text { The angular position of the sun at solar noon with respect to the plane of } \\
\text { the equator, north positive; }-23.45^{\circ} \leq \delta \leq 23.45^{\circ} \text {. }\end{array}$ \\
\hline$\beta$ & Tilt & $\begin{array}{l}\text { The angle between the plane of the surface in question and the horizontal; } \\
0^{\circ} \leq \beta \leq 180^{\circ} \text {. }\end{array}$ \\
\hline$\gamma_{H}$ & $\begin{array}{l}\text { Surface (Heliostat) } \\
\text { Azimuth Angle }\end{array}$ & $\begin{array}{l}\text { The deviation of the projection on a horizontal plane of the normal to the } \\
\text { surface from the local meridian, with zero due north, east positive, and } \\
\text { west negative; }-180^{\circ} \leq \gamma_{\mathrm{H}} \leq 180^{\circ} \text {. }\end{array}$ \\
\hline$\omega$ & Hour Angle & $\begin{array}{l}\text { The angular displacement of the sun east or west of the local meridian } \\
\text { due to rotation of the earth on its axis at } 15^{\circ} \text { per hour, morning negative, } \\
\text { afternoon positive. }\end{array}$ \\
\hline$\theta_{\mathrm{i}}$ & $\begin{array}{l}\text { Angle of } \\
\text { Incidence }\end{array}$ & $\begin{array}{l}\text { The angle between the beam radiation on a surface and the normal to that } \\
\text { surface. }\end{array}$ \\
\hline$\theta_{\mathrm{z}}$ & Zenith Angle & $\begin{array}{l}\text { The angle between the vertical and the line to the sun, i.e., the angle of } \\
\text { incidence of beam radiation on a horizontal surface. }\end{array}$ \\
\hline$\alpha$ & $\begin{array}{l}\text { Solar Altitude } \\
\text { Angle }\end{array}$ & $\begin{array}{l}\text { The angle between the horizontal and the line to the sun; the complement } \\
\text { of the zenith angle. }\end{array}$ \\
\hline$\gamma_{\mathrm{s}}$ & $\begin{array}{l}\text { Solar Azimuth } \\
\text { Angle }\end{array}$ & $\begin{array}{l}\text { The angular displacement from north of the projection of beam radiation } \\
\text { on the horizontal plane. Displacements east of north are positive and } \\
\text { west of north are negative; }-180^{\circ} \leq \gamma_{\mathrm{s}} \leq 180^{\circ} \text {. }\end{array}$ \\
\hline
\end{tabular}


Figure 2-3 shows how the coordinate system is set up for solar equations. Unit vectors $\mathrm{i}, \mathrm{j}$, and $\mathrm{k}$ are shown corresponding to the zenith, east, and north directions, respectively. The altitude, zenith, and azimuth angles are also shown as defined in Table 2-1.

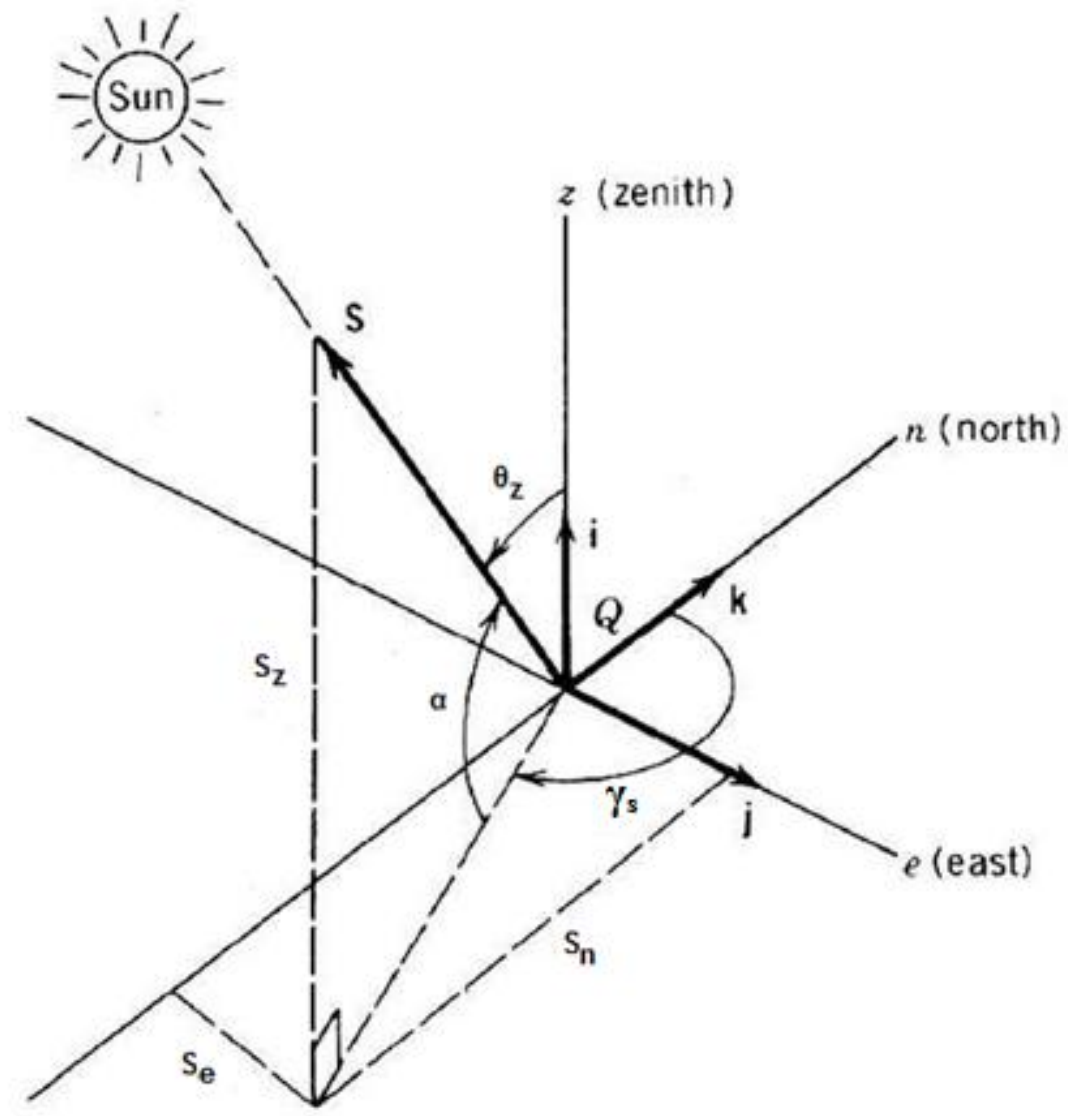

Figure 2-3: Coordinate system for observer at $Q$ showing solar azimuth angle $\left(\gamma_{s}\right)$, altitude angle $(\alpha)$, solar zenith angle $\left(\theta_{z}\right)$, and solar unit vector $S$. Unit vectors $i, j$, and $k$ are also shown for reference [7].

Declination $\delta$ is defined from reference [23] as:

$$
\delta=23.45 \sin \left(360 \frac{284+\mathrm{n}}{365}\right)
$$

Where $\mathrm{n}$ is the day of the year (ranging from 1-365).

The zenith angle can be described by the angle of incidence on a horizontal surface. It is given in [23] as:

$$
\cos \left(\theta_{\mathrm{z}}\right)=\cos (\varphi) \cos (\delta) \cos (\omega)+\sin (\varphi) \sin (\delta)
$$


To calculate the solar azimuth angle, the hour angles $\omega$ and $\omega_{\mathrm{ew}}$ are used. An expression for the solar azimuth angle is transcribed in [23]:

$$
\gamma_{\mathrm{s}}=\mathrm{C}_{1} \mathrm{C}_{2} \gamma_{\mathrm{s}}^{\prime}+\mathrm{C}_{3}\left(\frac{1-\mathrm{C}_{1} \mathrm{C}_{2}}{2}\right) 180
$$

where

$$
\sin \left(\gamma_{\mathrm{s}}^{\prime}\right)=\frac{\sin (\omega) \cos (\delta)}{\sin \left(\theta_{z}\right)}
$$

and

$$
\begin{gathered}
\cos \left(\omega_{e w}\right)=\frac{\tan (\delta)}{\tan (\varphi)} \\
C_{1}=\left\{\begin{array}{c}
1 \text { if }|\omega| \leq \omega_{e w} \\
-1 \text { if }|\omega|>\omega_{e w}
\end{array}\right. \\
C_{2}=\left\{\begin{array}{c}
1 \text { if } \varphi-\delta \geq 0 \\
-1 \text { if } \varphi-\delta<0
\end{array}\right. \\
C_{3}=\left\{\begin{array}{c}
1 \text { if } \omega \geq 0 \\
-1 \text { if } \omega<0
\end{array}\right.
\end{gathered}
$$

Using Equations 2-2 through 2-9, the solar azimuth, zenith, and altitude angles can be calculated for any hour of the year for any location on the planet. 


\subsection{Tracking the Sun}

In order to solve for the heliostat incident angle, $\theta_{\mathrm{i}}$, and find the appropriate orientation of each individual heliostat, unit vectors are defined as shown in Figure 2-4. $\mathbf{S}$ is the unit vector pointed from the heliostat directly to the sun. $\mathbf{H}$ is the unit normal vector from the heliostat surface. Finally, $\mathbf{R}$ is the unit vector pointing from the heliostat to the receiver on the tower (aim point). Tracking equations in this section are taken from reference [7].

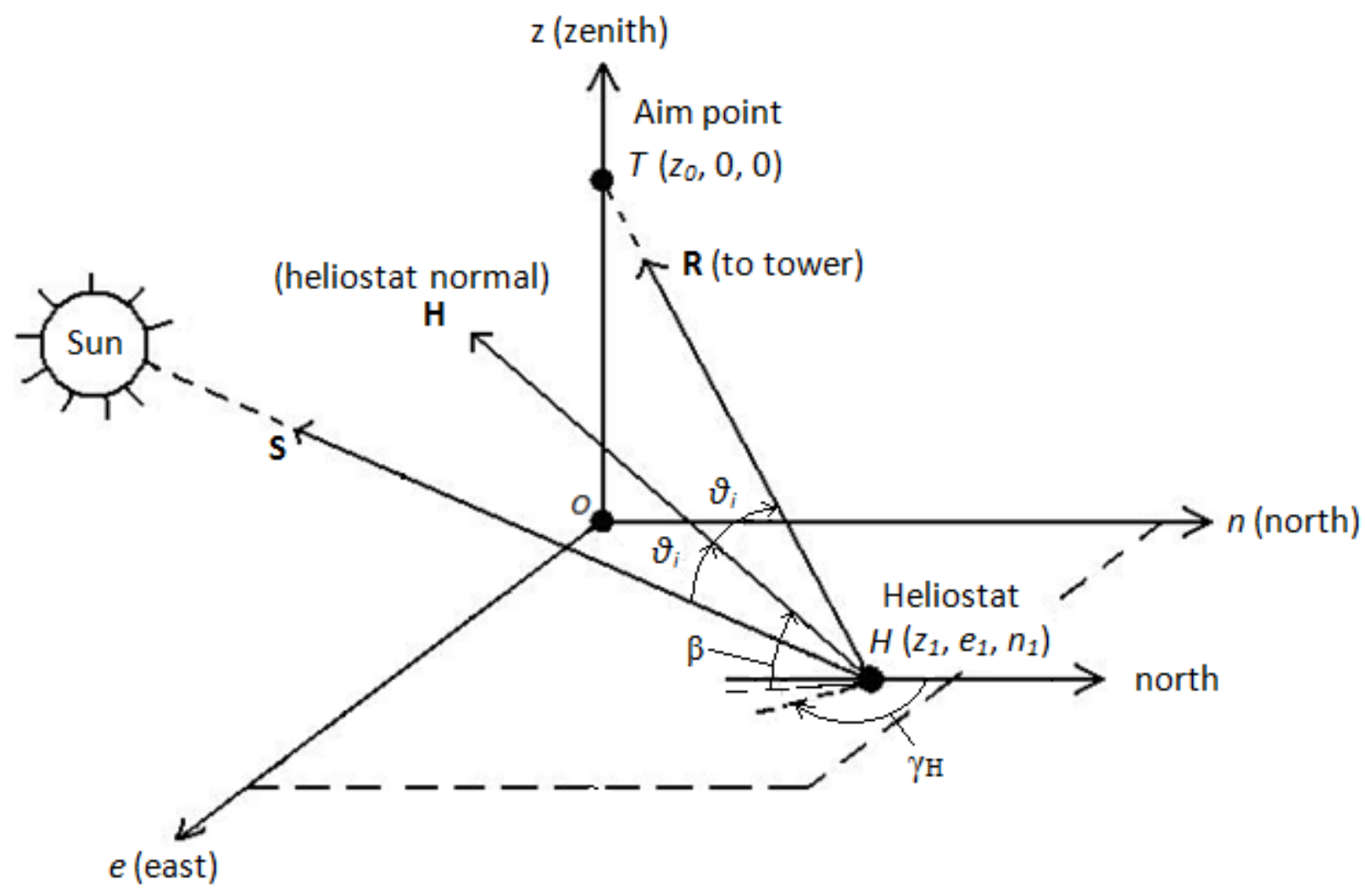

Figure 2-4: Tower and heliostat geometry [7].

According to the law of reflection for mirrors,

$$
\theta_{\text {incident }}=\theta_{\text {reflected }}
$$

Therefore, vector $\mathbf{H}$ must bisect the angle between vectors $\mathbf{S}$ and $\mathbf{R}$ to allow the reflected light to hit the aim point. This is why the incident angle appears twice in Figure 2-4; it is shown as the angle of incidence and reflection for the heliostat surface. 
The unit vectors $\mathbf{S}, \mathbf{R}$, and $\mathbf{H}$ are expressed in their vector components as shown in the following equations:

$$
\begin{gathered}
\mathbf{S}=\mathrm{S}_{\mathrm{z}} \mathbf{i}+\mathrm{S}_{\mathrm{e}} \mathbf{j}+\mathrm{S}_{\mathrm{n}} \mathbf{k} \\
\mathbf{R}=\mathrm{R}_{\mathrm{z}} \mathbf{i}+\mathrm{R}_{\mathrm{e}} \mathbf{j}+\mathrm{R}_{\mathrm{n}} \mathbf{k} \\
\mathbf{H}=\mathrm{H}_{\mathrm{z}} \mathbf{i}+\mathrm{H}_{\mathrm{e}} \mathbf{j}+\mathrm{H}_{\mathrm{n}} \mathbf{k}
\end{gathered}
$$

Now incorporating the geometry of the sun, heliostat, and tower, $\mathbf{S}, \mathbf{R}$, and $\mathbf{H}$ are rearranged as follows:

$$
\begin{gathered}
\mathbf{S}=\sin (\alpha) \mathbf{i}+\cos (\alpha) \sin \left(\gamma_{\mathrm{s}}\right) \mathbf{j}+\cos (\alpha) \cos \left(\gamma_{\mathrm{s}}\right) \mathbf{k} \\
\mathbf{R}=\frac{\left(\mathrm{z}_{0}-\mathrm{z}_{1}\right) \mathbf{i}-\mathrm{e}_{1} \mathbf{j}-\mathrm{n}_{1} \mathbf{k}}{\sqrt{\left(\mathrm{z}_{\mathbf{0}}-\mathrm{z}_{\mathbf{1}}\right)^{2}+\mathrm{e}_{\mathbf{1}}^{2}+\mathrm{n}_{\mathbf{1}}^{2}}} \\
\mathbf{H}=\frac{\mathbf{R}+\mathbf{S}}{2 \cos \left(\theta_{\mathrm{i}}\right)}=\frac{\left(\mathrm{R}_{\mathrm{z}}+\mathrm{S}_{\mathrm{z}}\right) \mathbf{i}+\left(\mathrm{R}_{\mathrm{e}}+\mathrm{S}_{\mathrm{e}}\right) \mathbf{j}+\left(\mathrm{R}_{\mathrm{n}}+\mathrm{S}_{\mathrm{n}}\right) \mathbf{k}}{2 \cos \left(\theta_{\mathrm{i}}\right)}
\end{gathered}
$$

Where,

$$
\begin{gathered}
\cos \left(2 \theta_{\mathrm{i}}\right)=\mathbf{S} \cdot \mathbf{R} \\
\cos \left(2 \theta_{\mathrm{i}}\right)=\mathrm{R}_{\mathrm{z}} \sin (\alpha)+\mathrm{R}_{\mathrm{e}} \cos (\alpha) \sin \left(\gamma_{\mathrm{s}}\right)+\mathrm{R}_{\mathrm{n}} \cos (\alpha) \cos \left(\gamma_{\mathrm{s}}\right)
\end{gathered}
$$


And incorporating the components of $\mathbf{R}$ from (2-15 gives:

$$
\cos \left(2 \theta_{\mathrm{i}}\right)=\frac{\left(\mathrm{z}_{0}-\mathrm{z}_{1}\right) \sin (\alpha)-\mathrm{e}_{1} \cos (\alpha) \sin \left(\gamma_{\mathrm{s}}\right)-\mathrm{n}_{1} \cos (\alpha) \cos \left(\gamma_{\mathrm{s}}\right)}{\sqrt{\left(\mathrm{z}_{0}-\mathrm{z}_{1}\right)^{2}+\mathrm{e}_{1}^{2}+\mathrm{n}_{1}^{2}}}
$$

Now the heliostat orientation angles are defined as follows:

$$
\begin{gathered}
\sin (\beta)=\frac{\mathrm{R}_{\mathrm{z}}+\sin (\alpha)}{2 \cos \left(\theta_{\mathrm{i}}\right)}=\frac{\left(\mathrm{z}_{0}-\mathrm{z}_{1}\right)+\sin (\alpha)}{2 \cos \left(\theta_{\mathrm{i}}\right)} \\
\sin \left(\gamma_{\mathrm{H}}\right)=\frac{\mathrm{R}_{\mathrm{e}}+\cos (\alpha) \sin \left(\gamma_{\mathrm{s}}\right)}{2 \cos \left(\theta_{\mathrm{i}}\right) \cos (\beta)}=\frac{-\mathrm{e}_{1}+\cos (\alpha) \sin \left(\gamma_{\mathrm{s}}\right)}{2 \cos \left(\theta_{\mathrm{i}}\right) \cos (\beta)}
\end{gathered}
$$

Using Equations 2-19 through 2-21, the incident angle of radiation on the heliostat as well as the heliostat orientation (tilt and azimuth) may be calculated. 


\section{Chapter 3: Microturbine Analysis}

\subsection{Microturbine Solar Modifications}

In order to run the microturbine with solar heating, several modifications ensure smooth operation at all conditions. A well-streamlined discharge from the outlet of the compressor to the solar receiver is installed in order to transport the compressed air up to the tower for preheating before combustion.

Microturbines equipped with a recuperator or side mounted combustion chamber require minimal modifications for this outlet [24]. Other changes that will likely occur involve the air ducts, combustion chamber, injector, igniter, control system logic, and the high temperature fasteners and gaskets [14]. This thesis does not describe these modifications in depth, but rather assumes they are likely procedures carried out in the future.

Figure 3-1 below shows the schematic for a solarized gas turbine. The solar receiver preheats air coming from the recuperator to the combustor.

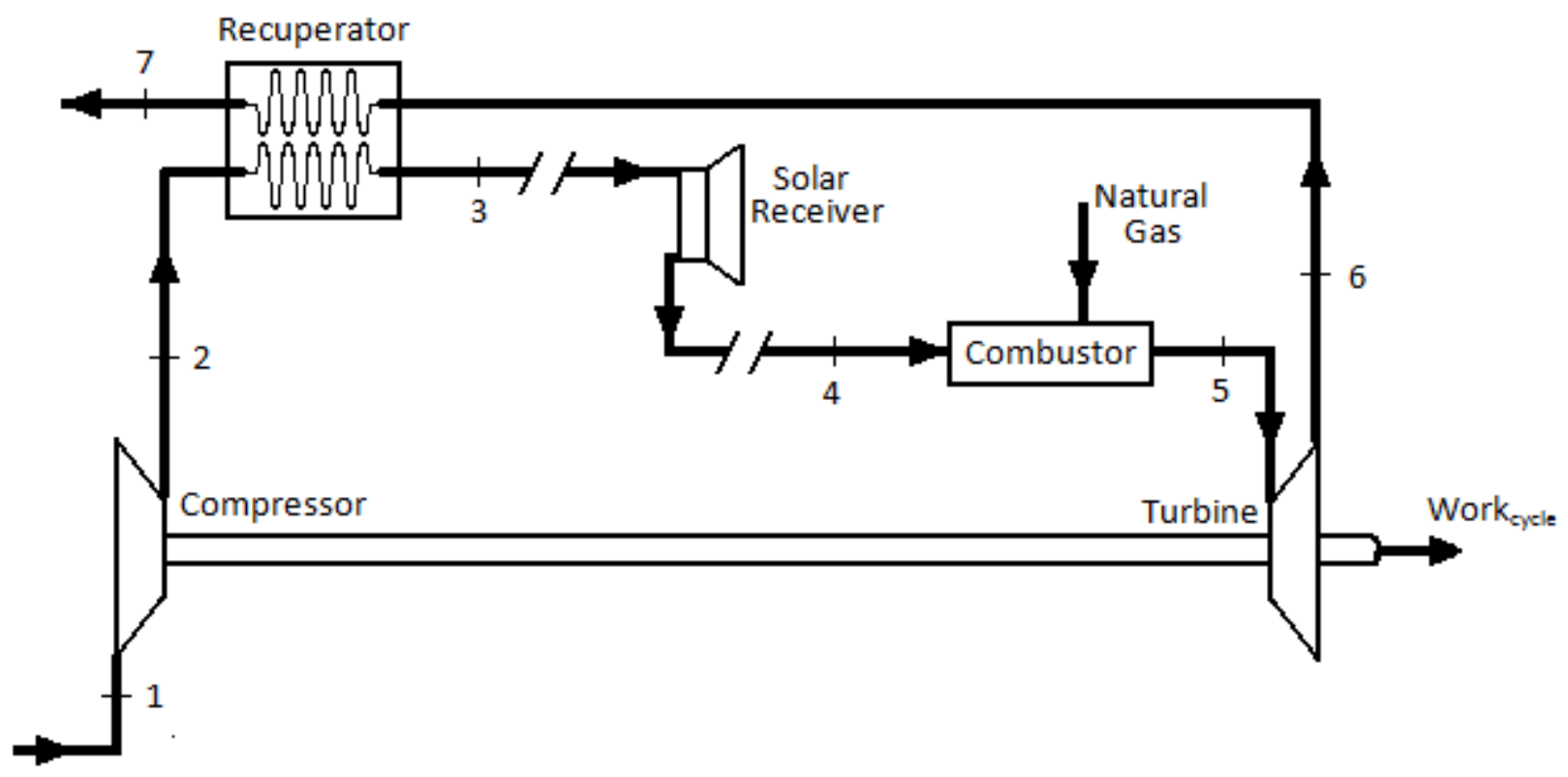

Figure 3-1: The schematic for a gas-solar hybrid microturbine. 
Figure 3-2 below shows the detailed pressure-volume diagram for the solarized microturbine. In an ideal process, the solar and natural gas heating become constant pressure processes, while 1 to 2 and 5 to 6 become constant entropy processes. In reality, this is not the case, due to imperfections and losses in the system.

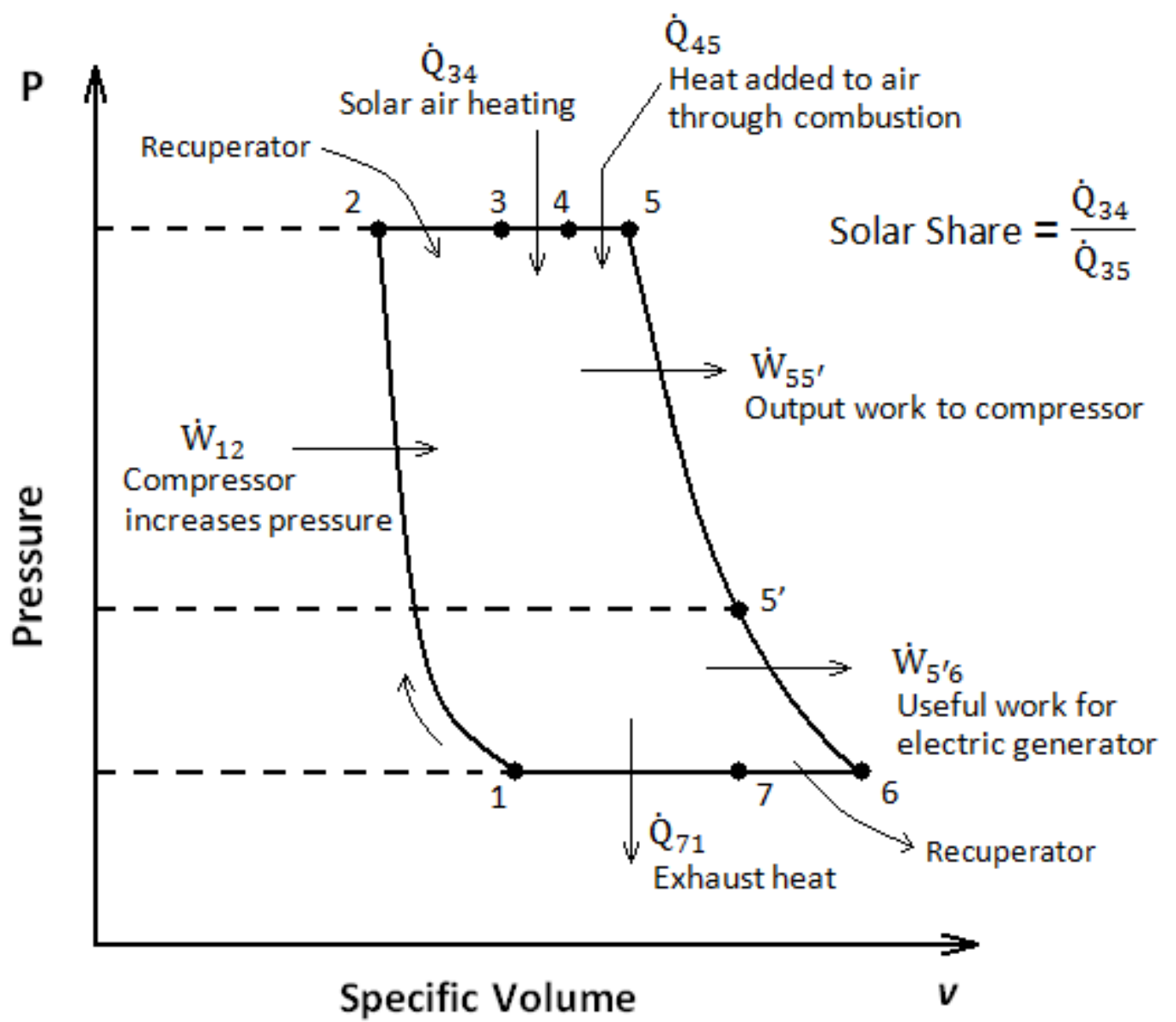

Figure 3-2: Detailed pressure-volume diagram for a gas-solar hybrid microturbine. 
Figure 3-3 shows the temperature-entropy diagram for the microturbine. Processes 1 to 2 and 5 to 6 become vertical, isentropic lines in an ideal system.

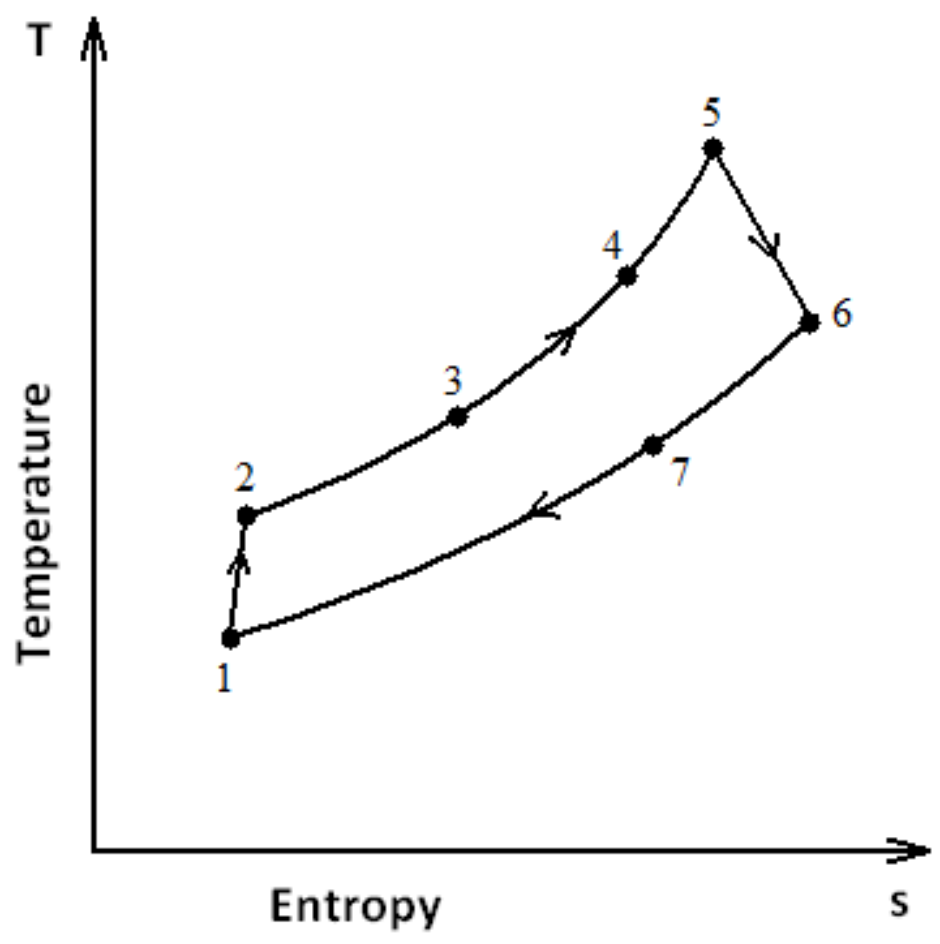

Figure 3-3: Temperature-entropy diagram for a gas-solar hybrid microturbine.

\subsubsection{Calculation of State Points}

Appendix A shows the ideal gas properties of air in Table A-1 from reference [19] used in the calculations of temperature, pressure, and enthalpy states. From reference [17], the exit conditions are known, and assuming an ambient $20^{\circ} \mathrm{C}$ inlet temperature at 1 and using Table $\mathrm{A}-1, \mathrm{~T}_{1}=293.0 \mathrm{~K}$, $\mathrm{h}_{1}=293.2 \mathrm{~kJ} / \mathrm{kg}, \mathrm{T}_{7}=575.0 \mathrm{~K}$, and $\mathrm{h}_{7}=580.8 \mathrm{~kJ} / \mathrm{kg}$.

From reference [19], using the inlet air temperature and the compressor pressure ratio (CPR) allows the calculation of state point 2 as follows:

$$
\mathrm{p}_{\mathrm{r} 2}=\mathrm{p}_{\mathrm{r} 1} \times \mathrm{CPR}
$$

Where $p_{\mathrm{r}}$ represents the relative pressure. At an ambient air inlet temperature of $293.0 \mathrm{~K}$, Table A-1 gives $\mathrm{p}_{\mathrm{r} 1}=1.3$ and $\mathrm{h}_{1}=293.2 \mathrm{~kJ} / \mathrm{kg}$. 
Using (3-1 with $\mathrm{p}_{\mathrm{r} 1}$ and a CPR of 4 gives $\mathrm{p}_{\mathrm{r} 2}=5.1$ which from Table A-1 gives $\mathrm{h}_{2}=$ $436.1 \mathrm{~kJ} / \mathrm{kg}$, and $\mathrm{T}_{2}=434.6 \mathrm{~K}$. However, this value of $\mathrm{h}_{2}$ is for an isentropic process. In reality, Figure 3-3 shows how the compression from point 1 to 2 is actually not isentropic. Therefore, an isentropic compressor efficiency of $80 \%$ [19] is assumed in (3-2:

$$
\eta_{c}=\frac{h_{2 s}-h_{1}}{h_{2}-h_{1}}
$$

Where $\mathrm{h}_{2 \mathrm{~s}}$ represents the ideal, isentropic value of enthalpy at state point 2 . Therefore, $\mathrm{h}_{2 \mathrm{~s}}=436.1 \mathrm{~kJ} / \mathrm{kg}, \mathrm{h}_{1}=293.2 \mathrm{~kJ} / \mathrm{kg}$, and $\eta_{\mathrm{c}}=0.8$. $\left(3-2\right.$ gives $\mathrm{h}_{2}=471.9 \mathrm{~kJ} / \mathrm{kg}$.

The following thermodynamic equations from reference [19] will help describe the other numbered state points:

$$
\begin{gathered}
\dot{\mathrm{W}}_{\text {compressor }}=\dot{\mathrm{m}}\left(\mathrm{h}_{2}-\mathrm{h}_{1}\right) \\
\eta_{\text {recuperator }}=\frac{\mathrm{h}_{3}-\mathrm{h}_{2}}{\mathrm{~h}_{6}-\mathrm{h}_{2}} \\
\mathrm{~h}_{3}-\mathrm{h}_{2}=\mathrm{h}_{6}-\mathrm{h}_{7} \\
\dot{\mathrm{Q}}_{\text {solar }}=\dot{\mathrm{m}}\left(\mathrm{h}_{4}-\mathrm{h}_{3}\right) \\
\dot{\mathrm{Q}}_{\text {natural gas }}=\dot{\mathrm{m}}_{5}\left(\mathrm{~h}_{5}-\mathrm{h}_{4}\right) \\
\dot{\mathrm{Q}}_{\text {in }}=\dot{\mathrm{Q}}_{\text {solar }}+\dot{\mathrm{Q}}_{\mathrm{natural} \mathrm{gas}}
\end{gathered}
$$




$$
\begin{gathered}
\dot{\mathrm{W}}_{\text {mechanical }}=\dot{\mathrm{W}}_{\text {turbine }}-\dot{\mathrm{W}}_{\text {compressor }}=\dot{\mathrm{m}}\left[\left(\mathrm{h}_{5}-\mathrm{h}_{6}\right)-\left(\mathrm{h}_{2}-\mathrm{h}_{1}\right)\right] \\
\eta_{\text {mechanical }}=\frac{\dot{\mathrm{W}}_{\text {mechanical }}}{\dot{\mathrm{Q}}_{\text {in }}}=\frac{\left(\mathrm{h}_{5}-\mathrm{h}_{6}\right)-\left(\mathrm{h}_{2}-\mathrm{h}_{1}\right)}{\left(\mathrm{h}_{5}-\mathrm{h}_{3}\right)}
\end{gathered}
$$

Where $\dot{W}$ is the rate of work done on or by the system in $\mathrm{kW}, \dot{\mathrm{Q}}$ is the rate of heat added to the system in $\mathrm{kW}, \eta_{\text {recuperator }}$ is the recuperator effectiveness, $\eta_{\text {mechanical }}$ is the efficiency of the mechanical cycle, and $\dot{\mathrm{m}}$ is the mass flow rate in $\mathrm{kg} / \mathrm{s}$.

(3-11 describes the efficiency of the thermodynamic cycle only. It is important to note that the turbine manufacturer specified efficiency also takes into account the efficiency of the electric generator as specified in $(3-12$.

$$
\eta_{\text {electric }}=\eta_{\text {mechanical }} \eta_{\text {generator }}
$$

From reference [17], $\eta_{\text {electric }}=0.28$, and using a common generator efficiency of 0.95 [25], (3-12 gives $\eta_{\text {mechanical }}=0.295$.

Equations 3-4, 3-5, and 3-11 are used with $\dot{\mathrm{m}}=0.84 \mathrm{~kg} / \mathrm{s}[17], \mathrm{h}_{1}=293.2 \mathrm{~kJ} / \mathrm{kg}, \mathrm{h}_{2}=471.9 \mathrm{~kJ} / \mathrm{kg}$, $\mathrm{h}_{7}=580.8 \mathrm{~kJ} / \mathrm{kg}, \eta_{\text {recuperator }}$ set to 0.7 [19], and $\eta_{\text {mechanical }}=0.295$ to obtain state points 3,5 and 6 . Their values are shown in Table 3-1 along with the other known points. State point 4 remains variable since solar radiation input varies greatly over time. State point 7 was obtained from reference [17].

Table 3-1: Calculated state points for the gas-solar hybrid microturbine.

$\begin{array}{ccccc}\text { State Point } & \mathbf{h}(\mathbf{K J} / \mathbf{k g}) & \mathbf{T}(\mathbf{K}) & \mathbf{T}\left({ }^{\circ} \mathbf{C}\right) & \mathbf{T}\left({ }^{\circ} \mathbf{F}\right) \\ 1 & 293.2 & 293.0 & 20.0 & 68.0 \\ 2 & 471.9 & 469.7 & 196.7 & 386.1 \\ 3 & 726.5 & 712.3 & 439.3 & 822.7 \\ 5 & 1134.6 & 1077.1 & 804.1 & 1479.4 \\ 6 & 835.6 & 812.4 & 539.4 & 1002.9 \\ 7 & 580.8 & 575.0 & 302.0 & 575.6\end{array}$




\subsection{Pressure Drop}

Running pipe between the compressor outlet and combustor inlet introduces a pressure drop in the system. This means that some of the work used to compress the air is wasted, and therefore the efficiency will decrease slightly. In order to quantify this pressure drop, an analysis with an assumed 6 inch diameter pipe is introduced.

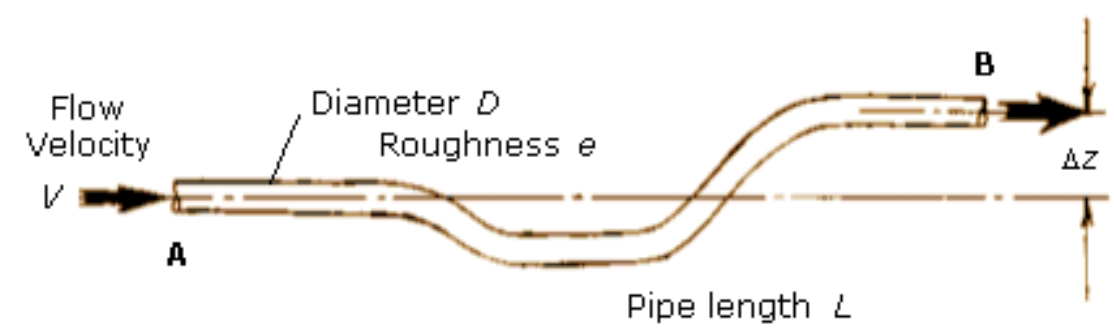

Figure 3-4: Pipe geometry [26].

The pressure drop for the pipe of Figure 3-4 is given in [26] as:

$$
\mathrm{p}_{\mathrm{A}}-\mathrm{p}_{\mathrm{B}}=\rho \mathrm{g}\left(\Delta \mathrm{z}+f \frac{\mathrm{L}}{\mathrm{D}} \frac{\mathrm{V}^{2}}{2 \mathrm{~g}}\right)
$$

Where $\mathrm{L}$ is the pipe length between points $\mathrm{A}$ and $\mathrm{B}, \mathrm{p}_{\mathrm{A}}$ and $\mathrm{p}_{\mathrm{B}}$ are the pressures at points $\mathrm{A}$ and $\mathrm{B}$, respectively, $\rho$ is the density of the fluid, $\Delta \mathrm{z}$ is the change in pipe elevation $\left(\mathrm{z}_{\mathrm{B}}-\mathrm{z}_{\mathrm{A}}\right)$, and $f \frac{\mathrm{L}}{\mathrm{D}} \frac{\mathrm{V}^{2}}{2 \mathrm{~g}}$ is known as the viscous head term. The viscous head term is quantified by the pipe friction factor, $f$. The pipe friction factor is determined by the Reynolds Number, Re, and the relative roughness, e/D, of the pipe wall. The Reynolds Number is calculated as follows:

$$
\operatorname{Re}=\frac{\rho \mathrm{VD}}{\mu}
$$

Where $\mathrm{V}$ is the mean velocity through the pipe, $\mathrm{D}$ is the inner diameter of the pipe, and $\mu$ is the dynamic viscosity of the fluid. The relative roughness is the size of bumps and imperfections on the inner wall of the pipe compared to the diameter of the pipe. Commercial pipes have a very small value of relative roughness, while perfectly smooth pipes have an e/D value of zero. 
For laminar flow $(\operatorname{Re}<2000), f$ is determined from the following:

$$
f=\frac{64}{\operatorname{Re}}
$$

For turbulent flow $(\operatorname{Re}>3000), f$ is determined from the Moody Chart, made from plotting (3-16 below and shown in Figure 3-5.

$$
\frac{1}{\sqrt{f}}=-2 \log \left(\frac{\mathrm{e} / \mathrm{D}}{3.7}+\frac{2.51}{\operatorname{Re} \sqrt{f}}\right)
$$

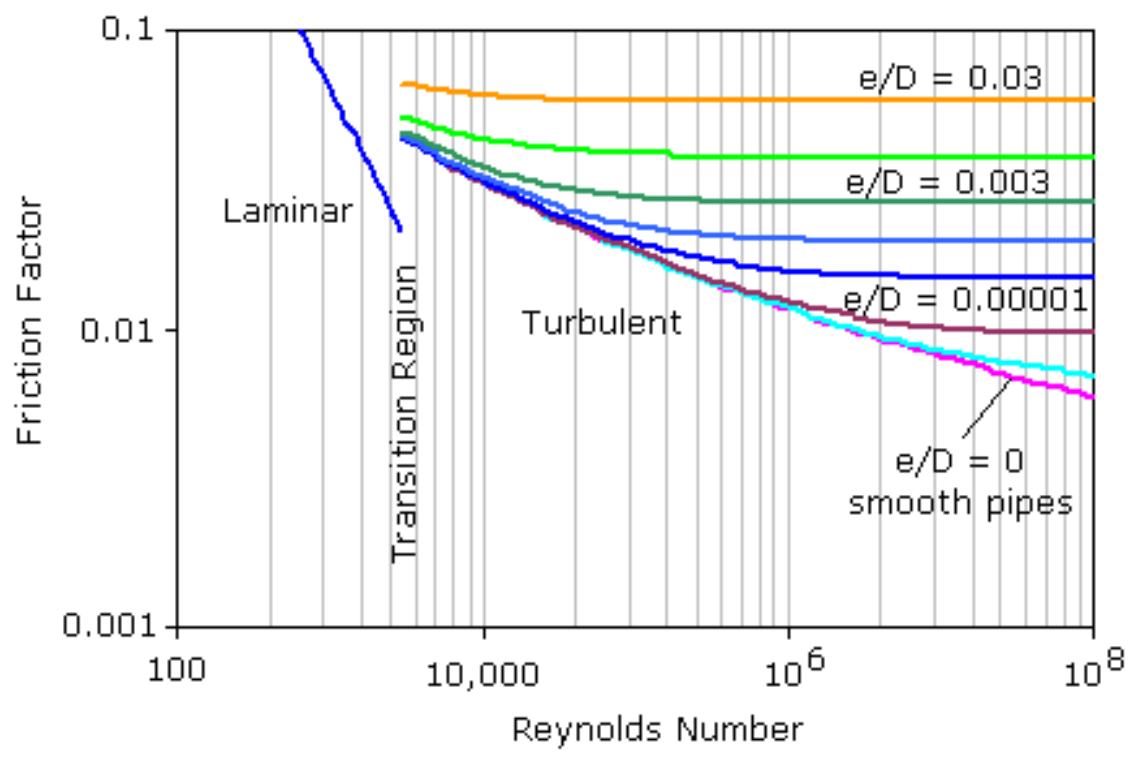

Figure 3-5: Moody diagram [26].

With a compressor pressure ratio of four [17], the compressor outlet pressure is four times the ambient inlet pressure, namely, $404 \mathrm{kPa}$. With a mass flow rate of $0.84 \mathrm{~kg} / \mathrm{s}$, the mean fluid velocity is calculated using the continuity equation:

$$
\dot{\mathrm{m}}=\rho \mathrm{AV}
$$

(3-18 shows how to calculate density from the ideal gas law.

$$
\rho=\frac{P}{R T}
$$

Where $\mathrm{P}$ is the pressure, $\mathrm{R}$ is the ideal gas constant for air $(286.9 \mathrm{~J} / \mathrm{kg}-\mathrm{K})$, and $\mathrm{T}$ is the temperature in Kelvin. The pressure drop up the tower will first be calculated. 
The following values are used in Equations 3-13 through 3-18 along with Figure 3-5:

$$
\begin{aligned}
& \dot{\mathrm{m}}=0.84 \mathrm{~kg} / \mathrm{s} \\
& \mathrm{D}=6 \text { inches }(0.1524 \mathrm{~m}) \\
& \rho=1.98 \mathrm{~kg} / \mathrm{m}^{3}(712.3 \mathrm{~K} \text { air, } 404 \mathrm{kPa},(3-18) \\
& \mathrm{g}=9.81 \mathrm{~m} / \mathrm{s}^{2} \\
& \mathrm{p}_{\mathrm{A}}=404 \mathrm{kPa} \\
& \Delta \mathrm{z}=36 \text { feet (up to tower) } \\
& \mathrm{L}=36 \text { feet } \\
& \mathrm{e}=0.0018 \text { inches }(\text { commercial steel pipe [26]) } \\
& \mathrm{e} / \mathrm{D}=0.0003 \\
& \mu=3.454 \times 10^{-5} \mathrm{~kg} / \mathrm{m}-\mathrm{s}[27]
\end{aligned}
$$

The pressure drop $\left(\mathrm{p}_{\mathrm{A}}-\mathrm{p}_{\mathrm{B}}\right)$ is found to be $0.896 \mathrm{kPa}$. Adding the pressure loss across the solar receiver of $2 \mathrm{kPa}$ [14] to the pressure drop calculated gives $401.1 \mathrm{kPa}$ as the pressure at the outlet of the solar receiver. Assuming the solar receiver is running at maximum solar radiation, the air temperature from the receiver will be $800^{\circ} \mathrm{C}$. (3-18 gives the density of air at this temperature and pressure as 1.302 $\mathrm{kg} / \mathrm{m}^{3}$. The same analysis is used for calculating the pressure drop down the tower, with delta $\mathrm{z}$ now -36 feet. This yields a pressure drop down the tower of $0.93 \mathrm{kPa}$. Therefore, there is a total pressure drop of $3.83 \mathrm{kPa}$ for piping up and down the tower.

If a constant specific volume and an adiabatic, reversible process for piping the fluid up and down the tower is assumed, an estimate of the work loss is given by (3-19 below, from reference [19]:

$$
\dot{\mathrm{W}}_{\text {loss }}=\dot{\mathrm{m}} v\left(\mathrm{P}_{2}-\mathrm{P}_{1}\right)
$$

Where $v$ is the specific volume or $1 / \rho$.

Using (3-18 to calculate the specific volume at state point 5 from Table 3-1, the approximate work loss is found:

$$
\dot{\mathrm{W}}_{\text {loss }}=0.84 \frac{\mathrm{kg}}{\mathrm{s}} \times 0.77 \frac{\mathrm{m}^{3}}{\mathrm{~kg}} \times 3.83 \mathrm{kPa}=2.48 \mathrm{~kW}
$$


This represents approximately $2.5 \%$ of the net work output from the microturbine.

\subsection{Thermal Losses}

The hot compressed air must be transported up to the tower in order for further heating by the solar receiver to occur. Flowing a hot fluid through pipes introduces a thermal loss in the fluid. In order to quantify this loss, the same 6 inch diameter pipe is analyzed with an assumed 1/8 inch thickness and 4 inch thickness of insulation. The overall heat transfer coefficient from reference [28] is described by (3-20.

$$
\mathrm{U}=\left(\frac{\mathrm{D}_{3}}{\mathrm{D}_{1} \cdot \mathrm{h}_{\mathrm{in}}}+\frac{\mathrm{D}_{3} \cdot \ln \left(\frac{\mathrm{D}_{2}}{\mathrm{D}_{1}}\right)}{2 \cdot \mathrm{k}_{\text {pipe }}}+\frac{\mathrm{D}_{3} \cdot \ln \left(\frac{\mathrm{D}_{3}}{\mathrm{D}_{2}}\right)}{2 \cdot \mathrm{k}_{\text {insulation }}}+\frac{1}{\mathrm{~h}_{\text {out }}}\right)^{-1}
$$

Where $\mathrm{h}$ represents convective heat transfer coefficient values and $\mathrm{k}$ represents thermal conductivity values. The variables are further defined in Figure 3-6.

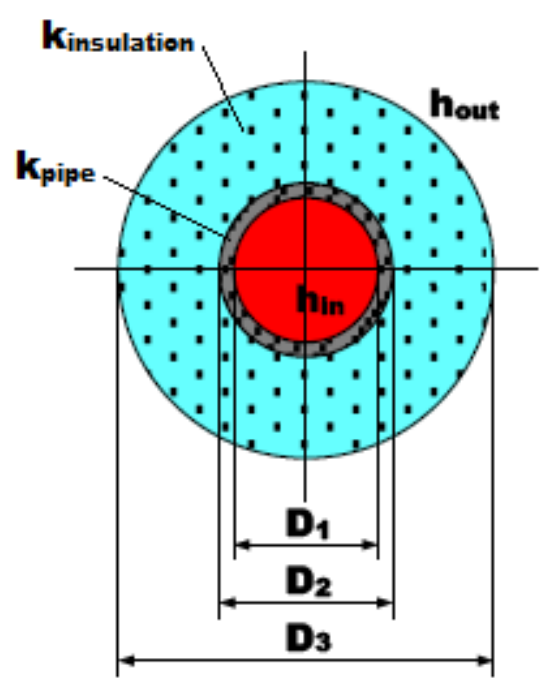

Figure 3-6: Cross section of a pipe with insulation showing diameter (D), h and $k$ values defined as used in (3-20 [28].

The heat loss is now defined.

$$
\dot{\mathrm{Q}}=\pi \cdot \mathrm{L} \cdot \mathrm{D}_{3} \cdot \mathrm{U} \cdot\left(\mathrm{T}_{\text {in }}-\mathrm{T}_{\text {out }}\right)
$$


The following values are used to calculate the heat loss to the top of the tower:

$\mathrm{T}_{\text {in }}=\mathrm{T}_{3}=712.3 \mathrm{~K}($ Table $3-1)$

$\mathrm{T}_{\text {out }}=\mathrm{T}_{1}=293 \mathrm{~K}$

$\mathrm{D}_{1}=6$ inches $(0.1524 \mathrm{~m})$

$\mathrm{D}_{2}=6.25$ inches $(0.1588 \mathrm{~m})$

$\mathrm{D}_{3}=14.25$ inches $(0.3620 \mathrm{~m})$

$\mathrm{K}_{\text {pipe }}=20.0 \mathrm{~W} / \mathrm{m}-\mathrm{K}$ (steel pipe [27])

$\mathrm{K}_{\text {insulation }}=0.03 \mathrm{~W} / \mathrm{m}-\mathrm{K}$ (foam insulation [27])

$\mathrm{h}_{\text {in }}=\mathrm{h}_{\text {out }}=17.0 \mathrm{~W} / \mathrm{m}-\mathrm{K}$ (free convection of air [27])

Equations 3-20 and 3-21 give $\dot{\mathrm{Q}}=1.63 \mathrm{~kW}$.

This means that the point just before entering the solar receiver can now be calculated as follows:

$$
\dot{\mathrm{Q}}=\dot{\mathrm{m}}\left(\mathrm{h}_{3}-\mathrm{h}_{\text {receiver inlet }}\right)
$$

(3-22 gives $h_{\text {receiver inlet }}=724.6 \mathrm{~kJ} / \mathrm{kg}$, which is now essentially the new value for state point 3 . It is assumed that the receiver will outlet air at maximum pressurized volumetric receiver outlet temperature of about $800^{\circ} \mathrm{C}[14]$. Therefore, $\mathrm{h}_{\text {receiver outlet }}=1129.83 \mathrm{~kJ} / \mathrm{kg}$ from Table A-1.

Using the same pipe and now at $800^{\circ} \mathrm{C}$ inner temperature, the heat loss traveling back down the tower to the combustor is calculated. Equations 3-20 and 3-21 give the maximum heat loss down the tower as $3.04 \mathrm{~kW}$.

This means that the combustor must provide $1.63+3.04=4.67 \mathrm{~kW}$ extra heat.

Therefore, with the piping, the new efficiency can now be calculated as shown in (3-23.

$$
\eta_{\text {mechanical }}=\frac{\dot{\mathrm{m}}\left(\mathrm{h}_{5}-\mathrm{h}_{6}\right)-\dot{\mathrm{m}}\left(\mathrm{h}_{2}-\mathrm{h}_{1}\right)-2.48}{\dot{\mathrm{m}}\left(\mathrm{h}_{5}-\mathrm{h}_{3}\right)+4.67}
$$

Substituting $\mathrm{h}$ (enthalpy) values from Table $3-1$ gives $\eta_{\text {mechanical }}=0.284$, and with the $95 \%$ efficient generator, $\eta_{\text {electric }}$ is approximately 0.269 . 


\section{Chapter 4: Field Efficiency}

Evaluating the performance of the heliostats and receiver gives the field efficiency. The field efficiency describes how much energy is expected to hit the receiver based on the total heliostat area. Figure 4-1 shows the losses involved with heliostats.

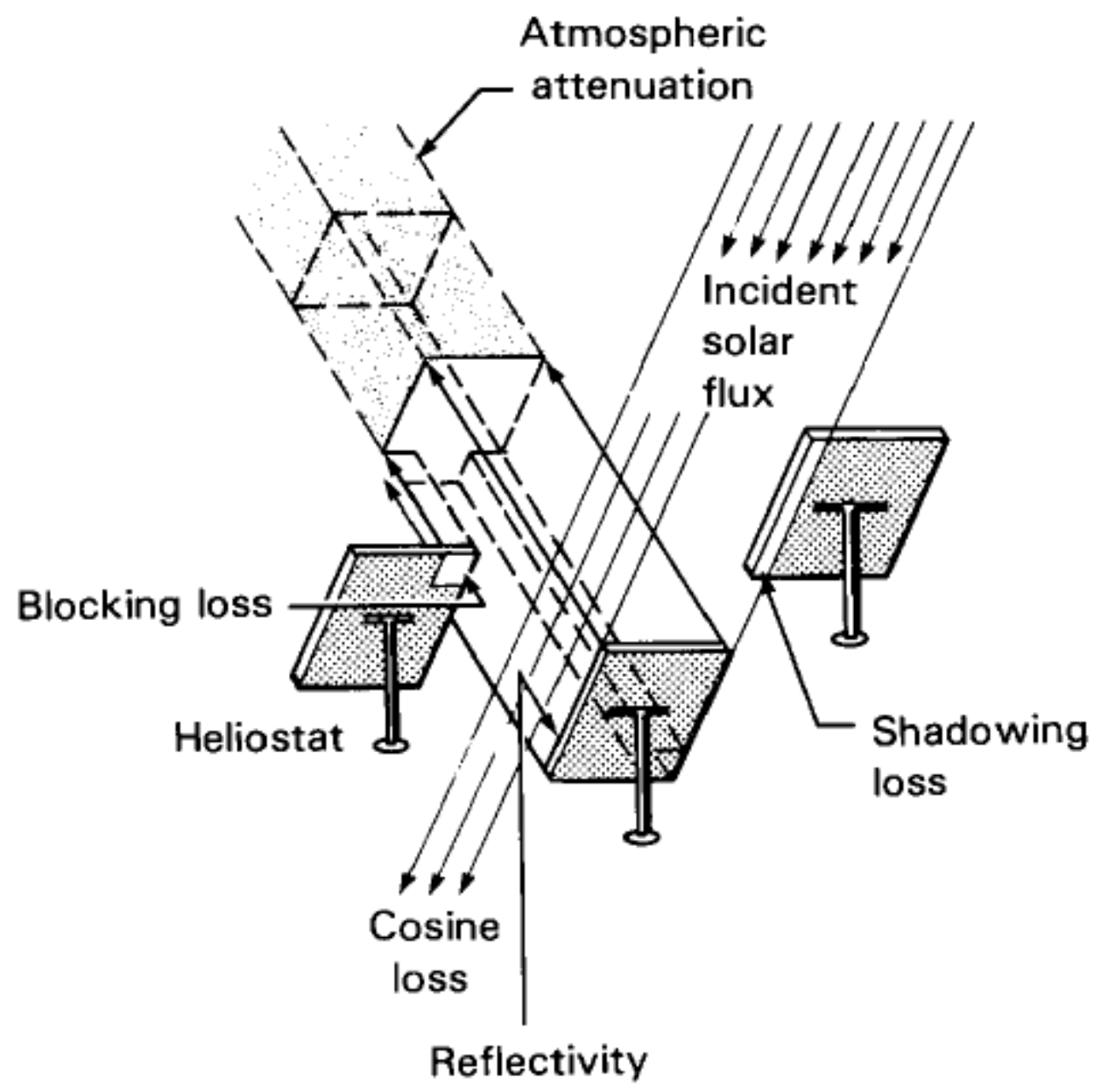

Figure 4-1: Heliostat losses [15].

\subsection{Atmospheric Attenuation}

Some of the reflected energy is scattered and absorbed by the atmosphere, and consequently will not reach the receiver. This is referred to as the atmospheric attenuation loss. A good visibility day will have a small percentage loss per kilometer [15], so for this small-scale application, it is assumed essentially zero. 


\subsection{Shadowing and Blocking}

Shadowing losses arise when a shadow is cast by a heliostat onto a neighboring heliostat. Shadowing reduces the overall reflective area of the heliostat. Blocking losses occur when a heliostat's reflected flux is blocked by a heliostat in the foreground. The detailed, time dependant calculations of shadowing and blocking require complex procedures involving intricate ray tracing of individual heliostats. This sort of analysis is beyond the scope of this thesis. Therefore, typical yearly averaged values for Thermata heliostats (Section 5.3) are used, from reference [29]. These values are 10\% shadowing losses and 5\% blocking losses.

\subsection{Spillage}

When the receiver is not large enough to intercept the entire image of the heliostats, spillage losses occur. Spillage may be eliminated if the receiver area is increased; however at some point, the process of increasing the receiver aperture size becomes detrimental due to the increased levels of heat loss. These two effects need to be balanced in order to determine the optimum receiver size. According to reference [10], spillage is typically in the range of one to four percent for optimal receiver designs. Therefore spillage losses are taken as $4 \%$ in order to design for worst case spillage.

\subsection{Reflectivity and Soiling}

Losses due to reflectivity occur when imperfections on the mirror surface itself lead to a loss of reflected radiation. Imperfections are typically small defects in the surface itself. From reference [29], for Thermata Heliostats, typically reflectivity losses are about $8 \%$.

Depending upon how clean the surface of the mirrors is, there may be soiling losses between 210\%. These losses arise when dust and dirt form a layer over the mirror surface, preventing the reflection of light. Soiling losses are taken as 5\%, assuming relatively frequent cleaning. 


\subsection{Cosine Efficiency}

A heliostat's reflected beam is most powerful when the heliostat is normal to the incoming beam of sunlight. If vector $\mathbf{H}$ is not in line with vector $\mathbf{S}$ (Figure 2-4), an incident angle, $\theta_{\mathrm{i}}$, is introduced, as shown below.

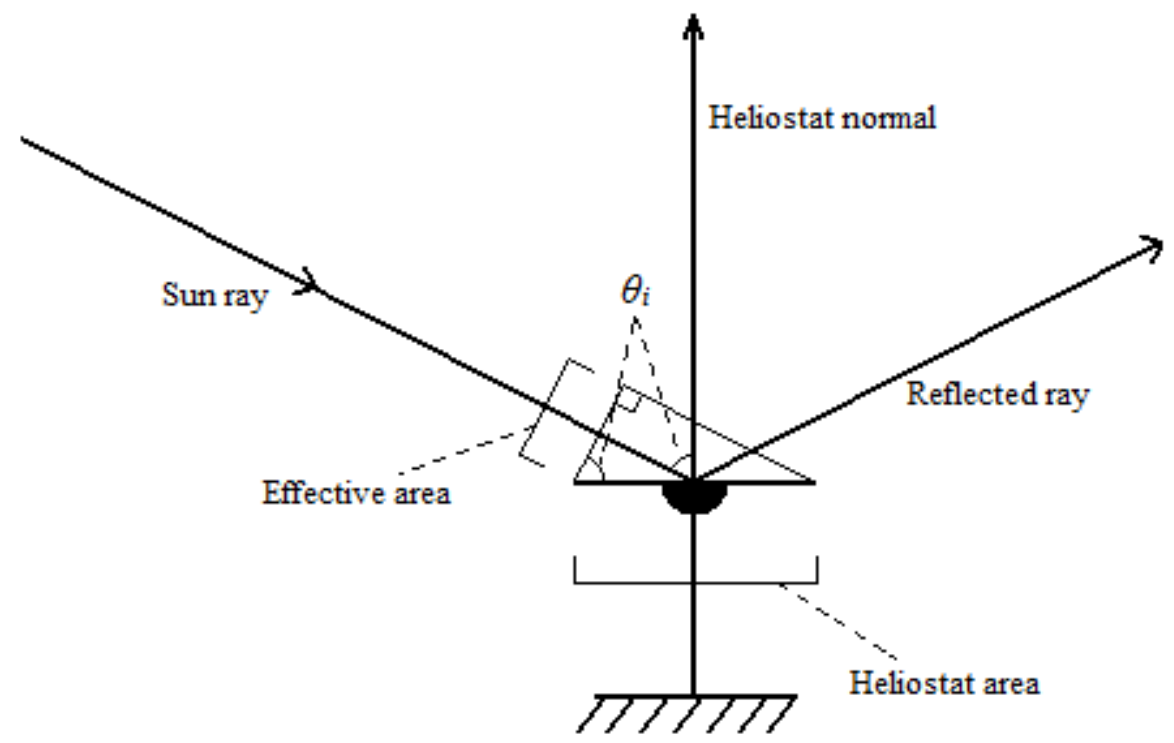

Figure 4-2: Heliostat effective area reduction through the cosine effect.

From Figure 4-2, the effective area is expressed as follows:

$$
\text { Effective Area }=\text { Heliostat Area } \times \cos \left(\theta_{\mathrm{i}}\right)
$$

The result of reducing the effective area by introducing an incident angle is known as the cosine effect. 
Figure 4-3 shows how the cosine effect varies for different heliostat field layouts.
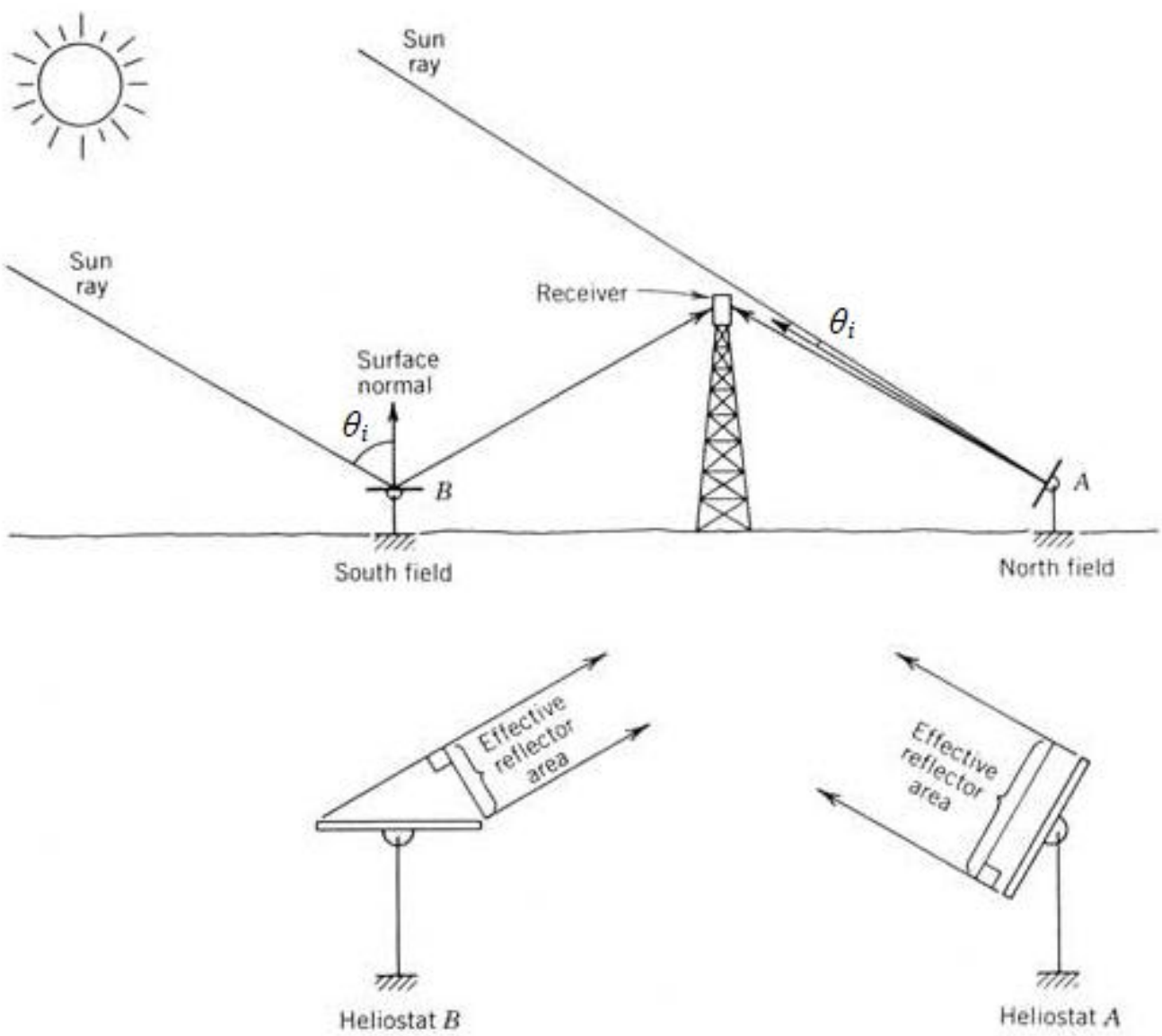

Figure 4-3: The benefits of a northern field over a southern field, with respect to the tower [7].

From (4-1, cosine losses are described as an efficiency equivalent to the cosine of the incidence angle. Using (2-19 and solving for $\cos \left(\theta_{\mathrm{i}}\right)$, the field locations which provide the highest cosine efficiency can be obtained. Using the latitude of San Luis Obispo, CA, the solar angles were calculated for a March day. Because March $21^{\text {st }}$ is in the middle of the winter and summer solstices, it provides cosine efficiency values that are close to yearly average values. 
The cosine efficiencies for 256 points on a virtual field were calculated and averaged for the entire day using MATLAB and plotted in Figure 4-4.

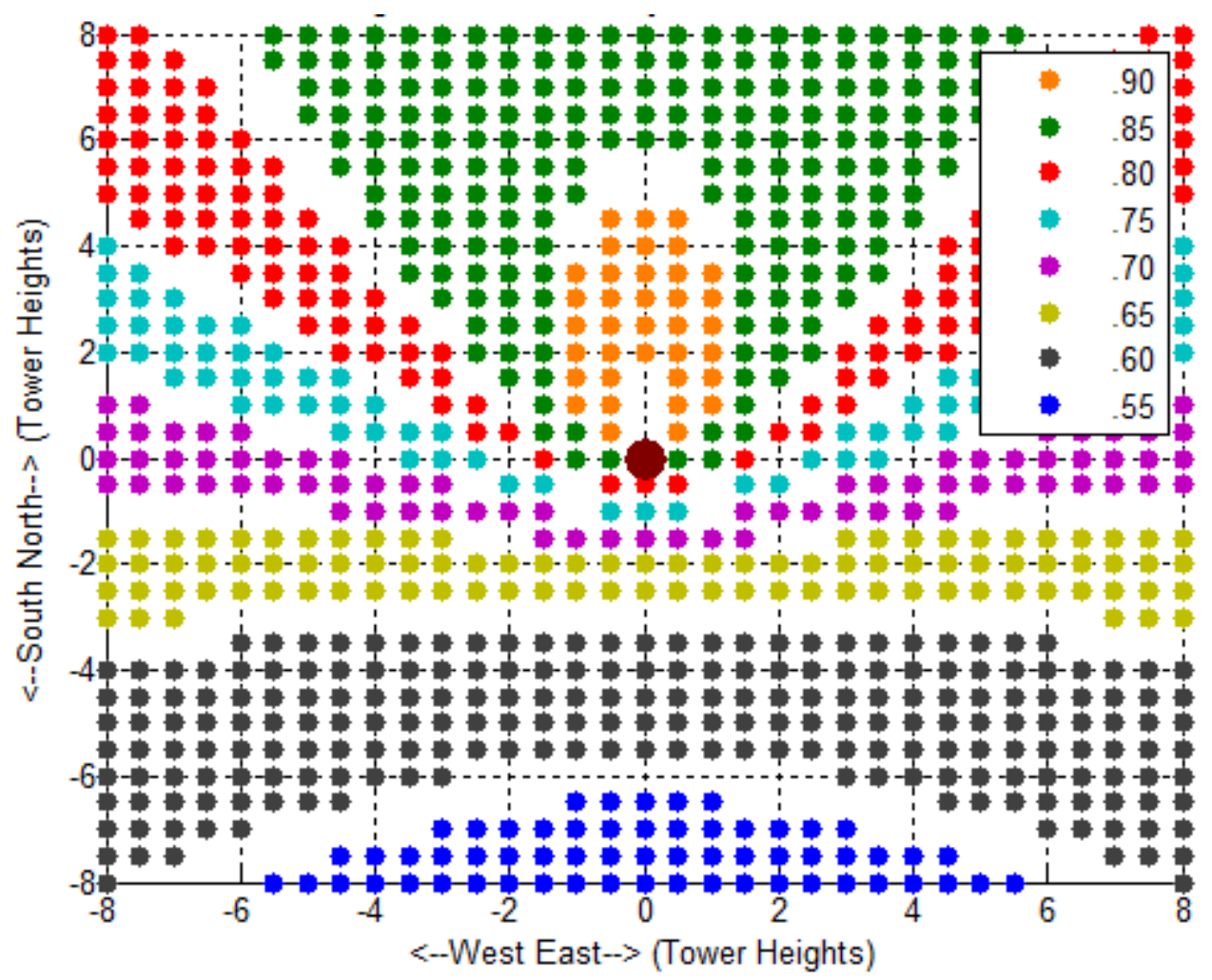

Figure 4-4: Cosine efficiencies for different positions in a virtual field on March $21^{\text {st }}$ in San Luis Obispo, CA. The distance from the tower is normalized by the tower height. The origin represents the tower.

In Figure 4-4, efficiencies of 75-90\% are realized on the northern side of the tower, while efficiencies of only 55-75\% are demonstrated on the southern side of the tower. Therefore, a northern field (southern facing) is the best option for the field layout. This is due to the fact that most of the radiation over the course of the day occurs when the sun is in the southern sky.

In order to obtain the exact cosine efficiency for a particular time, the number and orientation of the heliostats must be known. However, in order to know the number of heliostats needed, there must be an estimate of the cosine efficiency, as this affects how much total heliostat area is needed. For this application, most of the heliostats will be located in the orange region of the graph, due to the size of the field. Therefore a cosine efficiency of $90 \%$ is used to get a rough value of the size of the heliostat field. 


\subsection{Heliostat Tracking}

The tracking capabilities of the heliostats are limited to the precision of the tracking motors as well as errors due to wind blowing the heliostats. From reference [29], Thermata heliostat tracking technology is accurate to $\leq 3 \mathrm{mrad} \mathrm{RMS}$ or $0.172^{\circ}$ in calm conditions, and $\leq 4 \mathrm{mrad} \mathrm{RMS}$ or $0.229^{\circ}$ in windy conditions. Calm winds are defined as maximum gusts at $27 \mathrm{mph}$ with an $18 \mathrm{mph}$ mean. Windy conditions have up to $35 \mathrm{mph}$ gusts with a $22 \mathrm{mph}$ mean. Small tracking errors and significant wind loads can cause misalignment among heliostats, which can cause additional spillage losses. From reference [29], these errors typically cause up to about $10 \%$ additional spillage losses.

\subsection{Total Field Efficiency}

The total field efficiency can now be calculated:

$$
\begin{gathered}
\eta_{\text {field }}=\eta_{\text {attenuation }} \cdot \eta_{\text {shadowing }} \cdot \eta_{\text {blocking }} \cdot \eta_{\text {spillage }} \cdot \eta_{\text {reflectivity }} \\
\cdot \eta_{\text {soiling }} \cdot \eta_{\text {cosine }} \cdot \eta_{\text {heliostat tracking }} \\
\eta_{\text {field }}=1 \cdot 0.90 \cdot 0.95 \cdot 0.96 \cdot 0.92 \cdot 0.95 \cdot 0.90 \cdot 0.90=0.58
\end{gathered}
$$




\section{Chapter 5: Design Parameters}

\subsection{Field Size}

The field that will be used for this project equates to roughly a half acre, and is approximately a $206 \times 105$ feet rectangular field. The field is located on Cal Poly campus property, and has been approved for solar power plant use by the university.

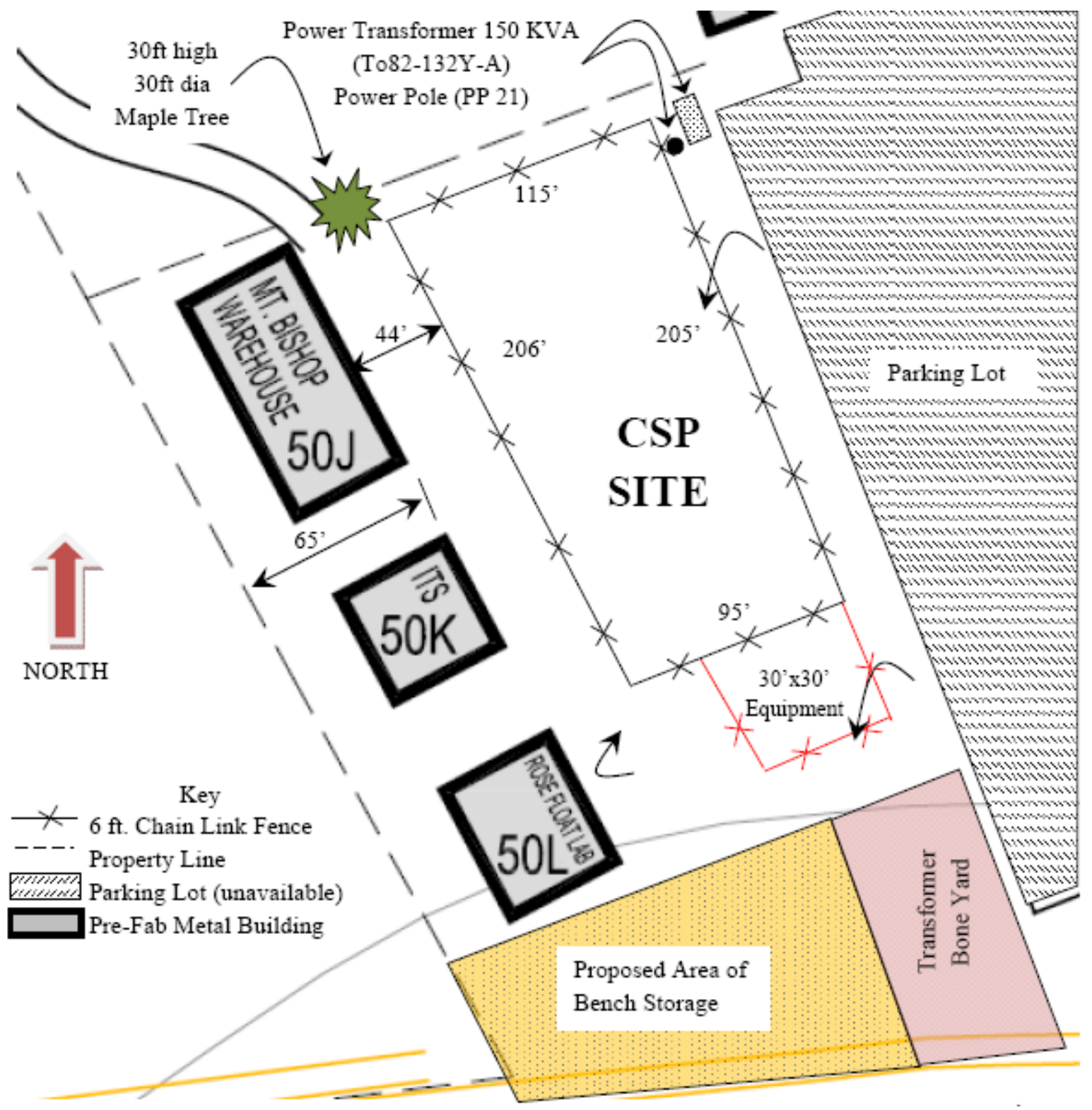

Figure 5-1: Diagram of the land area to be used for solar equipment on Cal Poly campus property. 


\subsection{Tower Height}

From reference [15], optimum tower height is generally about 1/6 the length of the farthest heliostat in the field to the tower, as shown in Figure 5-2.

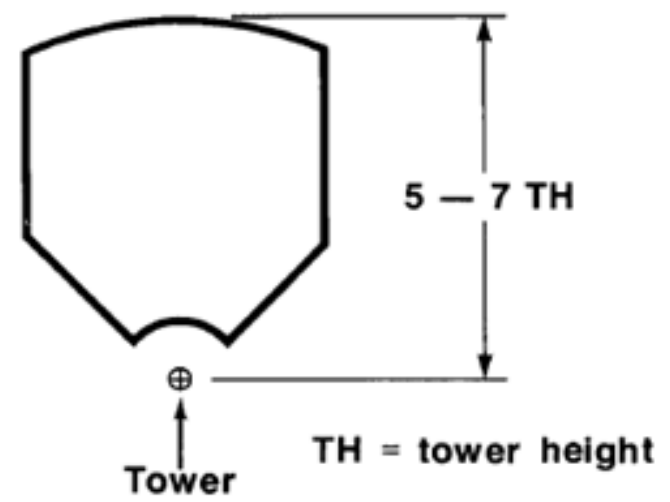

Figure 5-2: Optimal tower heights [15].

With the farthest heliostat about 215 feet away from the tower (approximate length of the field including the equipment area), the tower height is taken to be $1 / 6$ of this value, or about 36 feet. 
It is helpful to define several terms that depend upon the tower height, $H$. The rim angle $\left(\theta_{\mathrm{r}}\right)$, air distance $\left(\mathrm{D}_{\text {air }}\right)$, and ground distance $\left(\mathrm{D}_{\text {ground }}\right)$ are defined as shown in Figure 5-3 below:

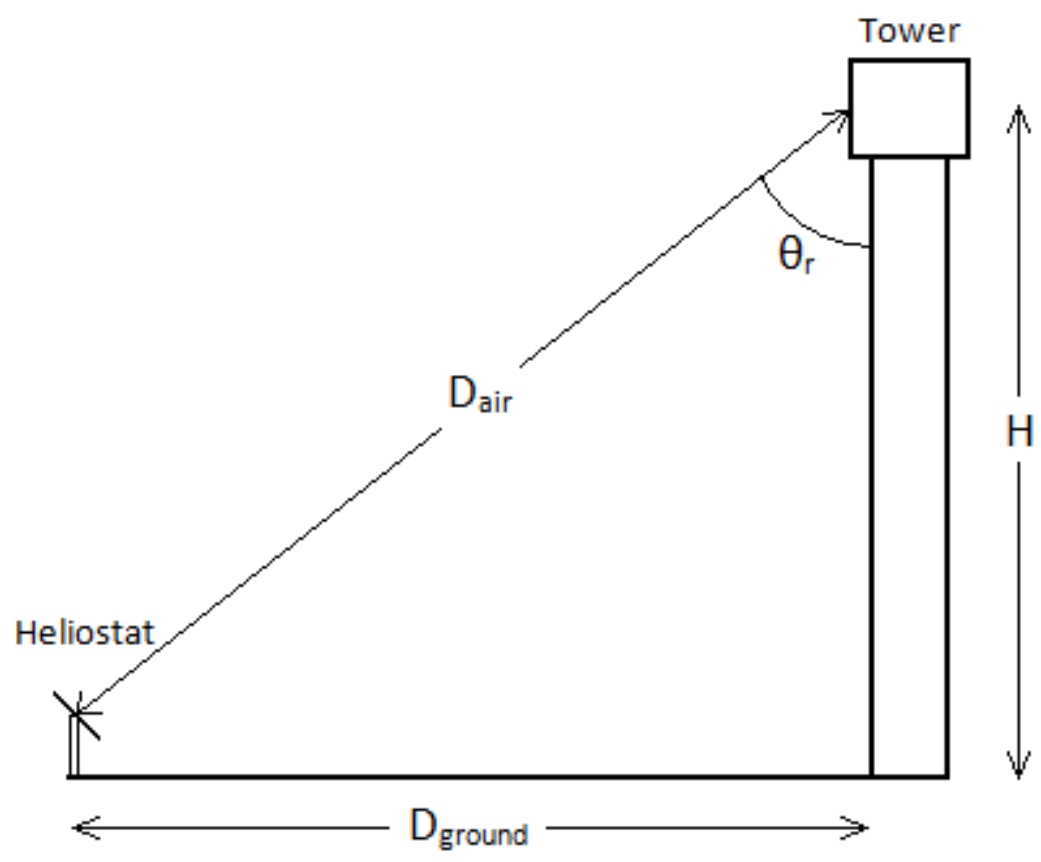

Figure 5-3: Tower and heliostat geometry.

Figure 5-3 gives the following equations:

$$
\begin{gathered}
\theta_{\mathrm{r}}=\tan ^{-1}\left(\frac{\mathrm{D}_{\text {ground }}}{\mathrm{H}}\right) \\
\mathrm{D}_{\text {air }}=\frac{\mathrm{H}}{\cos \left(\theta_{\mathrm{r}}\right)} \\
\mathrm{D}_{\text {air }}=\sqrt{\mathrm{D}_{\text {ground }}^{2}+\mathrm{H}^{2}}
\end{gathered}
$$




\subsection{Heliostat Sizing}

Initially, the designer might think to use the largest heliostats possible in order to reduce the total amount of heliostats needed and thus the amount of field wiring. If fewer heliostats are needed, capital and operation and maintenance costs are lowered. This results in a reduced cost per unit area of reflective surface. However, when using larger heliostats, the reflected image size increases proportionally, and therefore the receiver size must also increase in order to effectively intercept the reflected radiation. Larger heliostats are more difficult to clean, require more land area in order to avoid shadowing and blocking, and they are more prone to wind loads, which can cause increased spillage at the receiver. If the support structure is not sufficient, deflections may occur in the mirror surface caused by its own weight, again creating more spillage at the receiver. Therefore the economic advantages of using larger heliostats must be balanced against the possibility of an increased receiver size and the losses due to possible increased spillage [30].

After speaking with the Vice President of Thermata, Bob Musselman [29], it was determined that a Thermata product would be appropriate to use for this application, due to its low cost and small size. In a small-scale application, using readily available products as opposed to designing new products is sensible. Thermata is a company that manufactures low-cost heliostat systems. The heliostats used come as a pod of 6 mirrors, as shown below.

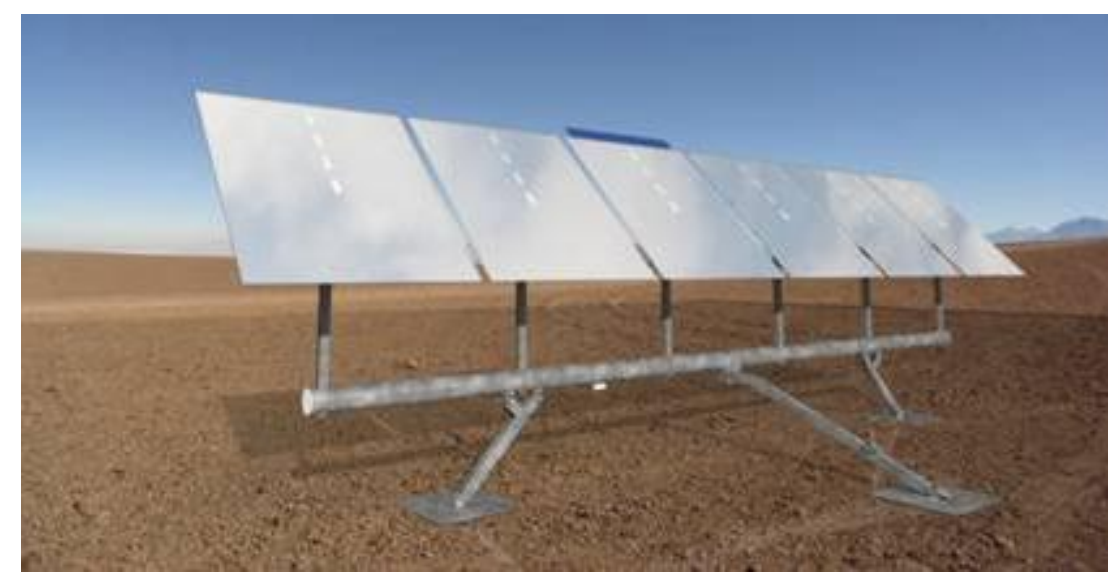

Figure 5-4: A heliostat with 6 mirrors from Thermata [29]. Each mirror is independently controlled. The heliostat has a width of $5.68 \mathrm{~m}$ and a depth of $1.6 \mathrm{~m}$, with mirror surfaces $0.913 \mathrm{~m} \times 1.095 \mathrm{~m}$ (approximated as square $1 \mathrm{~m} \times 1 \mathrm{~m}$ for modeling simplicity) [29]. 


\subsection{Receiver Sizing}

It is not known whether a pressurized volumetric receiver as pictured in Figure 1-9 may be procured. In order to produce a working model of the system, it is assumed that this receiver is used. If one were to design a receiver, there are several things to consider. Minimizing the energy losses at the receiver is important because additional heliostats must be installed in order to make up the lost energy [10]. Increasing the size of the receiver reduces spillage losses, but also increases convective and radiative heat losses. Receiver design optimization should be done based on cost per unit energy delivered to the heat transfer fluid on an annual basis [10]. For the receiver of [14], the maximum air outlet temperature is about $800^{\circ} \mathrm{C}$. After this point, the heat losses become too large and the air cannot achieve a higher temperature.

From reference [14], receiver efficiency is taken as $85 \%$. This means that $85 \%$ of the energy incident upon the receiver aperture is transferred to the heat transfer fluid. The other $15 \%$ is lost to convection and radiation.

\subsubsection{Image Spread}

As the sun's rays head toward Earth, they are in reality not perfectly parallel. In fact, the emitted rays subtend from the sun's disk at an angle of about $0.53^{\circ}$ (9.25mrad) [10], as shown in Figure 5-5.

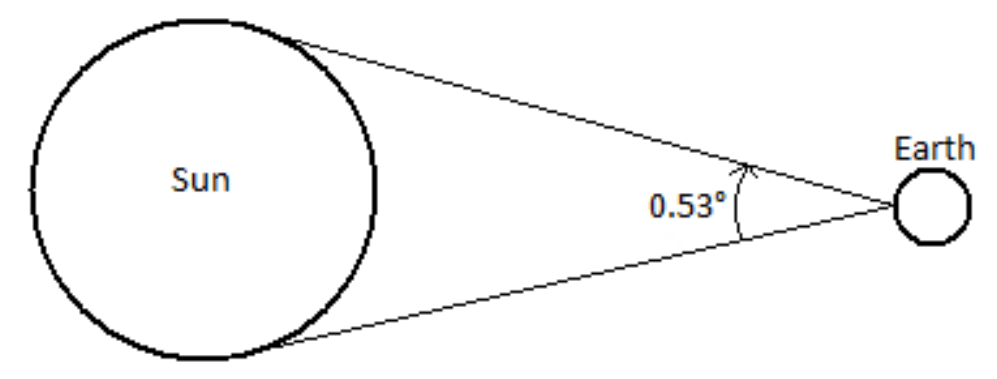

Figure 5-5: The angle subtended by the sun's rays is $0.53^{\circ}$. 
Therefore, once the rays hit a heliostat, the image spreads outward, increasing about $9.3 \mathrm{~m}$ per kilometer [15] or about 2.8 feet per 100 yards. This effect is shown in Figure 5-6.

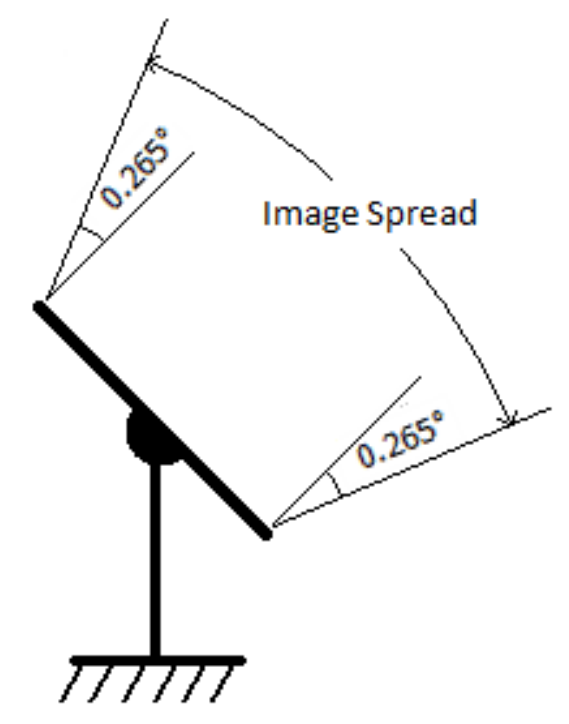

Figure 5-6: The effect of image spread.

Assuming a rectangular heliostat area, the size of the image at the receiver is approximated as:

$$
\begin{aligned}
& \text { Image Area }=\left[\text { Heliostat width }+\left(0.00925 \times \mathrm{D}_{\text {air }}\right)\right] \\
& \quad \times\left[\text { Heliostat length }+\left(0.00925 \times \mathrm{D}_{\text {air }}\right)\right]
\end{aligned}
$$

(5-4 gives the size of the image from any heliostat in the field. In order to design for $4 \%$ spillage, $D_{\text {air }}$ is calculated for the most northern heliostat, which is about 215 feet away from the tower. (5-3 gives $\mathrm{D}_{\text {air }}=218$ feet $(66.45 \mathrm{~m})$. This value is used with (5-4 and the approximate individual heliostat dimensions of $1 \times 1 \mathrm{~m}$ to give the image size as about $2.61 \mathrm{~m}^{2}$.

With a designed $4 \%$ spillage, the receiver area is sized to $96 \%$ of this image size, giving a receiver area of $2.5 \mathrm{~m}^{2}$. 


\subsubsection{Secondary Concentrator}

Pressurized volumetric receivers use hexagonal secondary concentrators, as shown below.
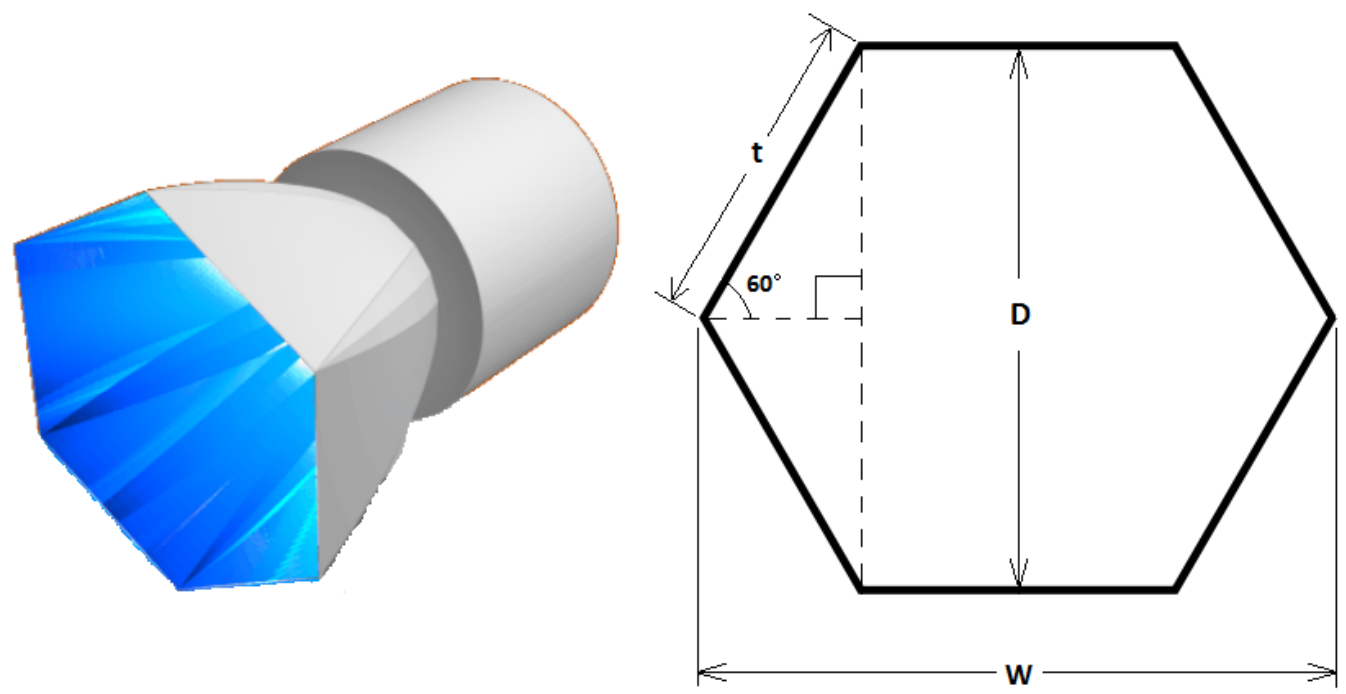

Figure 5-7: Secondary concentrator geometry [14].

Hexagonal shapes are used so that, if necessary, additional receivers may be clustered together (see Figure 1-10) without wasting much space.

Figure 5-7 shows that the width $(\mathrm{W})$ is calculated as:

$$
\mathrm{W}=\mathrm{t}+2 \mathrm{t} \times \cos \left(60^{\circ}\right)=2 \mathrm{t}
$$

And the area of a hexagon is described by (5-6.

$$
A=\frac{3 \sqrt{3}}{2} t^{2}=\frac{\sqrt{3}}{2} D^{2}
$$

With an aperture area of $2.5 \mathrm{~m}^{2}\left(26.91 \mathrm{feet}^{2}\right),(5-6$ gives $\mathrm{t}=3.22$ feet and $\mathrm{D}=5.57$ feet.

(5-5 lastly gives $\mathrm{W}=6.44$ feet.

The receiver aperture is an elliptic domed quartz window with a diameter at the entry of 2.034 feet, and a height of 1.378 feet, with 0.315 inch wall thickness (converted from mm, [13]). The hexagonal secondary concentrator with $\mathrm{t}=3.22$ feet, $\mathrm{D}=5.57$ feet, and $\mathrm{W}=6.44$ feet acts as the aperture and serves to increase the amount of flux received on the domed window without changing the size of window. 


\subsection{Field Layout}

To determine the heliostat field layout, the total number of heliostats must be known. The total number of heliostats is found by calculating the necessary total field mirror area.

Using (5-7 below, the net solar heat input is calculated at optimal solar conditions.

$$
\dot{\mathrm{Q}}_{\text {net solar }}=\dot{\mathrm{m}}\left(\mathrm{h}_{\text {receiver outlet }}-\mathrm{h}_{\text {receiver inlet }}\right)
$$

Using values from Section 3.3, $\dot{\mathrm{Q}}_{\text {net solar }}=340.4 \mathrm{~kW}$. Because the receiver can only outlet air at $800^{\circ} \mathrm{C}$, this solar input is designed for the maximum solar radiation of about $850 \mathrm{~W} / \mathrm{m}^{2}$. If the field were designed for a lower solar radiation value, to take into account weather conditions, the extra heliostats needed to compensate for lower radiation values would not be useful at maximum solar radiation. For this reason as well as the difficulty of predicting weather patterns and the limited field size, the field is designed for maximum "clear sky" solar radiation.

With $\dot{\mathrm{Q}}_{\text {net solar }}$ known, $\dot{\mathrm{Q}}_{\text {natural gas }}$ is now found as follows:

$$
\dot{\mathrm{Q}}_{\text {natural gas }}=\frac{100 \mathrm{~kW}}{\eta_{\text {electric }}}-\dot{\mathrm{Q}}_{\text {net solar }}
$$

With $\eta_{\text {electric }}=0.269$ and $\dot{Q}_{\text {net solar }}=340.4 \mathrm{~kW}, \dot{Q}_{\text {natural gas }}=31.35 \mathrm{~kW}$ at maximum solar radiation.

The heat provided by the sun as a percentage of the total heat input is known as the solar share, and is given by:

$$
\text { Solar Share }=\frac{\dot{\mathrm{Q}}_{\text {net solar }}}{\dot{\mathrm{Q}}_{\text {net solar }}+\dot{\mathrm{Q}}_{\text {natural gas }}} \times 100 \%
$$

At maximum solar radiation, solar share is about $91.6 \%$. As clouds cover the sun or when the nighttime approaches, solar share approaches zero.

The total solar input required can be calculated from the efficiency values:

$$
\dot{\mathrm{Q}}_{\text {total solar }}=\frac{\dot{\mathrm{Q}}_{\text {net solar }}}{\eta_{\text {field }} \cdot \eta_{\text {receiver }}}
$$

With $\dot{\mathrm{Q}}_{\text {net solar }}=340.4 \mathrm{~kW}, \eta_{\text {field }}=.58$, and $\eta_{\text {receiver }}=0.85, \dot{\mathrm{Q}}_{\text {total solar }}=690.5 \mathrm{~kW}$. 
Using $\dot{\mathrm{Q}}_{\text {total solar }}$ will define the total heliostat area as shown in (5-11.

$$
\text { Heliostat Area }=\frac{\dot{\mathrm{Q}}_{\text {total solar }}}{\text { Maximum DNI }}
$$

With $\dot{\mathrm{Q}}_{\text {total solar }}=694.2 \mathrm{~kW}$ and a maximum DNI of $850 \mathrm{~W} / \mathrm{m}^{2}$, the heliostat area is taken as 812.3 $\mathrm{m}^{2}$.

Thermata heliostats are each $6 \mathrm{~m}^{2}$, so the required amount of heliostats is 136 .

It is generally considered best to arrange the heliostats in a radially staggered form in order to minimize the effect of shadowing and blocking among neighboring heliostats. This is shown in Figure 5-8 below.

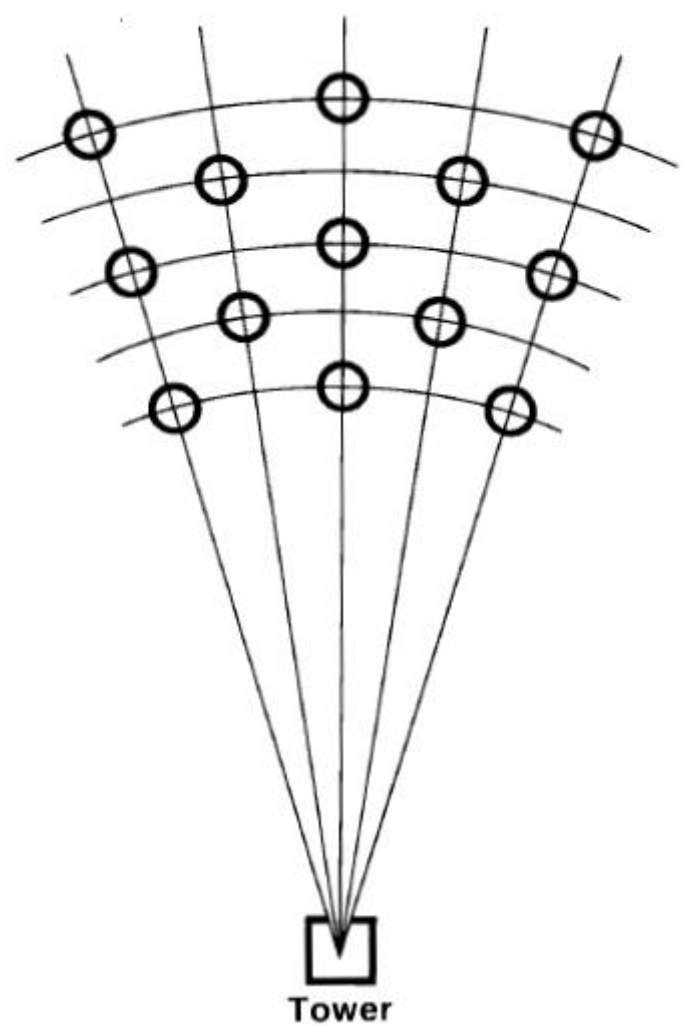

Figure 5-8: Radial Stagger Heliostat Layout [15]. 
Heliostats are tightly packed close to the tower, with enough clearance to prevent interference. As the distance from the tower increases, heliostats are angled closer to vertical in order to direct their reflected beams towards the receiver. Therefore, the radial spacing in between heliostats is increased in order to minimize the blocking of reflected beams by the row of heliostats directly ahead. Figure 5-9 shows the radially staggered field layout design that was chosen to fit with the field size from Figure 5-1.

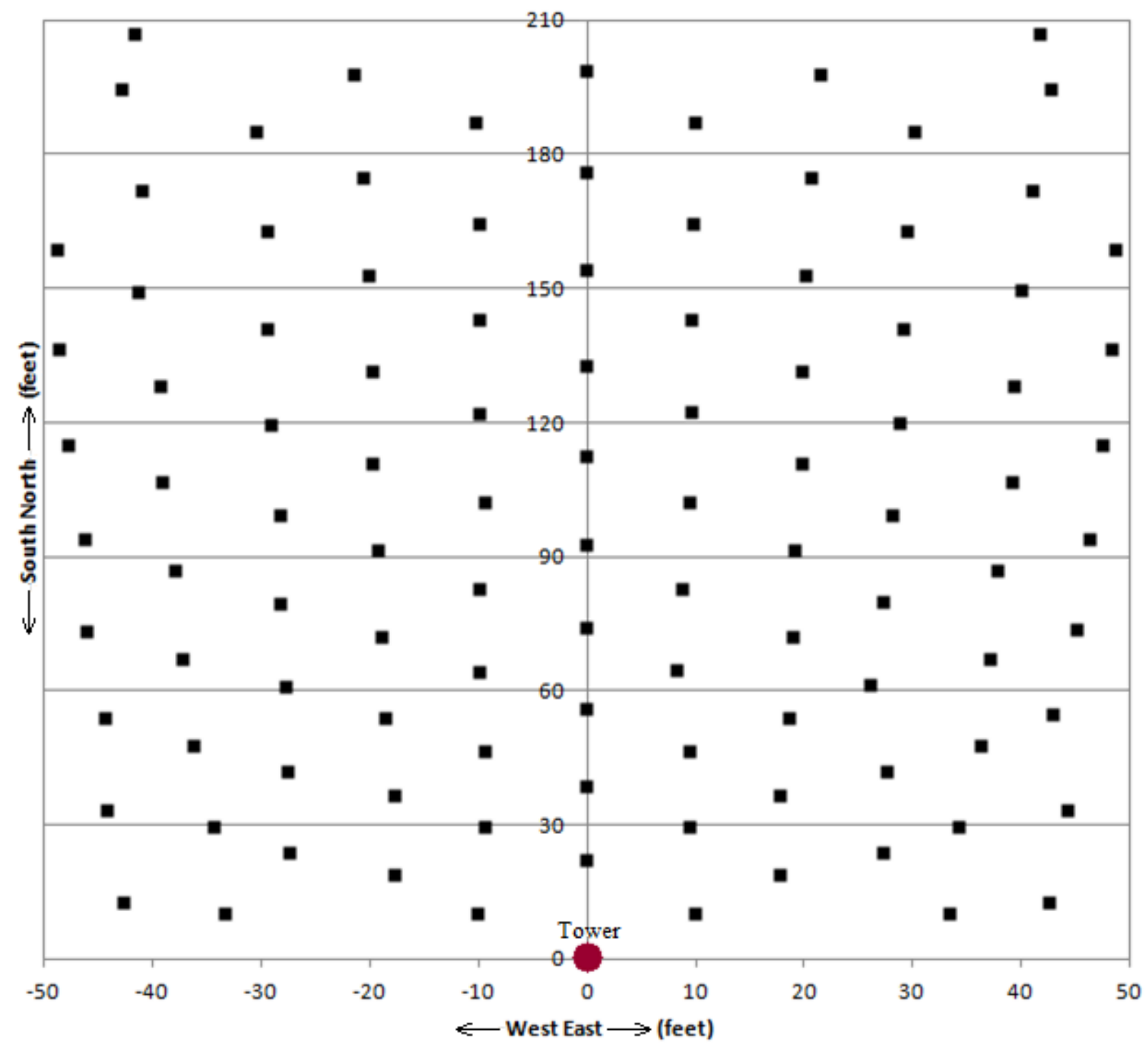

Figure 5-9: Heliostat placement for rough field dimensions of $210 \times 100$ feet. The origin represents the tower. 
For this field layout, the center of the radius of a row of heliostats is located 30 feet south of the tower. Correlations for radial spacing and angular spacing between heliostats are given in [10] for large fields. Because this is a very small field compared to most central receiver fields, these correlations are not useful. Therefore, this layout is designed mainly by eye, using dimensions from the heliostats to check for clearance between adjacent heliostats. If it were desired to optimize the field to its full potential, another ray tracing analysis procedure would be carried out with many different field layouts in order to determine the most efficient layout based on shadowing and blocking of neighboring heliostats.

While designing the heliostat field layout, it was discovered that the field could not support 136 heliostats, but only 108. Therefore the total heliostat reflective area becomes $648 \mathrm{~m}^{2}$. Equations 5-9 through 5-11 show that the maximum solar input for this heliostat field layout is is $272 \mathrm{~kW}$ at a solar share of $73.2 \%$. 


\subsection{Tower Shadowing}

Now that the heliostat layout is designed, it is useful to look at how the shadow casted by the tower onto the field affects the heliostats.

Because the tower is very tall, it casts a large shadow. If this shadow covers a line of heliostats, system energy output may decrease significantly. In order to figure out where the shadow will cast (angle $\mu$ ), and its length (L), the solar azimuth and altitude angles must be known, as well as the tower height (H), as shown below.

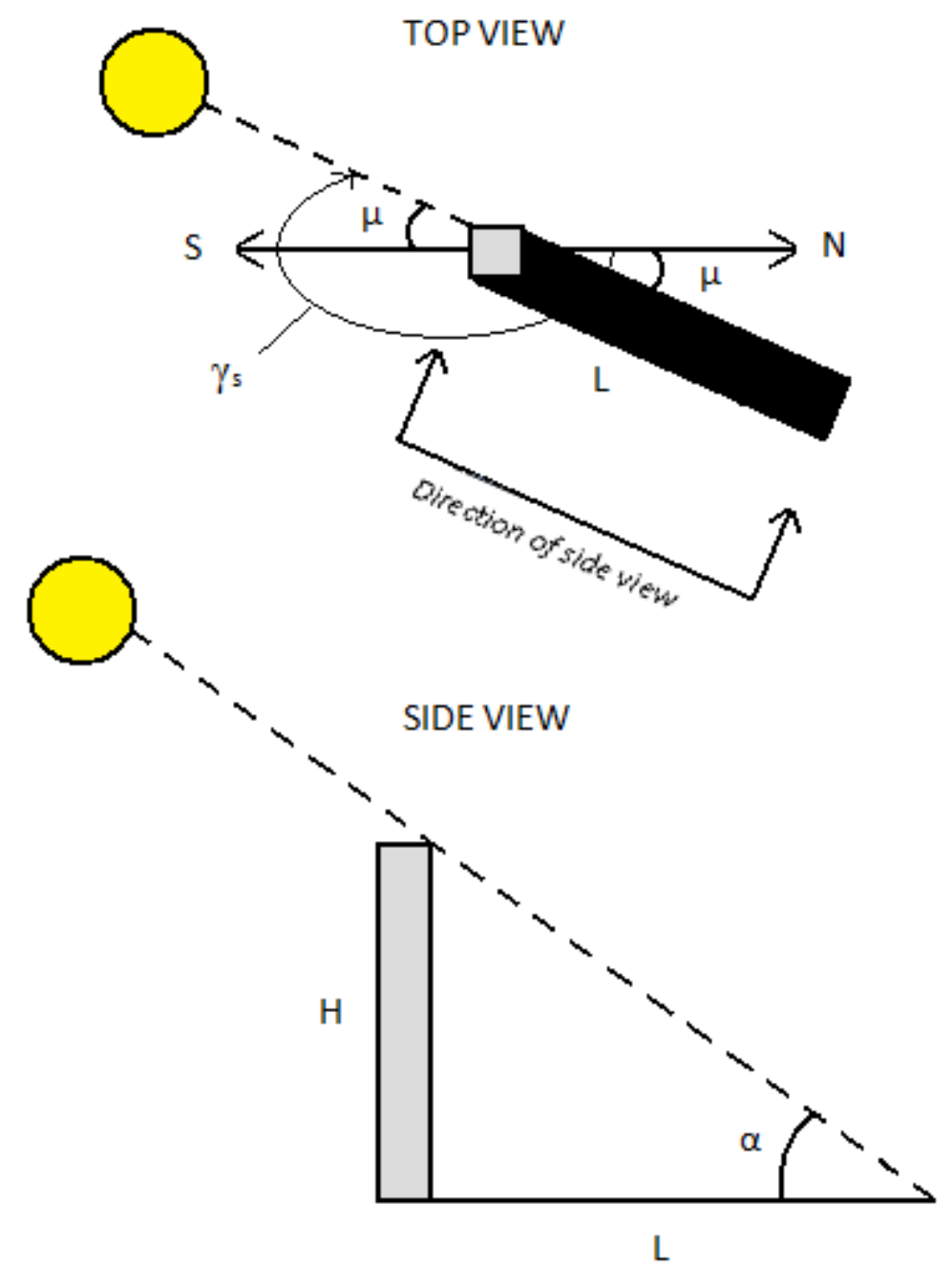

Figure 5-10: Geometry of tower shadowing. 
The direction the shadow is pointing in the ground plane is related to the azimuth angle as shown in the top view. The shadow will always point $\left(\gamma_{\mathrm{s}}-180^{\circ}\right)$ east of north. If this number comes out negative, the shadow is then pointing west of north (morning hours). Therefore,

$$
\mu=\gamma_{\mathrm{s}}-180^{\circ}
$$

As is evident from the side view, the length of the shadow will always be:

$$
L=\frac{H}{\tan (\alpha)}
$$


Now using Equations 5-12 and 5-13 and overlaying the shadow points on the heliostat coordinates gives Figure 5-11.

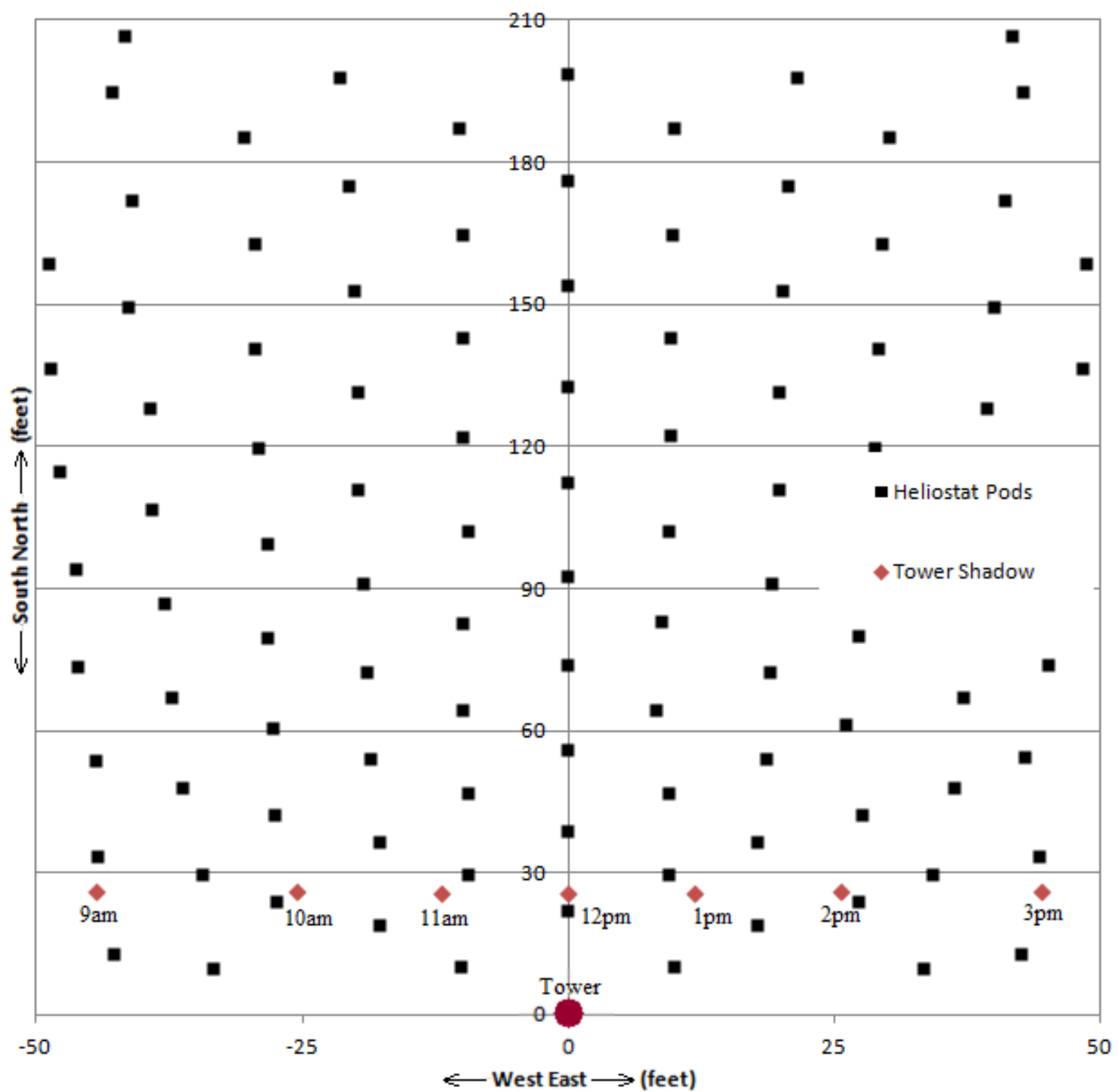

Figure 5-11: Tower shadow points overlaying the heliostat coordinates. Shadow points are calculated for a March $21^{\text {st }}$ day, which gives values similar to annual averages. The origin represents the tower.

The tower shadow points in Figure 5-11 represent the tip of the shadow. The origin of the shadow is located at $(0,0)$ on the graph. Because the tower itself is a steel truss structure (see Figure 1-11), it lets most of the sunlight through, and will not cast much of a shadow. The significant portion of the shadow is developed from the shape of the receiver. The height of the receiver (5.57 feet) makes up 
$15 \%$ of the total tower height. Therefore with the average tower shadow length of about 30 feet, the receiver's shadow is $15 \%$ of the total shadow length, or 4.6 feet long. It is assumed that the width of the tower is equal to the width of the secondary concentrator, which is 6.44 feet. For simplicity the receiver shadow is approximated as a rectangular shadow with dimensions 4.6 feet long and 6.44 feet wide. Considering each mirror is $1 \times 1 \mathrm{~m}(3.28 \times 3.28$ feet $)$ and radial spacing between rows of heliostats is between 8-13 feet, it is reasonable to assume that 2-4 mirrors are shaded during the hours of 10am to $2 \mathrm{pm}$. Outside of these hours, Figure 5-11 shows that heliostats are generally not shaded by the tower. The higher end of 4 mirrors shadowed between 10am to $2 \mathrm{pm}$ is assumed, keeping in mind that there is a small portion of shadowing from the steel truss structure of the tower.

If 4 mirrors are shadowed out of 648 (108 heliostats of 6 mirrors), a $0.62 \%$ loss is incurred. Because this analysis is based on intuition and the average tower shadowing losses are assumed so low, they are ignored. The shadowing from large tree located at the site on campus property shown in Figure 5-1 is also ignored, as cutting this tree down before power plant installation is highly advised. 


\section{Chapter 6: Performance}

Using the parameters defined in the previous chapters, this chapter presents an anticipated yearly performance summary of the power plant. Using the TMY3 solar data [31], the hourly anticipated solar input and solar share are calculated. The reported data is for the "average" day of the month. For solar angle calculations, the $15^{\text {th }}$ of each month was used with the equations of Section 2.3 , as this effectively represents the average day for the month. For solar DNI values, the entire month was averaged to create a single, averaged day from the TMY3 data. Therefore the radiation for the average day in one month may be less than the next month because of weather patterns that were typical in that month, which may have caused DNI values to plummet.

It is important to note that this chapter is not meant to predict output values for a specific hour of the year, but rather to show how a typical year might pan out. This is due to the nature of the TMY3 data and how it is meant to be used.

Hourly solar input is calculated as follows:

$$
\text { Hourly Solar Input }=\text { DNI } \cdot \eta_{\text {receiver }} \cdot \eta_{\text {field }} \cdot \text { Total Heliostat Area }
$$

Solar share is then calculated through the use of (5-9. 
Figures 6-1 and 6-2 show the final result: the annual solar input and solar share for the designed solar central receiver power plant for a typical year.

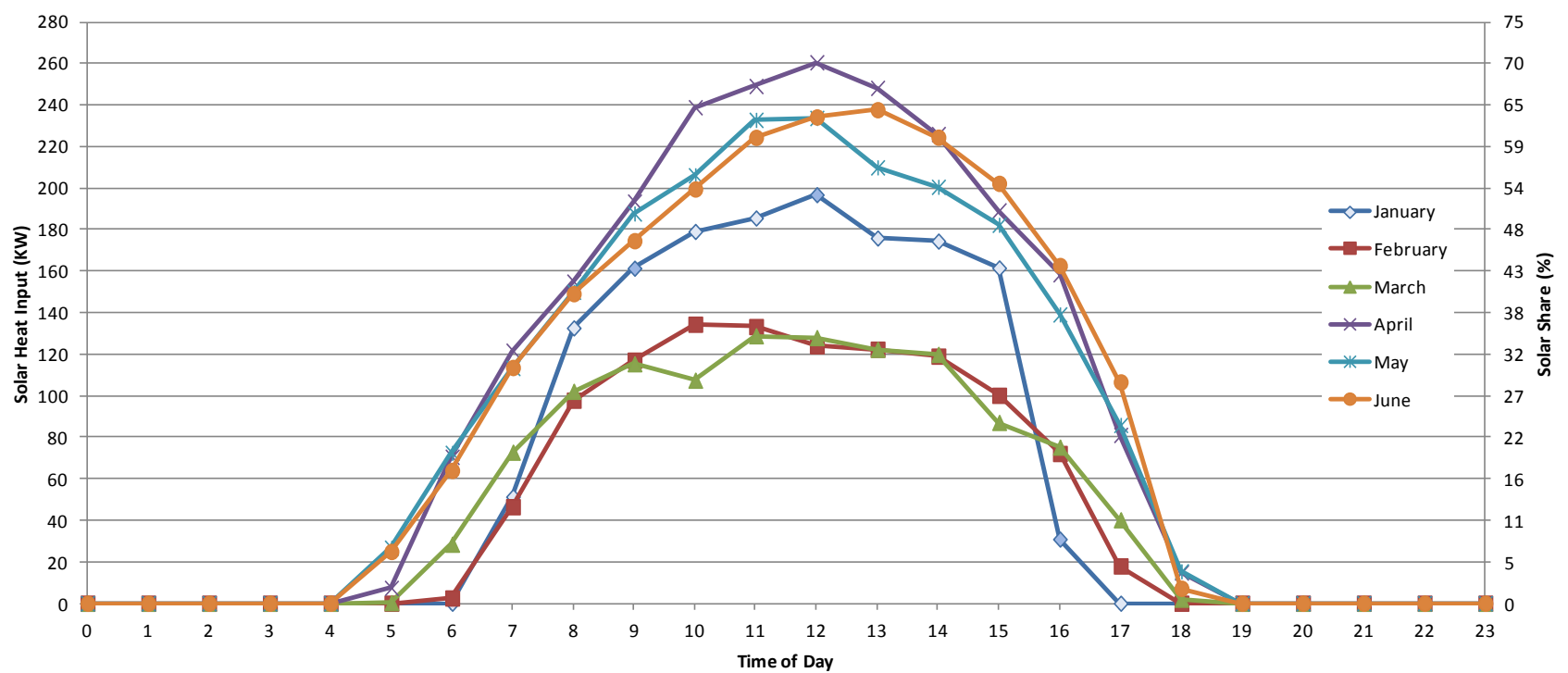

Figure 6-1: Solar heat input and solar share values for the designed solar central receiver power plant in San Luis Obispo, CA as a function of time of day for January through June.

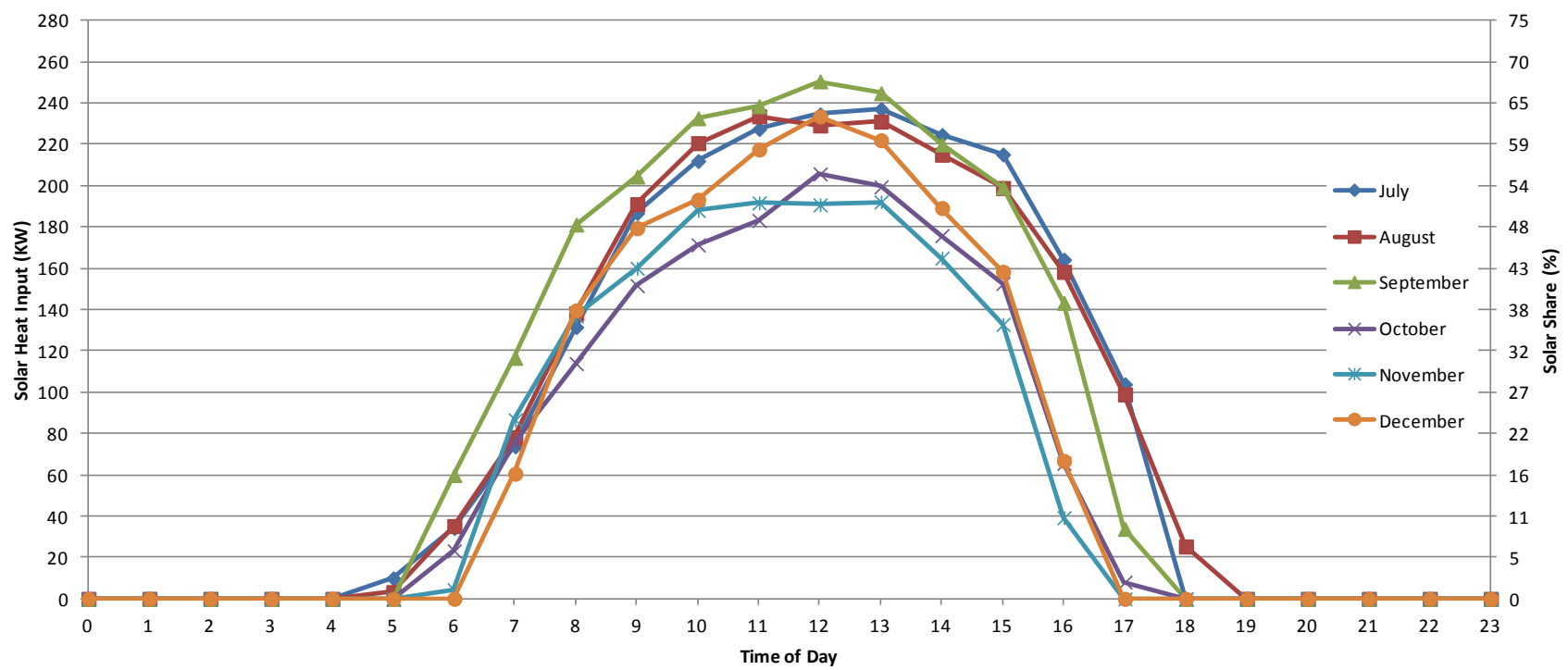

Figure 6-2: Solar heat input and solar share values for the designed solar central receiver power plant in San Luis Obispo, CA as a function of time of day for July through December. 
Figures 6-1 and 6-2 show that the winter and autumn months generally produce lower solar shares than the spring and summer months. April gives the highest solar share for our analysis because the TMY data suggests that April is generally the sunniest month in San Luis Obispo.

Now a fictional building drawing $100 \mathrm{~kW}$ electrical power is considered. The building draws power from the grid for 10 hours a day (typical business hours, 8 am to $6 \mathrm{pm}$ ) at $\$ 0.12 / \mathrm{kWh}[33]$. With natural gas pricing at $\$ 10.36$ per 1000 cubic feet (from March 2012 data in reference [33]) and by analyzing the typical year data from Figures 6-1 and 6-2, using the gas-solar hybrid system would reduce annual fuel costs from $\$ 48,200$ to $\$ 30,900$, a savings of $\$ 17,300$ per year. This is a significant reduction. This calculation does not include the added benefit of using the waste heat of the exhaust $(0.84 \mathrm{~kg} / \mathrm{s}$ air at $302^{\circ} \mathrm{C}$ ) from the gas-solar hybrid microturbine for other applications in the building, such as water heating or air conditioning systems. This will cause energy usage to drop even further which in turn will increase annual savings beyond the figure calculated. However, it is important to note that the power plant requires the use of a relatively large area of land, and is very expensive, although capital cost was not discussed in this thesis. 


\section{Chapter 7: Conclusions}

The solar central receiver power plant designed in this thesis is theoretically capable of producing up to $272 \mathrm{~kW}$ of thermal heat at solar shares up to $73.2 \%$ in order to produce $100 \mathrm{~kW}$ of electric power. The annual average solar share is calculated as $44 \%$ during typical business hours, and this system can result in annual savings of $\$ 17,300$ or more when compared to grid electricity usage.

Future improvements upon this design may involve in-depth ray tracing analyses in order to calculate the most optimal heliostat size, receiver size, and tower height. However, the procedures followed in this report are based on many other systems and in some cases, new, cutting-edge technology. Therefore, the results are taken as reasonable and intuitive for this application. 


\section{References}

[1] Sukhatme and Nayak. Solar Energy: Principles of Thermal Collection and Storage, Third Edition. New Delhi: Tata McGraw-Hill,2008.

[2] Tiwari, G.N. Solar Energy: Fundamentals, Design, modeling, and applications. New Delhi: Narosa Publishing House, 2002.

[3] Masters, Gilbert M. Renewable and Efficient Electric Power Systems. New Jersey: John Wiley \& Sons, Inc., 2004.

[4] http://americanhistory.si.edu/powering/images/gallry53.htm

[5] http://www.nrel.gov/csp/solarpaces/project_detail.cfm/projectID=38

[6] http://inhabitat.com/sevilles-solar-power-tower/

[7] PowerFromTheSun.net. William B. Stine and Michael Geyer. Published online, copyright 2001.

[8] Masters, Joel Thomas. Tower-Tracking Heliostat Array, a thesis. Cal Poly San Luis Obispo, 2011.

[9] http://practicalsolar.com/

[10] Battleson, K.W. Solar Power Tower Design Guide: Solar Thermal Central Receiver Power Systems, A Source of Electricity and/or Process Heat. Sandia National Labs Report, 1981.

[11] Fend, Thomas. High Porosity Materials as Volumetric Receivers for Solar Energetics. German Aerospace Center, 2010.

[12] Chavez, James M. Development and Testing of Advanced Central Receivers. Sandia National Labs Report, 1996.

[13] Buck, Abele, Kunberger, Denk, Heller, Lüpfert. Receiver for Solar-Hybrid Gas Turbine and Combined Cycle Systems. Stuttgart: Institute for Technical Thermodynamics, 1999.

[14] European Commission. SOLGATE - Solar Hybrid Gas Turbine Electric Power System. Luxembourg: Office for Official Publications of the European Communities, 2005.

[15] Falcone, Patricia Kuntz. A Handbook for Solar Central Receiver Design. Livermore: Sandia National Laboratories, 1986. 
[16] Energy and Environmental Analysis. Technology Characterization: Microturbines. Washington, D.C., 2008.

[17] Capstone TA100 microturbine engine specifications sheet.

http://www.horizonpowersystems.com/Amend/images/pdfs/TA100_331064A_lowres.pdf.

[18] Soares, Claire. Microturbines. Butterworth-Heinemann, 2007.

[19] Moran \& Shapiro. Fundamentals of Engineering Thermodynamics. New Jersey: John Wiley \& Sons, 2008.

[20] http://www.mechanicalengineeringblog.com/tag/produce-electricity-from-solar-heat/

[21] http://csirosolarblog.com/tag/pyrheliometer/

[22] Marion \& Wilcox. Users Manual for TMY3 Data Sets. National Renewable Energy Laboratory technical report, 2008.

[23] Duffie and Beckman. Solar Engineering of Thermal Processes, Second Edition. New York: John Wiley \& Sons, Inc., 1991.

[24] Fisher, Sugarmen, Ring, Sinai. Gas Turbine "Solarization" - Modifications for Solar/Fuel Hybrid Operation. ORMAT Industries Israel, 2004.

[25] http://www.maintenanceworld.com/Articles/turbosteam/thecost.html

[26] http://www.efunda.com/formulae/fluids/calc_pipe_friction.cfm

[27] http://www.engineeringtoolbox.com

[28] Morvay \& Gvozdenac. Applied Industrial Energy and Environmental Management, Part III:

Fundamentals for Analysis and Calculation of Energy and Environmental Performance. John Wiley \& Sons, Ltd.

[29] Musselman, Bob. Vice President of Thermata. Personal interview. March 2012.

[30] Gupta \& Traugott. Solar Thermal Technology - Research Development and Applications. Santa Fe: Hemisphere Publishing Corporation, 1990. 
[31] Renewable Resource Data Center, NREL. National Solar Radiation Database. www.rredc/nrel/solar.

[32] Romero, Buck, Pacheco. An Update on Solar Central Receiver Systems, Projects and Technologies. Journal of Solar energy Engineering, Trans. ASME, 124: 98, 2002.

[33] http://www.eia.gov/ 


\section{Appendix A: Thermodynamic Data}

Table A-1: Ideal gas properties of air [19].

\begin{tabular}{|c|c|c|c|c|c|c|c|c|c|c|c|}
\hline \multicolumn{12}{|c|}{$T(\mathrm{~K}), h$ and $u(\mathrm{~kJ} / \mathrm{kg}), s^{\circ}(\mathrm{kJ} / \mathrm{kg} \cdot \mathrm{K})$} \\
\hline \multirow[b]{2}{*}{$T$} & \multirow[b]{2}{*}{$h$} & \multirow[b]{2}{*}{$u$} & \multirow[b]{2}{*}{$s^{\circ}$} & \multicolumn{2}{|c|}{ when $\Delta s=0^{1}$} & \multirow[b]{2}{*}{$T$} & \multirow[b]{2}{*}{$h$} & \multirow[b]{2}{*}{$u$} & \multirow[b]{2}{*}{$s^{\circ}$} & \multicolumn{2}{|c|}{ when $\Delta s=0$} \\
\hline & & & & $p_{r}$ & $v_{\text {, }}$ & & & & & $p_{r}$ & $v_{\text {s }}$ \\
\hline 200 & 199.97 & 142.56 & 1.29559 & 0.3363 & 1707. & 450 & 451.80 & 322.62 & 2.11161 & 5.775 & 223.6 \\
\hline 210 & 209.97 & 149.69 & 1.34444 & 0.3987 & 1512. & 460 & 462.02 & 329.97 & 2.13407 & 6.245 & 211.4 \\
\hline 220 & 219.97 & 156.82 & 1.39105 & 0.4690 & 1346. & 470 & 472.24 & 337.32 & 2.15604 & 6.742 & 200.1 \\
\hline 230 & 230.02 & 164.00 & 1.43557 & 0.5477 & 1205. & 480 & 482.49 & 344.70 & 2.17760 & 7.268 & 189.5 \\
\hline 240 & 240.02 & 171.13 & 1.47824 & 0.6355 & 1084. & 490 & 492.74 & 352.08 & 2.19876 & 7.824 & 179.7 \\
\hline 250 & 250.05 & 178.28 & 1.51917 & 0.7329 & 979. & 500 & 503.02 & 359.49 & 2.21952 & 8.411 & 170.6 \\
\hline 260 & 260.09 & 185.45 & 1.55848 & 0.8405 & 887.8 & 510 & 513.32 & 366.92 & 2.23993 & 9.031 & 162.1 \\
\hline 270 & 270.11 & 192.60 & 1.59634 & 0.9590 & 808.0 & 520 & 523.63 & 374.36 & 2.25997 & 9.684 & 154.1 \\
\hline 280 & 280.13 & 199.75 & 1.63279 & 1.0889 & 738.0 & 530 & 533.98 & 381.84 & 2.27967 & 10.37 & 146.7 \\
\hline 285 & 285.14 & 203.33 & 1.65055 & 1.1584 & 706.1 & 540 & 544.35 & 389.34 & 2.29906 & 11.10 & 139.7 \\
\hline 290 & 290.16 & 206.91 & 1.66802 & 1.2311 & 676.1 & 550 & 554.74 & 396.86 & 2.31809 & 11.86 & 133.1 \\
\hline 295 & 295.17 & 210.49 & 1.68515 & 1.3068 & 647.9 & 560 & 565.17 & 404.42 & 2.33685 & 12.66 & 127.0 \\
\hline 300 & 300.19 & 214.07 & 1.70203 & 1.3860 & 621.2 & 570 & 575.59 & 411.97 & 2.35531 & 13.50 & 121.2 \\
\hline 305 & 305.22 & 217.67 & 1.71865 & 1.4686 & 596.0 & 580 & 586.04 & 419.55 & 2.37348 & 14.38 & 115.7 \\
\hline 310 & 310.24 & 221.25 & 1.73498 & 1.5546 & 572.3 & 590 & 596.52 & 427.15 & 2.39140 & 15.31 & 110.6 \\
\hline 315 & 315.27 & 224.85 & 1.75106 & 1.6442 & 549.8 & 600 & 607.02 & 434.78 & 2.40902 & 16.28 & 105.8 \\
\hline 320 & 320.29 & 228.42 & 1.76690 & 1.7375 & 528.6 & 610 & 617.53 & 442.42 & 2.42644 & 17.30 & 101.2 \\
\hline 325 & 325.31 & 232.02 & 1.78249 & 1.8345 & 508.4 & 620 & 628.07 & 450.09 & 2.44356 & 18.36 & 96.92 \\
\hline 330 & 330.34 & 235.61 & 1.79783 & 1.9352 & 489.4 & 630 & 638.63 & 457.78 & 2.46048 & 19.84 & 92.84 \\
\hline 340 & 340.42 & 242.82 & 1.82790 & 2.149 & 454.1 & 640 & 649.22 & 465.50 & 2.47716 & 20.64 & 88.99 \\
\hline 350 & 350.49 & 250.02 & 1.85708 & 2.379 & 422.2 & 650 & 659.84 & 473.25 & 2.49364 & 21.86 & 85.34 \\
\hline 360 & 360.58 & 257.24 & 1.88543 & 2.626 & 393.4 & 660 & 670.47 & 481.01 & 2.50985 & 23.13 & 81.89 \\
\hline 370 & 370.67 & 264.46 & 1.91313 & 2.892 & 367.2 & 670 & 681.14 & 488.81 & 2.52589 & 24.46 & 78.61 \\
\hline 380 & 380.77 & 271.69 & 1.94001 & 3.176 & 343.4 & 680 & 691.82 & 496.62 & 2.54175 & 25.85 & 75.50 \\
\hline 390 & 390.88 & 278.93 & 1.96633 & 3.481 & 321.5 & 690 & 702.52 & 504.45 & 2.55731 & 27.29 & 72.56 \\
\hline 400 & 400.98 & 286.16 & 1.99194 & 3.806 & 301.6 & 700 & 713.27 & 512.33 & 2.57277 & 28.80 & 69.76 \\
\hline 410 & 411.12 & 293.43 & 2.01699 & 4.153 & 283.3 & 710 & 724.04 & 520.23 & 2.58810 & 30.38 & 67.07 \\
\hline 420 & 421.26 & 300.69 & 2.04142 & 4.522 & 266.6 & 720 & 734.82 & 528.14 & 2.60319 & 32.02 & 64.53 \\
\hline 430 & 431.43 & 307.99 & 2.06533 & 4.915 & 251.1 & 730 & 745.62 & 536.07 & 2.61803 & 33.72 & 62.13 \\
\hline 440 & 441.61 & 315.30 & 2.08870 & 5.332 & 236.8 & 740 & 756.44 & 544.02 & 2.63280 & 35.50 & 59.82 \\
\hline
\end{tabular}


Table A-1: Continued.

\begin{tabular}{|c|c|c|c|c|c|c|c|c|c|c|c|}
\hline \multicolumn{12}{|c|}{$T(\mathrm{~K}), h$ and $u(\mathrm{~kJ} / \mathrm{kg}), s^{\circ}(\mathrm{kJ} / \mathrm{kg} \cdot \mathrm{K})$} \\
\hline \multirow[b]{2}{*}{$T$} & \multirow[b]{2}{*}{$h$} & \multirow[b]{2}{*}{$u$} & \multirow[b]{2}{*}{$5^{\circ}$} & \multicolumn{2}{|c|}{ when $\Delta s=0^{1}$} & \multirow[b]{2}{*}{$T$} & \multirow[b]{2}{*}{ h } & \multirow[b]{2}{*}{$u$} & \multirow[b]{2}{*}{$s^{\circ}$} & \multicolumn{2}{|c|}{ when $\Delta s=0$} \\
\hline & & & & $p_{\mathrm{r}}$ & $v$, & & & & & $p_{r}$ & $v_{r}$ \\
\hline 750 & 767.29 & 551.99 & 2.64737 & 37.35 & 57.63 & 1300 & 1395.97 & 1022.82 & 3.27345 & 330.9 & 11.275 \\
\hline 760 & 778.18 & 560.01 & 2.66176 & 39.27 & 55.54 & 1320 & 1419.76 & 1040.88 & 3.29160 & 352.5 & 10.747 \\
\hline 770 & 789.11 & 568.07 & 2.67595 & 41.31 & 53.39 & 1340 & 1443.60 & 1058.94 & 3.30959 & 375.3 & 10.247 \\
\hline 780 & 800.03 & 576.12 & 2.69013 & 43.35 & 51.64 & 1360 & 1467.49 & 1077.10 & 3.32724 & 399.1 & 9.780 \\
\hline 790 & 810.99 & 584.21 & 2.70400 & 45.55 & 49.86 & 1380 & 1491.44 & 1095.26 & 3.34474 & 424.2 & 9.337 \\
\hline 800 & 821.95 & 592.30 & 2.71787 & 47.75 & 48.08 & 1400 & 1515.42 & 1113.52 & 3.36200 & 450.5 & 8.919 \\
\hline 820 & 843.98 & 608.59 & 2.74504 & 52.59 & 44.84 & 1420 & 1539.44 & 1131.77 & 3.37901 & 478.0 & 8.526 \\
\hline 840 & 866.08 & 624.95 & 2.77170 & 57.60 & 41.85 & 1440 & 1563.51 & 1150.13 & 3.39586 & 506.9 & 8.153 \\
\hline 860 & 888.27 & 641.40 & 2.79783 & 63.09 & 39.12 & 1460 & 1587.63 & 1168.49 & 3.41247 & 537.1 & 7.801 \\
\hline 880 & 910.56 & 657.95 & 2.82344 & 68.98 & 36.61 & 1480 & 1611.79 & 1186.95 & 3.42892 & 568.8 & 7.468 \\
\hline 900 & 932.93 & 674.58 & 2.84856 & 75.29 & 34.31 & 1500 & 1635.97 & 1205.41 & 3.44516 & 601.9 & 7.152 \\
\hline 920 & 955.38 & 691.28 & 2.87324 & 82.05 & 32.18 & 1520 & 1660.23 & 1223.87 & 3.46120 & 636.5 & 6.854 \\
\hline 940 & 977.92 & 708.08 & 2.89748 & 89.28 & 30.22 & 1540 & 1684.51 & 1242.43 & 3.47712 & 672.8 & 6.569 \\
\hline 960 & 1000.55 & 725.02 & 2.92128 & 97.00 & 28.40 & 1560 & 1708.82 & 1260.99 & 3.49276 & 710.5 & 6.301 \\
\hline 980 & 1023.25 & 741.98 & 2.94468 & 105.2 & 26.73 & 1580 & 1733.17 & 1279.65 & 3.50829 & 750.0 & 6.046 \\
\hline 1000 & 1046.04 & 758.94 & 2.96770 & 114.0 & 25.17 & 1600 & 1757.57 & 1298.30 & 3.52364 & 791.2 & 5.804 \\
\hline 1020 & 1068.89 & 776.10 & 2.99034 & 123.4 & 23.72 & 1620 & 1782.00 & 1316.96 & 3.53879 & 834.1 & 5.574 \\
\hline 1040 & 1091.85 & 793.36 & 3.01260 & 133.3 & 22.39 & 1640 & 1806.46 & 1335.72 & 3.55381 & 878.9 & 5.355 \\
\hline 1060 & 1114.86 & 810.62 & 3.03449 & 143.9 & 21.14 & 1660 & 1830.96 & 1354.48 & 3.56867 & 925.6 & 5.147 \\
\hline 1080 & 1137.89 & 827.88 & 3.05608 & 155.2 & 19.98 & 1680 & 1855.50 & 1373.24 & 3.58335 & 974.2 & 4.949 \\
\hline 1100 & 1161.07 & 845.33 & 3.07732 & 167.1 & 18.896 & 1700 & 1880.1 & 1392.7 & 3.5979 & 1025 & 4.761 \\
\hline 1120 & 1184.28 & 862.79 & 3.09825 & 179.7 & 17.886 & 1750 & 1941.6 & 1439.8 & 3.6336 & 1161 & 4.328 \\
\hline 1140 & 1207.57 & 880.35 & 3.11883 & 193.1 & 16.946 & 1800 & 2003.3 & 1487.2 & 3.6684 & 1310 & 3.944 \\
\hline 1160 & 1230.92 & 897.91 & 3.13916 & 207.2 & 16.064 & 1850 & 2065.3 & 1534.9 & 3.7023 & 1475 & 3.601 \\
\hline 1180 & 1254.34 & 915.57 & 3.15916 & 222.2 & 15.241 & 1900 & 2127.4 & 1582.6 & 3.7354 & 1655 & 3.295 \\
\hline 1200 & 1277.79 & 933.33 & 3.17888 & 238.0 & 14.470 & 1950 & 2189.7 & 1630.6 & 3.7677 & 1852 & 3.022 \\
\hline 1220 & 1301.31 & 951.09 & 3.19834 & 254.7 & 13.747 & 2000 & 2252.1 & 1678.7 & 3.7994 & 2068 & 2.776 \\
\hline 1240 & 1324.93 & 968.95 & 3.21751 & 272.3 & 13.069 & 2050 & 2314.6 & 1726.8 & 3.8303 & 2303 & 2.555 \\
\hline 1260 & 1348.55 & 986.90 & 3.23638 & 290.8 & 12.435 & 2100 & 2377.4 & 1775.3 & 3.8605 & 2559 & 2.356 \\
\hline \multirow[t]{3}{*}{1280} & 1372.24 & 1004.76 & 3.25510 & 310.4 & 11.835 & 2150 & 2440.3 & 1823.8 & 3.8901 & 2837 & 2.175 \\
\hline & & & & & & 2200 & 2503.2 & 1872.4 & 3.9191 & 3138 & 2.012 \\
\hline & & & & & & 2250 & 2566.4 & 1921.3 & 3.9474 & 3464 & 1.864 \\
\hline
\end{tabular}

